UNIVERSIDADE DE SÃO PAULO

FACULDADE DE MEDICINA DE RIBEIRÃO PRETO

O IMPACTO DO VÍRUS DA FEBRE AMARELA NA POPULAÇÃO DE PRIMATAS NÃO HUMANOS DA REGIÃO SUL DO MUNICÍPIO DE RIBEIRÃO PRETO - SP

MÁRCIO JUNIO LIMA SICONELLI

Ribeirão Preto

2019 
MÁRCIO JUNIO LIMA SICONELLI

\section{O IMPACTO DO VÍRUS DA FEBRE AMARELA NA POPULAÇÃO DE PRIMATAS NÃO HUMANOS DA REGIÃO SUL DO MUNICÍPIO DE RIBEIRÃO PRETO - SP}

\section{Versão Original}

Dissertação de Mestrado apresentada ao Programa de PósGraduação em Imunologia Básica e Aplicada para obtenção do Título de Mestre em Ciências.

Área de Concentração: Imunologia Básica e Aplicada.

Orientador: Prof. Dr. Benedito Antonio Lopes da Fonseca

Ribeirão Preto

2019 
Siconelli, Márcio Junio Lima.

O impacto do vírus da Febre Amarela na população de Primatas Não Humanos da região Sul do Município de Ribeirão Preto, SP, 2019.

101 p. : il. ; $30 \mathrm{~cm}$

Dissertação de Mestrado, apresentada à Faculdade de Medicina de Ribeirão Preto/USP. Área de concentração: Imunologia Básica e Aplicada.

Orientador: Fonseca, Benedito Antonio Lopes.

1. Febre Amarela. 2. Primatas Não Humano. 3. PRNT. 4. Vigilância de arboviroses. 5. Zoonoses.

AUTORIZO A REPRODUÇÃO E DIVULGAÇÃO TOTAL OU PARCIAL DESTE TRABALHO, POR QUALQUER MEIO CONVENCIONAL OU ELETRÔNICO, PARA FINS DE ESTUDO E PESQUISA, DESDE QUE CITADA A FONTE. 


\section{FOLHA DE APROVAÇÃO}

Márcio Junio Lima Siconelli

O IMPACTO DO VÍRUS DA FEBRE AMARELA NA POPULAÇÃO DE PRIMATAS NÃO HUMANOS DA REGIÃO SUL DO MUNICÍPIO DE RIBEIRÃO PRETO - SP

Dissertação de Mestrado apresentada ao Programa de PósGraduação em Imunologia Básica e Aplicada para obtenção do Título de Mestre em Ciências

Área de Concentração: Imunologia Básica e Aplicada.

Orientador: Prof. Dr. Benedito Antonio Lopes da Fonseca

Aprovado em:

Banca Examinadora

Prof. Dr.

Instituição: Assinatura:

Prof. Dr.

Instituição: Assinatura:

Prof. Dr. Instituição: Assinatura: Desenvolvimento Científico e Tecnológico - Brasil”. 


\section{DEDICATÓRIA}

Aos meus pais, Márcio Antônio Siconelli e Maria Ferreira de Lima Siconelli, que mesmo em momentos de escuridão, foram luz em meu caminho e se mantiveram próximos, com carinho e amor, acreditando em tudo aquilo que, por opção, decidi trilhar. Amo vocês! 


\section{AGRADECIMENTOS}

À Deus, por todas as graças e conquistas obtidas, muitas ao longo dessa trajetória. Agradeço por sempre me guiar pelos caminhos certos e, principalmente, nos momentos certos, dentro da sua vontade;

Aos meus pais Márcio Antônio Siconelli e Maria Ferreria de Lima Siconelli, pelo amor, carinho, paciência e apoio incondicional; por jamais desistirem de mim, mesmo na minha impaciência. Vocês são parte fundamental disso. Vocês são o exemplo de vida que busco contruir diariamente;

Ao meu orientador, Prof. Dr. Benedito Antonio Lopes da Fonseca, que mesmo sem me conhecer, abriu as portas do seu laboratório e, após, me confiou o desenvolvimento desse projeto, nada trivial. Obrigado por todos os ensinamentos, amizade, disponibilidade e, principalmente, paciência com que tem me orientado em muitos momentos, alguns quando a ansiedade e a impaciência sobressaem. Muitas oportunidades têm surgido;

À Adriana Aparecida Dispósito Ferreira, que tem acompanhado essa trajetória, com confiança e amizade, sempre disposta a ajudar; facilitando e tornando possível muitas etapas dentro desses dois anos de projeto. Sem o seu auxílio, muita coisa não teria acontecido;

Ao Pedro Henrique Ferreira Teles ("Dr. Pedrinho"), do Departamento de Vigilância em Saúde Ambiental, por aderir à ideia e fornecer apoio técnico, me auxiliando nas capturas e ensinando como fazê-las corretamente;

À Luzia Márcia Romanholi Passos, da Secretaria Municipal de Saúde, por estar disponível e disposta a colaborar na busca de uma Saúde Pública melhor, acreditando e apoiando nosso projeto;

À Elisabete Paganini e ao Daniel Marques, do Grupo de Vigilância Epidemiológica (GVE) XXIV, amigos e apoiadores, que trabalharam em prol desse projeto tornando possível a entrada e captura em pontos estratégicos do Município; 
Ao Adriano Pínter e ao Celso Eduardo Souza, da Superintendência de Controle de Endemias (SUCEN/SP), por emprestar, sem ressalvas, as armadilhas, possibilitando a captura dos animais e viabilizado o projeto;

À Helia Maria Piedade, da Secretaria de Meio Ambiente do Estado (SMA), por ser uma entusiasta do projeto e abrir as portas dentro da SMA para que pudéssemos estabelecer parcerias e desenvolver, em tempo hábil, nossos objetivos;

Ao Alessandro Pecego Martins Romano, da Secretaria de Vigilância em Saúde (SVS/MS), também entusiasta desse projeto e que prontamente atendeu ao pedido de colaboração com o nosso grupo, emprestando equipamentos que possibilitaram a tentativa de captura de macacos de médio e grande porte;

Ao Vitor Gonçalves Floriano, ou "Vitão" por ter se dedicado ao meu projeto, mesmo fugindo totalmente à sua formação, não mediu esforços para ir à campo, carregar armadilhas, entrar literalmente no mato, capturar macacos, aguentar meu mau humor matinal e em virtude do cansaço, o estresse... foram muitas conversas e aprendizados, muitas aventuras. Sem a sua ajuda, com certeza esse projeto não teria seguido;

À Mayara Rovariz Agostinho, pela parceria e amizade desde a seleção do mestrado. Mesmo com algumas discussões, talvez por sermos parecidos em muitos aspectos, o bom senso sempre prevaleceu. Esse tempo juntos foi parte importante para crescermos;

Ao Daniel Marques, Jonathan Ballico de Moraes, Fábio (Francisco) Bezerra, à Larissa Viana e especialmente à Beatriz dos Santos Ribeiro que dedicaram parte do seu tempo para me auxiliar nas capturas, sem os quais, com certeza também não teria conseguido a coleta dessas preciosas amostras;

Ao Danillo Lucas Alves Espósito (Danillão), por ter me recebido no laboratório, ensinado e orientado nos primeiros passos rumo à essa jornada, sempre com paciência, colaborando durante todo o projeto. E embora não partilhemos as mesmas ideias, me fez ver outros pontos de vista e crescer; 
À Flávia Masson de Moraes (Flavinha), Taline Monteiro Klein (Talaine) e Marcus Vinícius G. da Silva (Marquinhus) que me receberam de braços abertos, compartilharam muitos almoços, conversas e que sempre estiveram dispostos a me auxiliar. Tornaram, sem dúvida, o caminho mais afável;

À Luiza Antunes de Castro Jorge, por me ajudar a organizar e finalizar essa etapa, com conversa, discussão e sobretudo, tranquilidade para enxergar qual o melhor caminho a ser seguido, a fim de obter os melhores resultados, ou os mais sensatos possível;

À Profa. Dra. Adolorata Aparecida Bianco Carvalho que, mesmo na distância se manteve por perto, acompanhando e me apoiando incondicionalmente em momentos de incertezas com conselhos e reflexões, além de uma amizade calorosa. Obrigado por continuar contribuindo com a minha formação, fazendo parte de mais essa etapa. Além de tudo isso, claro, de ter comprando as células VERO, doando-as para mim;

Ao Prof. Dr. Luiz Antônio Mathias, pelos conselhos, amizade e principalmente, pelo tempo e paciência que dedicou ao tirar muitas dúvidas durante esse período;

À Profa. Dra. Karina Paes Bürger, minha ex-orientadora e sempre incentivadora, que tem mantido aberta as portas da FCAV/Unesp, possibilitando compartilhar nossas experiências com as novas gerações de alunos;

À Andrea Souza Ramos de Medeiros, técnica da FCAV/Unesp, que tem sido o exemplo que busco seguir dentro das boas práticas laboratoriais. Carrego comigo seus ensinamentos, tentando melhorar a cada dia. Além disso, cultivou, cuidou e doou nossas preciosas células VERO;

À Profa. Dr. Maria Angélica Dias, na época Secretária da Saúde, mas sempre uma amiga, que confiou e me deu a oportunidade do primeiro emprego como médico veterinário. Embora curta, foi uma experiência rica e intensa, que me fez crescer profissional e pessoalmente;

Aos setores de Vigilâncias do Município de Jaboticabal, Vetores e Zoonoses, Epidemiológica e Sanitária à oportunidade de trabalharmos juntos e ao apoio profissional, em prol da saúde pública. Em especial, à equipe do setor Vigilância de Vetores e Zoonoses, que 
em momentos delicados entre o serviço e o mestrado, pude contar para desenvolver o meu trabalho da melhor forma possível;

À minha eterna R1 e amiga, Nathália Cristina Morais, que mesmo após a residência, esteve por perto, dedicando seu tempo à inúmeras conversas, sempre a me incentivar. E claro, por sempre estar disposta a cuidar do Joe;

À minha amiga e afilhada, Talita Beani Corsini Finardi, pela amizade e por me apoiar em períodos de mudança e, principalmente, por apoiar e colaborar no desenvolvimento desse projeto, colocando o LACVET à disposição;

À Lívia Perles e Julia Maria Ribeiro, pela amizade e que, mesmo distantes deram apoio técnico e profissional, ajudando-me com muitas dúvidas ao longo das capturas;

À Faculdade de Medicina de Ribeirão Preto, da Universidade de São Paulo e ao Programa de Imunologia Básica e Aplicada que me receberam de braços abertos, dando condições para que eu continuar construindo a minha formação e além disso, oportunidades ímpares dentro da academia. Em especial a Ana Cristine, secretária do programa, que colabora e faz com que qualquer etapa seja o mais tranquilo possível;

À todas as unidades e as equipes que possibilitaram e deram suporte às capturas, GVE XXIV/DRS XIII, Condomínio Residencial Quinta da Boa Vista "A" e "B", Hospital Santa Tereza de Ribeirão Preto e Estação Ecológica de Ribeirão Preto (Mata de Santa Tereza);

À Faculdade de Ciências Agrárias e Veterinárias da Universidade Estadual Paulista (Unesp), câmpus de Jaboticabal/SP, minha casa, onde me formei e que tem mantido as portas abertas para mim, oferecendo inúmeras oportunidades;

E não menos importante, ao meu cachorro, Joe (o Cão), que está sempre a minha espera, por opção ou não, mas independente com muito amor, alegria, lambidas e espirros inesperados. Você é meu suporte diário, principalmente em dias difíceis; 
Aos muitos que colaboraram com a minha formação acadêmica, profissional e pessoal nesses dois anos, direta ou indiretamente. Seja com uma simples mensagem, na distância, ou no convívio diário;

Ao Conselho Nacional de Pesquisa (CNPq) pelo auxílio financeiro na modalidade de Bolsa de Mestrado;

À FAEPA e ao processo FESIMA - Ofício CAF $n^{\circ}$. 003/2016 por concederem apoio financeiro, tornando possível o desenvolvimento desse projeto, tanto nas atividades de campo, quanto nas laboratoriais... 


\section{EPÍGRAFE}

Para ser grande, sê inteiro: nada

"Para ser grande, sê inteiro: nada

Teu exagera ou exclui. Sê todo em cada coisa. Põe quanto és No mínimo que fazes. Assim em cada lado a lua toda Brilha, porque alta vive."

Odes de Ricardo Reis (Fernando Pessoa) 


\section{RESUMO}

\section{SICONELLI, M. J. L. O impacto do vírus da Febre Amarela na população de primatas não humanos da região sul do Município de Ribeirão Preto - SP. 2019. 101f. Dissertação}

(Mestrado). Faculdade de Medicina de Ribeirão Preto - Universidade de São Paulo, Ribeirão Preto, 2019.

O vírus da febre amarela (YFV) pertence ao gênero Flavivirus (família: Flaviviridae), sendo responsável por causar doença de nome semelhante. A febre amarela (FA) é uma doença infecciosa de transmissão vetorial, de evolução aguda e que, na forma grave, é caracterizada por febre e hemorragias, alcançando em torno de $50 \%$ de letalidade. Dois diferentes ciclos estão estabelecidos no Brasil, um urbano (Aedes aegypti) e outro silvestre (Haemagogus sp.; Sabethes sp.). Neste último tem-se o envolvimento primatas não humanos (PNHs), cuja letalidade, a depender da espécie (Alouatta sp.), pode ultrapassar os 80\%, susceptibilidade esta que o torna um excelente animal sentinela para a detecção do YFV. Assim, a vigilância de epizootias em PNHs é uma importante ferramenta epidemiológica de prevenção de casos humanos. Em 2016, o Município de Ribeirão Preto registrou a circulação do YFV em área urbana e periurbana, acometendo respectivamente, PNHs da espécie Callithrix penicillata e uma pessoa. Desta forma, o objetivo do presente trabalho foi avaliar o impacto do YFV na população de PNHs na área onde houve o caso humano. Para isso buscou-se a presença de anticorpos neutralizantes contra o YFV, pela técnica $\mathrm{PRNT}_{50}$, além de avaliar a possível manutenção da circulação viral por meio do teste rápido NS1-YFV e RT-qPCR. O estudo foi realizado na região sul do Município de Ribeirão Preto, dentro de uma área de $5,77 \mathrm{Km}^{2}$. No período de abril a dezembro de 2018, foram capturados 39 animais, sendo 38 C. penicillata e 01 Sapajus nigritus. Os animais foram capturados com o auxílio de armadilhas tipo "Tomahawk" e na sequência foram submetidos a contenção química por midazolam e cetamina, o que possibilitou o exame físico, a biometria e a colheita de sangue. Para o PRNT $_{50}$ foram utilizadas duas cepas virais distintas, uma selvagem (JabSPM02) e outra vacinal (17DD). 87,18\% (34/39) dos animais foram positivos pela cepa selvagem, com títulos de anticorpo variando de 10 a 160 . Diferentemente, pela cepa vacinal, nenhum animal foi positivo. Ao avaliar a presença de antígeno viral NS1-YFV e também a RT-qPCR todos foram negativos, não havendo evidências da circulação viral naquela região, no momento do estudo. A população de $\mathrm{PNH}$ mais abundante no local estudado foi a espécie $C$. penicillata, e consequentemente a mais frequente nas capturas. A alta soropositividade nessa espécie aliada a boa condição clínica dos animais sugere que essa espécie se infecta pelo YFV, vindo à óbito somente em raras ocasiões e, portanto, possivelmente menos susceptível. Embora seja a espécie mais frequente em áreas urbanas, não pode ser considerada espécie sentinela por não sucumbirem à infecção, e por não se saber quão intensa é a viremia do YFV nestes animais, o que é ruim do ponto de vista da saúde pública. Contudo, um alto número de soropositividade significa uma possível proteção contra um novo surto na região, até que a população de PNHs susceptíveis seja renovada. Ademais, deve-se considerar que as populações do gênero Alouatta reduziram significativamente em todo o estado, fazendo com que a sensibilidade de detecção de um próximo surto seja prejudicada. Dessa maneira, recomenda-se uma revisão na metodologia de vigilância, uma vez que a vigilância passiva pode não ser suficiente para a detecção precoce do YFV, culminando no atraso da implantação de medidas preventivas, e consequentemente o óbito de seres humanos. Assim, a vigilância ativa parece ser mais assertiva em predizer possíveis risco no aumento da circulação viral e, consequentemente, a ocorrência de um surto.

Palavras-chave: vigilância de epizootias, febre amarela, primatas não humanos, zoonose reemergente, PRNT. 


\begin{abstract}
SICONELLI, M. J. L. The Yellow Fever virus impact on the population of nonhuman primates in the southern region of the Municipality of Ribeirão Preto - SP. 2019. 101f. Dissertação (Master degree). Faculdade de Medicina de Ribeirão Preto - Universidade de São Paulo, Ribeirão Preto, 2019.
\end{abstract}

The yellow fever virus (YFV) belongs to the genus Flavivirus (Flaviviridae family) and it is the sole virus causing the Yellow Fever disease (YF). YF is an acute infectious disease transmitted by mosquito vectors that, in its severe presentation, is characterized by fever and hemorrhages with a mortality rate of approximately 50\%. Two different cycles have been established in Brazil, an urban (Aedes aegypti) and another sylvatic (Haemagogus sp.; Sabethes sp.). The non-human primates (NHPs) are involved in the sylvatic one, whose lethality, depending on the species (i.e. Alouatta sp.), can exceed $80 \%$. This susceptibility makes it an excellent sentinel animal to detect the YFV outbreaks. Thus, surveillance of epizootic diseases in NHPs is an important epidemiological tool to prevent human cases. In 2016, the Municipality of Ribeirão Preto recorded the circulation of YFV in urban and periurban areas, affecting both, Callithrix penicillata monkeys and one human being. The objective of this study was to evaluate the impact of YFV infection on the NHP's population in the area where a human death occurred. For this purpose, the presence of neutralizing antibodies against YFV in NHPs was investigated by the $\mathrm{PRNT}_{50}$ technique and the possible viral circulation maintenance was evaluated through the NS1-YFV rapid test and RT-qPCR. The study was conducted in the southern region of Ribeirão Preto, covering an area of $5.77 \mathrm{~km}^{2}$. From April to December 2018, 39 animals were captured, being 38 C. penicillata and 01 Sapajus nigritus. They were captured with the Tomahawk traps and then underwent chemical restrainment by midazolam and ketamine, which allowed for physical examination, biometric evaluation and blood collection. For PRNT 50 , two distinct viral strains were used, a sylvatic (JabSPM02) and a vaccine (17DD). $87.18 \%$ (34/39) of the animals were positive for the sylvatic strain, with antibody titers ranging from 10 to 160 . In contrast, none animal neutralized the vaccine strain. When the presence of NS1-YFV viral antigen and also RT-qPCR were evaluated in the collected samples, all animals were negative, with no evidence of viral circulation in that region, at the time of the study. The most abundant NHP population in the study site was the $C$. penicillata species, and consequently the most frequent captured animals. The high seropositivity in this species combined with the good clinical condition of the animals suggest that this species is less susceptible to YFV infections and die only on rare occasions. Although it is the most common species in urban areas, it cannot be considered a sentinel animal because they do not succumb to the infection and because it is unknown how intense YFV viremia is in these animals, which is a drawback from the public health point of view. On the other hand, a high number of seropositivity points at a possible protection against a new outbreak in that region, until the susceptible NHP population is renewed. In addition, it should be considered that populations of the genus Alouatta have been reduced significantly throughout the state, lowering the detection sensitivity of an upcoming outbreak. Thus, a revision of the surveillance methodology is recommended, since passive surveillance may not be enough for early detection of YFV, culminating in the delay of implementation of preventive measures, and consequently the death of humans. Finally, active surveillance seems to be more assertive to predict a possible risk of the increase of YFV circulation and, consequently, the occurrence of an outbreak.

Key words: Epizooties surveillance, Yellow Fever, Non-Human Primates, Reemerging zoonosis, PRNT 


\section{LISTA DE FIGURAS}

Figura 1. A) Mapa do Brasil com destaque para o Estado de São Paulo em VERMELHO; B) MAPA DO ESTADO DE SÃo PAUlO SUBDIVIDIDO POR REGIÕES DE SAÚdE, DESTACANDO-SE A REGIÃO XIII, EM AZUL, ONDE ESTÁ LOCALIZADO O MUNICÍPIO DE RIBEIRÃO PRETO. FONTE: A: HTTPS:/COMMONS.WIKIMEDIA.ORG/WIKI/FILE:SAOPAULO_MESOMICROMUNICIP. SVG; B: HTTP://NEPHRP.COM.BR/NEPH-DRS.HTML 32

Figura 2. MAPA dOS MUNICÍPIOS QUE COMPÕE A REGIÃo DE SAÚDE XIII E O GVE XXIV. ÁREA DESTACADA COM PONTOS AZUIS CORRESPONDE AO MUNICÍPIO DE RIBEIRÃO Preto. Verde: Horizonte VERdE; AMARELO: AquífERo GuARANI; VERMELHO ALARANJADO: VALE DAS CACHOEIRAS. FONTE: HTTP:/NEPHRP.COM.BR/NEPHDRS.HTML

FigurA 3. VISTA AÉREA DO MUNICÍPIO DE RIBEIRÃo PRETO E REGIÃO. LINHA AZUL: TRECHO aQuÁtico, Rio "RIBEIRÃo PRETO", CRUZANDO O MUNICÍPIO; PONTO VERMELHO (LOSANGO): ANIMAIS DA ESPÉCIE ALOUATTA CARAYA, POSITIVOS PARA FEBRE AMAREla (FA); PONTO VERMELHO (H): CASO HUMANO POSITIVO PARA FA; Pontos AMARELOS (LOSANGO): ANIMAIS DA ESPÉCIE CALLITHRIX PENICILLATA, POSITIVOS PARA FA. FONTE: GOOGLE EARTH, 2019.

Figura 4. Vista AÉREA da REGIÃo SUl MunicíPIO DE RibEIRÃo PRETO E OS RESPECTIVOS LOCAIS ONDE AS CAPTURAS FORAM REALIZADAS. LINHA AZUL: TRECHO AQUÁTICO, RIO “RIBEIRÃo PRETO”; PONTO VERMELHO (H): CASO HUMANO POSITIVO PARA FA; GOOGLE EARTH, 2019.

Figura 5. INVESTIGAÇÃO EPIDEMIOLÓGICA DE EPIZOOTIA DE FEBRE AMARELA, CONDUZIDA PElo CVE/SES/SP E SVS/MS nO MunicíPIO DE SÃo Roque, SÃo PAulo, DURANTE O SURTO EM 2017. VISUALIZA-SE OS EQUIPAMENTOS DE PROTEÇÃO INDIVIDUAL (EPIS) REQUERIDOS PARA A ATIVIDADE, COMO: ÓCULOS DE PROTEÇÃO, MÁSCARA DE PROTEÇÃO RESPIRADOR PFF3/P3, AVENTAL DE MANGA LONGA E CUMPRIDO, LUVAS E BOTAS.

FIGURA 6. ESPÉCIES DE PRIMATAS NÃO HUMANOS COMUNS NO MUNICÍPIO DE RIBEIRÃO PRETO E REgião. A) CALLITHRIX PENICILlata (SAgui de tufos PRETOS); B) SAPAJUS NIGRITUS (MACACO-PREGO); C) ALOUATTA CARAYA (BUGIO PRETO)...................... 36

FigURA 7. ARMADILHAS TIPO TOMAHAWK UTILIZADAS DURANTE AS CAPTURAS. A E D) CONDOMÍNIO RESIDENCIAL "QUINTA DA BOA VISTA B”, ARMADILHA PEQUENA (50 X 21,5 X 20 CM) PARA CAPTURA DE SAGUIS, CEDIDAS PELA SUCEN/SP; C E D) EERP, ARMADILHA MÉDIA ( 90 X 45 X 50 CM) PARA CAPTURA DE MACACOS-PREGO, CEDIDAS PELA SVS/MS.

Figura 8. PNHS CAPTURAdOS NA REGIÃO SUl dO MunicíPIO DE RibEIRÃo PRETO. A E C) PNHS DA ESPÉCIE CALLITHRIX PENICILLATA; B) PNH FÊMEA DA ESPÉCIE SAPAJUS NIGRITUS..... 38

Figura 9. ANIMAIS CAPTURADOS ACIDENTALMENTE. A E B) DIDELPHIS ALBIVENTRIS(GAMBÁDE-ORELHA-BRANCA); C) TANGARA SAYACA (SANHAÇU-CINZENTO); D) ICTERUS PYRRHOPTERUS (ENCONTRO).

FIGURA 10. A) LIMITADOR DE ESPAÇO SENDO UTILIZADO PARA ENCURRALAR O ANIMAL EM UM CANTO DA ARMADILHA, FACILITANDO A APLICAÇÃO DA MEDICAÇÃO ANESTÉSICA; B) APLICAÇÃO DA MEDICAÇÃO ANESTÉSICA ATRAVÉS DA ARMADILHA, EM PNH DA ESPÉCIE C. PENICILLATA.

FIGURA 11. EQUIPAMENTOS UTILIZADOS À CAMPO PARA A REALIZAÇÃO DA AVALIAÇÃO DOS animais e COlHeita DE SANGUE. A e D) MEsa COM todos os EQUiPAMENTOS E 
INSUMOS NECESSÁRIOS PARA AVALIAÇÃO, BIOMETRIA E COLHEITA DE SANGUE DOS ANIMAIS E ARMAZENAMENTO/TRANSPORTE DAS AMOSTRAS; B) CAIXA DE MEDICAÇÃO E INSUMOS PARA COLHEITA DE SANGUE; C) ARMADILHA PARA CAPTURA DE PNHS DA ESPÉCIE C. PENICILLATA, LIMITADOR DE ESPAÇO TIPO GARFO E CAIXA DE RECUPERAÇÃO PÓS-ANESTESIA.

Figura 12. PROCEDIMENTO DE AVALIAÇÃO FÍSICA, COLHEITA DE SANGUE, E BIOMETRIA. A) CONTENÇÃO DO PNH PARA COLHEITA DE SANGUE; B) AVALIAÇÃO DA CAVIDADE ORAL DA FÊMEA DE $S$. NIGRITUS; C) AVALIAÇÃO DA REGIÃO DA VENOPUNÇÃO; D) EXAME FÍSICO; E) C. PENICILLATA SENIL, CAPTURA NO CONDOMÍNIO RESIDENCIAL QUINTA DA BOA VISTA "B".

FIGURA 13. PNH SENDO COLOCADO NA CAIXA DE RECUPERAÇÃO, PARA RETORNO DA ANESTESIA, APÓS O FIM DO PROCEDIMENTO.

Figura 14. PRNT DA AMOSTRA P20SA0718 EM PLACA DE 24 POÇOS, DA DILUIÇÃO 1:10 ATÉ 1:5120 (EM DUPLICATA), CORADO COM CRISTAL VIOLETA APÓS 5 - 6 DIAS INCUBAÇÃO. ÁREA ROXA: TAPETE CELULAR INTEGRO, SEM EFEITO CITOPÁTICO; PONTOS BRANCOS/TRANSPARENTES: EFEITO CITOPÁTICO (PLAQUES), CAUSADO PELA INFEÇÃO VIRAL. CV: CONTROLE DE VÍRUS; CN: CONTROLE NEGATIVO (AMOSTRA HUMANA ISENTA DE ANTICORPOS ANTI-YFV, NA DILUIÇÃO 1:10)......45

FIGURA 15. ESQUEMA DE UM TESTE RÁPIDO PARA O ANTÍGENO NS1 E SUAS POSSÍVEIS INTERPRETAÇÕES. HONTE: HTTP://PORTUGUESE.CUSTOM-MONO CLONALANTIBODY.COM/SALE-3166512-DENGUE NS1-RAPID-MEDICAL-HOMERAPID-URINE-DRUG-ABUSE-TEST-KIT.HTML ..................................................4

Figura 16. VALIDAÇÃO DO TESTE RÁPIDO IMUNOCROMATOGRÁFICO ASAN EASY TEST ${ }^{\circledR}$ YELLOW FEVER NS1 AG COM AMOSTRA DE SANGUE TOTAL DE PNH QUE VEIO À ÓBITO POR FEBRE AMARELA, CONFIRMADO POR RT-QPCR E IMUNOHISTOQUÍMICA.

Figura 17. Vista AÉREA dA REGIÃo SUl MunicíPIO DE RIBEIRÃo PRETO E OS RESPECTIVOS PONTOS ONDE AS CAPTURAS FORAM REALIZADAS. LINHA AZUL: TRECHO AQUÁTICO, RIO "RIBEIRÃO PRETO"; PONTO VERMELHO (H): CASO HUMANO POSITIVO PARA FA; Ponto Roxo (losango): PNHs da espécie C. Penicillata; Ponto verde (LOSANGO): PNH DA ESPÉCIE S. NIGRITUS. GOOGLE EARTH, 2019.

Figura 18. MiCROFILÁRIAS DO MORFOGRUPO MANSONELLA EM SANGUE DE PNH (C. PENICILLATA) ADULTO, CORADAS POR PANÓTICO RÁPIDO ${ }^{\circledR}$. A) PARTE POSTERIOR DA MICROFILÁRIA, EM AUMENTO DE 40X; B) MICROFILÁRIA EM AUMENTO DE 100X,

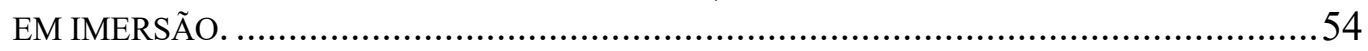

FigurA 19. DIFERENÇA ENTRE PRNT 50 DA AMOSTRA P36MP0918, COM DILUIÇÃO SERIADA (FATOR 2) DE 1:10 ATÉ 1:5.120 (EM DUPLICATA) UTILIZANDO AS DIFERENTES CEPAS DO VÍRUS DA FEBRE AMARELA. NA PRIMEIRA PLACA (À ESQUERDA) FOI UTILIZADA A CEPA SELVAGEM JABSPM02 E NOTA-SE A REDUÇÃO $\geq 50 \%$ NO NÚMERO DE PLAQUES (NEUTRALIZAÇÃO) ATÉ A DILUIÇÃO 1:160. JÁ NA SEGUNDA PLACA (À DIREITA) UTILIZOU-SE A CEPA VACINAL 17DD, NÃO SENDO POSSÍVEL IDENTIFICAR A NEUTRALIZAÇÃO EM NENHUMA DAS DILUIÇÕES. O MESMO RESULTADO FOI OBSERVADO NAS OUTRAS AMOSTRAS DOS PNHS TESTADAS COM O VÍRUS SELVAGEM (JABSPM02) E VACINAL (17DD). CV: CONTROLE DE VÍRUS; CN: CONTROLE NEGATIVO (AMOSTRA HUMANA ISENTA DE ANTICORPOS ANTI-YFV, NA DILUIÇÃO 1:10). .55

Figura 20. TESTE RÁPIDO IMUNOCROMATOGRÁFICO ASAN EASY TEST ${ }^{\circledR}$ YELLOW FEVER NS1 Ag(Asan Pharm, SeOUl, Korea). TODAS AS AMOSTRAS Foram NEGATIVAS, NÃO TENDO SIDO DETECTADA A PRESENÇA DA SEGUNDA BANDA EM NENHUM DOS TESTES. 


\section{LISTA DE TABELAS}

TABEla 1. OligonUCleotídeOS UTILIZAdOS NA DETECÇÃo DO RNA DO YFV POR RT-PCR

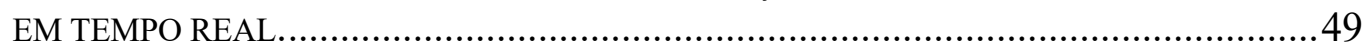

TABEla 2. PARÂMETROS HEMATOLÓGICOS DE PRIMATAS NÃO HUMANOS, DA ESPÉCIE CALLITHRIX PENICILLATA, DE VIDA LIVRE CAPTURADOS EM ÁREA URBANIZADA DO MUNICÍPIO DE RIBEIRÃO PRETO/SP. .53

TABELA 3. RESULTADOS DO PRNT 50 (EXPRESSO EM TÍTULOS DE ACORDO COM A DILUIÇÃO), NS1 - YFV (ASAN) E YFV RT-QPCR DAS AMOSTRAS DE PNHS CAPTURADOS NA REGIÃO SUL DE RIBEIRÃO PRETO, ENTRE ABRIL E DEZEMBRO DE 2018. 


\section{SUMÁRIO}

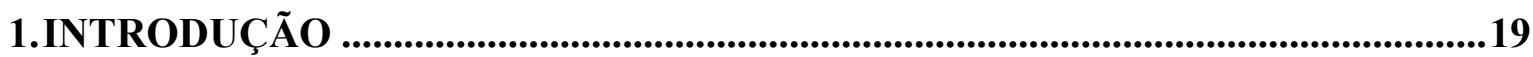

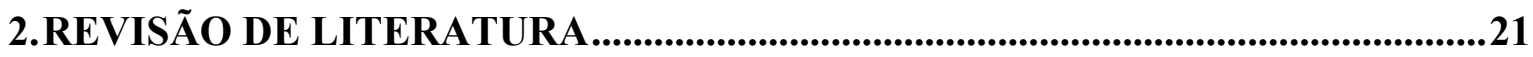

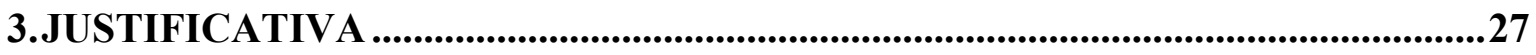

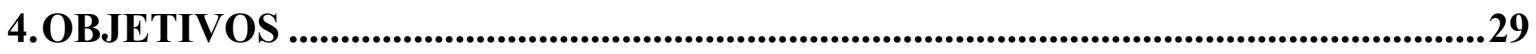

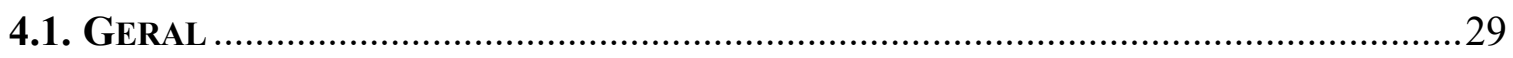

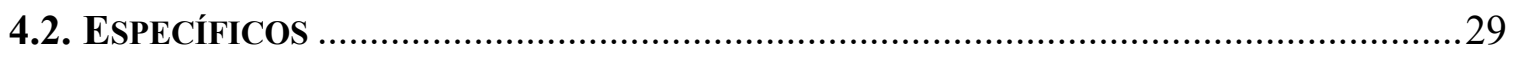

5.MATERIAIS E MÉTODOS ...................................................................................31

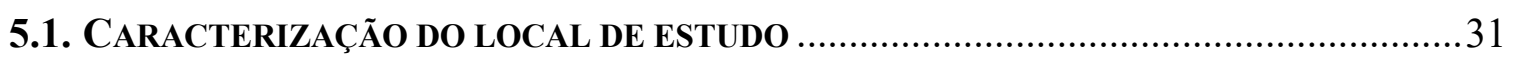

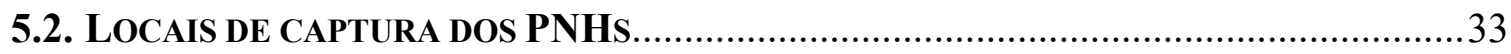

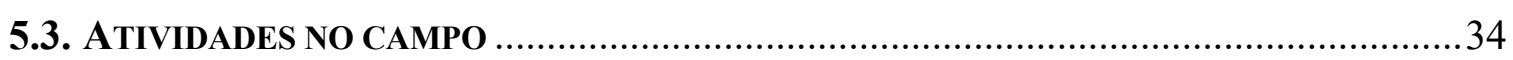

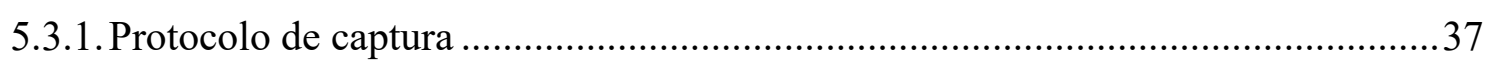

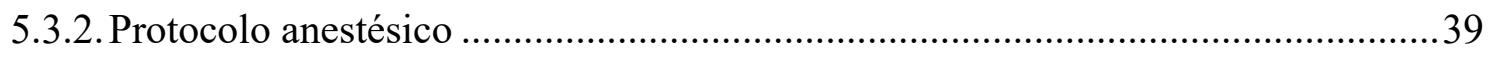

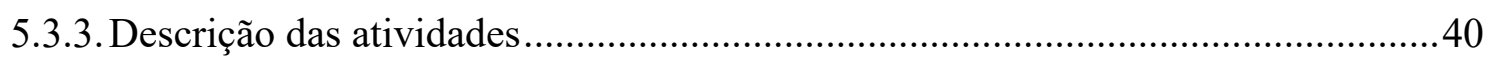

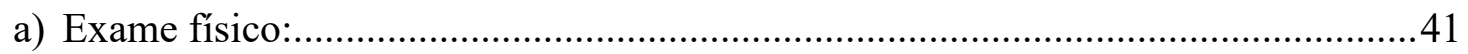

b) Coleta e processamento de material biológico:..........................................................4 41

c) Acondicionamento e encaminhamento das amostras: ...........................................42

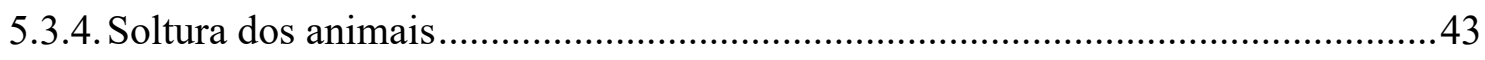

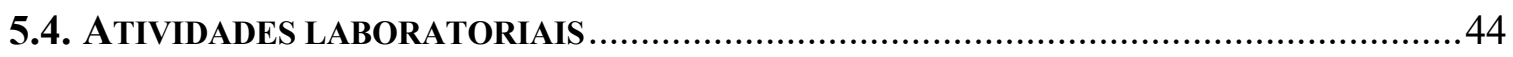

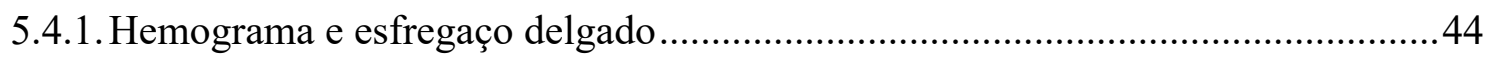

5.4.2. Detecção de anticorpos neutralizantes anti-YFV nas amostras clínicas de PNH por PRNT (Plaque Reduction Neutralization Test) ..............................................4

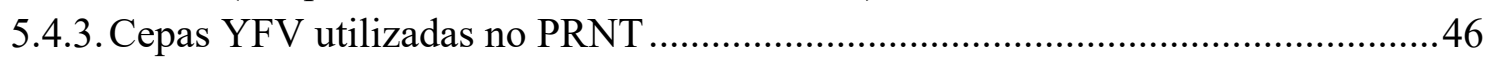

5.4.4. Detecção da circulação do vírus da febre amarela na população de primatas não

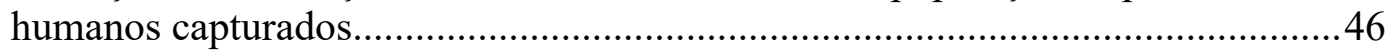

5.4.4.1. Detecção de antígeno viral NS1 do vírus da febre amarela..........................47

5.4.4.2. Diagnóstico molecular para o vírus da febre amarela ...................................48

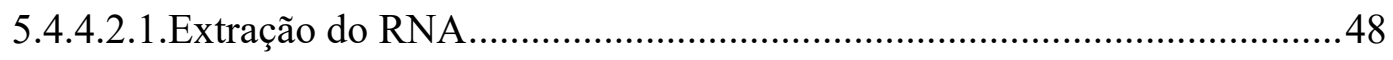

5.4.4.2.2.RT-qPCR para febre amarela silvestre .............................................. 48

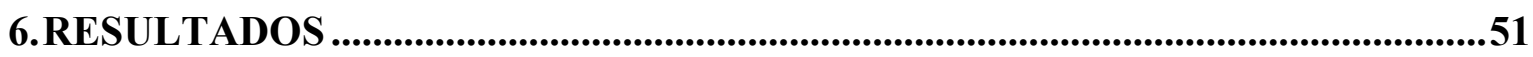

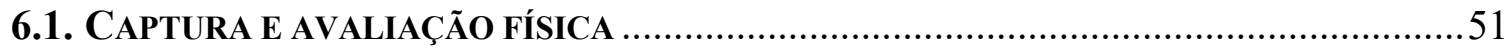

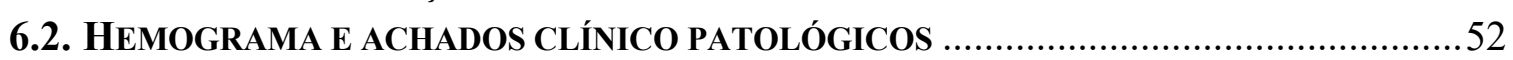

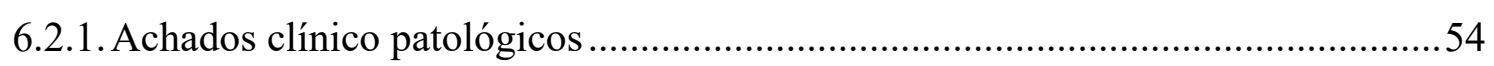

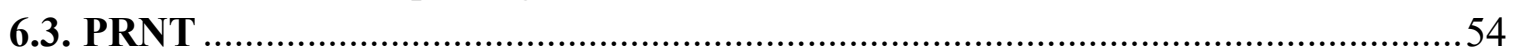

6.4. DETECÇÃO DO ANTÍGENO NS1 PARA O VÍRUS DA FEBRE AMARELA...........................55

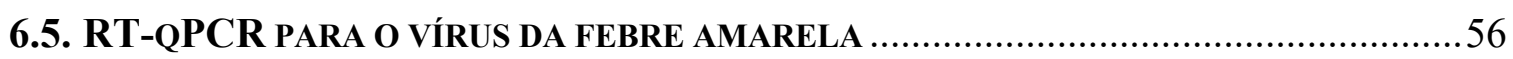

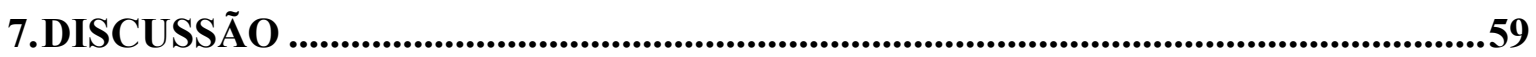

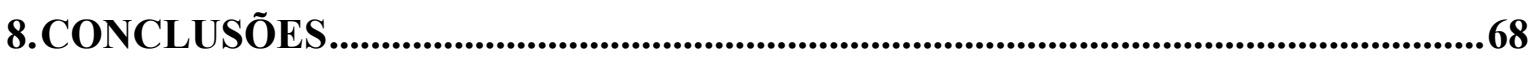

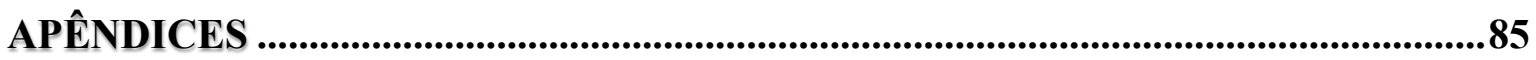

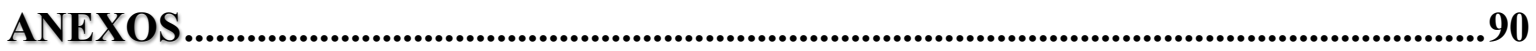




\section{INTRODUÇÃO}




\section{INTRODUÇÃO}

A febre amarela (FA) resulta da infecção pelo vírus do mesmo nome e caracteriza-se por ser uma enfermidade infecciosa aguda e não contagiosa que, na sua forma mais grave, manifesta-se com sinais hemorrágicos. A FA foi responsável pela morte de milhares de pessoas no século passado e que, atualmente, devido a sua reemergência da sua forma silvestre, preocupa as autoridades de saúde do país. Entre 2016 e 2019, foram registradas mais de 2000 mil mortes no Brasil.

A transmissão do vírus nos primatas não humanos $(\mathrm{PNH})$ e no ser humano se dá pela picada das fêmeas de insetos hematófagos da família Culicidae, destacando-se os gêneros Aedes, Haemagogus e Sabethes. Epidemiologicamente, no Brasil observam-se dois ciclos de transmissão, um urbano e outro silvestre, cuja diferença se dá exclusivamente pelo vetor envolvido, o que caracteriza também o ambiente de transmissão.

A FA urbana no Brasil teve seu último caso em 1942 no Acre, não havendo, desde então, registros semelhantes confirmados. Contudo, devido a infestação pelo Ae. aegypti e Ae. albopictus, em todo o território nacional, a preocupação das autoridades sanitárias de que ocorra a reurbanização da doença é constante. Fato esse que é agravado pela presença de PNHs em centros urbanos, situação em que seres humanos e PNHs convivem diretamente.

Diante disso, a vigilância de epizootias em PNH caracteriza-se como evento sentinela e constitui uma ferramenta essencial dentro do Programa de Vigilância, Prevenção e Controle da FA para a detecção precoce da circulação do vírus, fornecendo dados para a implementação de atividades de prevenção e controle, evitando que a doença chegue à população humana e ocasione óbitos. 
REVISÃO DE LITERATURA 


\section{REVISÃO DE LITERATURA}

O vírus da febre amarela (do inglês, International Committee on Taxonomy of Viruses ICTV: Yellow Fever Virus - YFV) é considerado o vírus protótipo do gênero o qual pertence, Flavivirus e à família Flaviviridae. Esse gênero compreende mais de 70 vírus, sendo alguns exemplos dengue (DENV), Zika (ZIKV), Ilhéus (ILHV), Febre do Nilo Ocidental (WNV), Encefalite de Saint Louis (SLEV), Rocio (ROCV), Bussuquara (BSQV), Encefalite Japonesa (JEV) (ZANOTTO et al., 1995; VASCONCELOS, 2003; MAEDA; MAEDA, 2013; PIERSON; DIAMOND, 2013; MONATH; VASCONCELOS, 2015; MORALES et al., 2017). É um vírus envelopado de cadeia simples de RNA, de aproximadamente $11 \mathrm{~Kb}$, sentido positivo, que codifica uma única poliproteína, dividida em estrutural ( $\mathrm{C}, \mathrm{prM}$, and $\mathrm{E})$ e não estrutural (NS1, NS2A, NS2B, NS3, NS4A, NS4B, e NS5) (RICE et al., 1985; CHAMBERS et al., 1990; STAPLES et al., 2018).

Nas Américas, a FA apresenta dois diferentes ciclos de transmissão, o urbano e o silvestre, que se diferenciam apenas pela espécie do mosquito transmissor e ambiente de ocorrência (CONSOLI et al., 1998). O ciclo urbano caracteriza-se pela transmissão ser humanomosquito, sendo o Aedes aegypti o vetor responsável por transmitir a doença. Já o ciclo silvestre é mais complexo e várias espécies de mosquito podem estar envolvidas na transmissão; por exemplo, na África os mosquitos responsáveis são do gênero Aedes e na América dos gêneros Haemagogus e Sabethes (STRODE, 1951). O ciclo natural de transmissão de FA envolve primatas não humanos e mosquitos silvestres (TIGERTT et al., 1960; MONATH et al., 1981).

$\mathrm{Na}$ América Latina, a transmissão do vírus se dá, geralmente, pelo ciclo silvestre, que envolve PNH e mosquitos dos gêneros Haemagogus (Hg. janthinomys, Hg. albomaculatus e Hg. leucocelaenus) e Sabethes (Sa. chloropterus), os quais infectam acidentalmente seres humanos (CONSOLI et al., 1998). No Brasil, a espécie Hg. janthinomys é a que mais se destaca na manutenção do vírus no ambiente silvestre (BRASIL, 1999). Contudo, no Estado de São Paulo, na epizootia de 2008 a 2009, isolou-se pela primeira vez o vírus da FA em um mosquito Hg. leucocelaenus, mostrando que a complexidade do ciclo silvestre varia de acordo com a região estudada (SOUZA et al., 2011). Esses mosquitos possuem hábitos diurnos e habitam as copas das árvores, onde picam os hospedeiros, às vezes descendo ao solo, na presença de humanos ou quando a densidade de macacos é baixa (BRASIL, 1999).

O ciclo silvestre é endêmico nas regiões tropicais da África e das Américas, como por exemplo a região amazônica, apresentando-se sob a forma de surtos com intervalos conhecidos de tempo, que em média variam de cinco a sete anos, chegando até dez anos, alternados por 
períodos com menor número de casos (VASCONCELOS, 2003; SOUZA, 2013; BRASIL, 2016a). Pode-se averiguar claramente essa periodicidade nos surtos registrados no Estado de Goiás, Brasil, nos anos de 1972/1973, 1980, 1988, 2000 e 2007/2008 (PINHEIRO et al., 1978; VASCONCELOS et al., 2001; VASCONCELOS, 2002; 2003; 2010). Esses ciclos ou intervalos epizoóticos ocorrem provavelmente em decorrência da renovação de populações de $\mathrm{PNH}$, já que novos susceptíveis permitem que o vírus circule e se amplifique, o que não ocorre com a população de vetores, mesmo considerando a possibilidade de transmissão transovariana (VASCONCELOS, 2010).

De forma geral, as espécies de PNH presentes na América do Sul são susceptíveis ao YFV (SOUZA, 2013). Entre os símios neotropicais a doença se apresenta em proporções epizoóticas, sobretudo nos do gênero Alouatta (bugio), nos quais geralmente verifica-se elevada mortalidade, representando uma preocupação em relação à conservação da espécie e equilíbrio ecológico da área (HOLZMANN et al., 2010, ALMEIDA et al., 2012; FIALHO et al., 2012, MORENO et al., 2013). Essa espécie, quando infectada laboratorialmente com doses mínimas do vírus da febre amarela, desenvolve infecção fulminante, comportamento similar aos casos humanos fatais (STRODE, 1951). Outros primatas gravemente afetados são: Ateles sp. (macaco-aranha), Aotus sp. (macaco-da-noite) e espécies dos gêneros Saguinus, Cebus, Sapajus, Callithrix e Callicebus. Os macacos do gênero Cebus e Sapajus, apesar de se infectarem facilmente, apresentam infecção subclínica com baixa letalidade e, geralmente, desenvolvem imunidade protetora, podendo apresentar anticorpos neutralizantes, indicando provável infecção e sobrevivência (VASCONCELOS, 2003; KINDLOVITS et al., 2009; LIMA et al., 2010). Primatas do gênero Callithrix (saguis) revelam-se muito sensíveis ao vírus amarílico, sendo na maioria das vezes letal (LAEMMERT, 1944).

O diagnóstico da FA tanto em seres humanos, quanto em PNHs poder ser realizado por isolamento viral, detecção do genoma viral por biologia molecular, exames histopatológicos e sorologia; a técnica a ser escolhida depende do tempo de evolução da doença (MAEDA; MAEDA, 2013; BRASIL, 2019a). Por ser uma doença de evolução aguda, utiliza-se com maior frequência e agilidade a RT-qPCR para a identificação da presença de genoma viral circulante, contudo isso só é possível durante o período virêmico, que dura de 3 a 6 dias. (MONATH, 2001; STAPLES et al., 2018). A partir do $5^{\circ}$ dia do início dos sintomas, podem ser empregadas técnicas sorológicas como o ELISA, IH (inibição da hemaglutinação), IF (imunofluorescência) e PRNT (plaque reduction neutralization test), contudo em países tropicais a chance de reatividade cruzada entre outros vírus da mesma família é alta (VASCONCELOS, 2003; MAEDA; MAEDA, 2013; MONATH; VASCONCELOS, 2015; STAPLES et al., 2018; 
BRASIL, 2019a). O PRNT ou neutralização viral, embora de difícil realização, é a técnica padrão ouro para diagnóstico de Flavivirus, reduzindo a reatividade cruzada e permitindo a diferenciação entre outros Flavivirus (KUNO, 2003; ROEHRIG et al., 2008; MAEDA; MAEDA, 2013). Assim, a associação de diferentes técnicas sorológicas pode ajudar a fornecer um diagnóstico mais fidedigno.

Desde 1942, em, Sena Madureira, não há registros no Brasil da transmissão da FA pelo vetor Ae. aegypti. Apesar disso, nas Américas, o último registro da FA urbana foi em TrinidadTobago, ano de 1954. Até 2008, os surtos de FA na América do Sul mantiveram-se, exclusivamente, no ciclo silvestre, quando então no Paraguai houve a reemergência do ciclo urbano (BRASIL, 2008a). Diferente do destacado, todos os casos confirmados entre 2016 e 2017 no Brasil foram classificados como casos de FA silvestre. Os focos endêmicos até 1999 estavam situados nos estados das regiões Norte, Centro-Oeste e área pré-amazônica do Maranhão, além de registros esporádicos na parte oeste de Minas Gerais (BRASIL, 2016a,b).

Em 2000, houve transmissão humana nas regiões da Bahia e de São Paulo, as quais por muito tempo não apresentaram casos autóctones. Na região noroeste do Estado de São Paulo, nos Municípios de Santa Albertina e Ouroeste, dois óbitos humanos por FA, com provável autoctonia, foram confirmados (SAAD; BARATA, 2016). Esse foi o primeiro registrado no Estado de São Paulo, após a década de 40 (VASCONCELOS, 2010). A partir daí, em 2001, após a confirmação da reintrodução do vírus no Estado, ampliaram-se as áreas de recomendação da vacina, chegando a 277 municípios, abrangendo nove Grupos de Vigilância Epidemiológica (GVE) (SAAD; BARATA, 2016). Nos anos seguintes, 2001 e 2002, em Minas Gerais também foram notificados casos em pelo menos duas regiões (RIBEIRO; ANTUNES, 2009). Ainda em 2001, no oeste do Rio Grande do Sul, constataram-se óbitos de PNH e a circulação do vírus na população foi confirmada laboratorialmente.

Diferentemente do que vinha ocorrendo, nos anos 2000 a 2003 pode-se observar a expansão da circulação viral no sentido leste-sul do País, detectando-se a presença do vírus em áreas tidas como silenciosas por várias décadas. De acordo com Ribeiro e Antunes (2009), em 2002 e 2003, na região de Diamantina, leste de Minas Gerais, considerada indene, foram notificados 36 casos autóctones de FA e essa situação contribuiu para a redefinição das áreas de risco no Brasil, em 2003 (BRASIL, 2005a,b).

A partir de então, além da ampliação da área de transição, foi estabelecida uma nova área, de risco potencial, dentro da área indene, englobando municípios do sul de Minas Gerais, da Bahia e a região centro-norte do Espírito Santo (COSTA et al., 2002; BRASIL, 2005a,b). Até 2003, no Brasil, a área endêmica abrigava uma população de aproximadamente 30 milhões 
de habitantes (BRASIL, 2005a,b). A nova área epizoótica ou de transição foi formada por parte das regiões oeste do Piauí, Bahia, Minas Gerais, São Paulo, Paraná, Santa Catarina e Rio Grande do Sul. As regiões central e/ou leste desses estados, bem como os demais estados localizados na costa brasileira, são considerados indenes, onde vivem cerca de 115 milhões de habitantes (VASCONCELOS, 2003; BRASIL, 2005a,b).

No Estado de São Paulo, no ano de 2008, nos meses de janeiro a junho, foi registrada a morte de 140 macacos em área de transição para FA. Das 140 amostras obtidas, apenas 96 $(68,6 \%)$ foram enviadas para diagnóstico, sendo confirmada, laboratorialmente, a ocorrência de epizootia pelo vírus da FA na região de Mendonça, Nova Aliança e Urupês. Bady Bassit teve um caso confirmado por critério epidemiológico, sendo que todas essas cidades pertencem à região de São José do Rio Preto (SÃO PAULO, 2008). No mesmo ano, 2008, nos meses de abril e maio, na região nordeste do Estado de São Paulo, foram notificados dois óbitos humanos autóctones, confirmados pela imuno-histoquímica para FA, nos Municípios de Cravinhos e Luís Antônio, região de Ribeirão Preto, ambos com histórico de não vacinação e atividade de risco (pescaria) (SAAD; BARATA, 2016). Durante a investigação epidemiológica foram coletadas amostras de humanos, macacos e vetores, resultando positivas três amostras humanas e quatro de macacos na pesquisa de anticorpos IgM. Também foi isolado o vírus de mosquitos provenientes do Município de Urupês, região de São José do Rio Preto. Diante da expansão geográfica do vírus, ampliaram-se as áreas com recomendação de vacinação para residentes e viajantes, onde foram incluídos mais 62 municípios dos GVEs de Araraquara e Bauru (BRASIL, 2008b,c; COIMBRA et al., 2008; SÃO PAULO, 2009)

A partir desses casos, em outubro de 2008, o Ministério da Saúde realizou uma nova delimitação, considerando fatores como circulação viral, ecossistemas, corredores ecológicos, trânsito de pessoas, tráfico de animais silvestres e critérios de ordem operacional; também organizou a rede de serviços de saúde para que facilitasse os procedimentos operacionais e logísticos nos municípios. Ficaram definidas duas grandes áreas, uma com recomendação de vacina - ACRV (áreas endêmicas, de transição, com a inclusão do sul de Minas Gerais, até então considerada "área indene de risco potencial), e outra área sem recomendação de vacina ASRV (áreas indenes, o sul da Bahia e o norte do Espírito Santo) (BRASIL, 2016a). Atualmente, face à crescente ocorrência de casos em ASRV, foi incluída a área com recomendação temporária de vacina (BRASIL, 2017a,b).

No ano de 2009, de fevereiro a abril, 138 casos humanos suspeitos foram notificados no Estado de São Paulo e a doença assumiu caráter epidêmico na região de Botucatu, área que era tida como indene e sem recomendação de vacinação. Na ocasião, esse evento foi considerado 
internacionalmente como uma emergência em saúde pública de importância nacional, previsto no Regulamento Sanitário Internacional de 2005. Dos casos notificados, 28 foram confirmados em cinco municípios da região (Sarutaiá, Piraju, Avaré, Buri e Tejupá), 11 deles com óbito (BRASIL, 2014; BRASIL, 2008b,c; BRASIL, 2009). Com a comprovação da circulação do vírus da FA nesses municípios, a área de recomendação de vacinação no Estado de São Paulo foi ampliada, incluindo mais 49 municípios abrangendo cinco GVEs (Figura 5) (BRASIL, 2008b,c; SÃO PAULO, 2009; MARKOFF, 2013; BRASIL, 2014).

Em 2016, no Brasil foram notificados seis casos humanos de FA confirmados para a OMS, sendo dois óbitos no Estado de São Paulo, um no mês de abril, no Município de Bady Bassit, e o outro em dezembro, no Município de Ribeirão Preto (SÃO PAULO, 2016a,b; BRASIL, 2017a; PAHO, 2017). Ainda em 2016, até o mês de dezembro, no Estado de São Paulo, foram efetuadas 163 notificações de PNH com suspeita de FA, totalizando 227 animais do quais 24 animais foram diagnosticados positivos nas regiões de Ribeirão Preto (Jaboticabal, Monte Alto e Ribeirão Preto); Barretos (Cajobi e Severínea) e São José do Rio Preto (Pindorama, Potirendaba, Catanduva, Ibirá, Adolfo, Catiguá e São José do Rio Preto (SÃO PAULO, 2016a,b; SICONELLI et al., 2019). De julho de 2016 a dezembro de 2018 o Brasil registrou cerca de 2.156 casos humanos confirmados, com 746 óbitos, e pelo menos 14.513 epizootias notificadas, sendo confirmadas laboratorialmente cerca de 1.525 (BRASIL, 2017c,d; 2018a,b). A região Sudeste foi responsável por mais de $90 \%$ de todos os casos notificados e confirmados no país durante esse período (BRASIL, 2017c,d; 2018a,b).

De janeiro a maio de 2019 foram notificados 1.281 casos humanos, sendo 82 confirmados. Destes, 14 evoluíram para óbito. No mesmo período foram notificadas 1.240 epizootia, com a confirmação de 48 . Vale ressaltar que, embora, até $22^{\mathrm{a}}$ semana epidemiológica, o maior número de casos em humanos confirmados tenha sido registrado no Estado de São Paulo, o maior número de epizootias confirmadas foi no Estado do Paraná (BRASIL, 2019b,c). Isso mostra que a circulação do YFV tem se sustentado e avançado no sentido sul do país, em áreas até então não afetadas, evidenciando a necessidade da manutenção da vigilância. 
JUSTIFICATIVA 


\section{JUSTIFICATIVA}

O conceito "One World, One Health" foi criado para promover a interdisciplinaridade e a multiprofissionalidade, promovendo a interface entre a saúde dos seres humanos, dos animais e do meio ambiente. Atualmente, estima-se que $60 \%$ dos patógenos que causam doenças nos seres humanos sejam zoonóticos, mantidos na natureza em ciclos enzoóticos (NORRIS, 2004; OIE, 2017). Exemplos disso são os vírus do gênero Flavivirus, muitos sendo transmitidos por vetores. Têm-se verificado nos últimos anos a emergência de novas enfermidades, como a febre Zika e Febre do Nilo Ocidental e também a reemergência de enfermidades tidas como controladas, como a FA, que surgem em forma de grandes surtos devido, principalmente, ao desequilíbrio ambiental ocasionado pelo ser humano.

Uma vez que a transmissão do YFV tem se mantido ativa no Brasil e, principalmente no Estado de São Paulo, faz-se necessário o desenvolvimento de novas estratégias de investigação, na busca de antecipar o aparecimento de casos humanos. A morte de PNHs mostra apenas o "rastro" por onde o YFV passou, ou seja, a vigilância passiva está sempre um passo atrás. Assim, a vigilância ativa em PNHs pode detectar precocemente a circulação do vírus, antes que este chegue a locais com populações susceptíveis e predizer o risco de um surto, antes que esteja instalado. Dessa maneira, o serviço de vigilância conseguira instituir ações para prevenir casos humanos.

No ano de 2016 o Município de Ribeirão Preto/SP se destacou, pois vivenciou uma epidemiologia fora dos moldes clássicos, com três PNHs do gênero Callithrix positivos para FA em área urbana, região central do município; ademais, não foram encontrados nesses locais vetores silvestres, vetores urbanos positivos, ou casos humanos confirmados. Tais circunstâncias inferem o surgimento de um novo padrão epidemiológico da enfermidade, de forma que o ciclo de transmissão do vírus vem se adaptando às pressões ambientais, moldadas pela inter-relação de componentes silvestres e de seres humanos em áreas urbanizadas, necessitando-se, portanto, de estudos para melhor compreensão. 


\section{OBJetivos}




\section{OBJETIVOS}

\subsection{Geral}

Avaliar o impacto da infecção pelo vírus da febre amarela na população de primatas não humanos da área urbanizada do Município de Ribeirão Preto/SP, tomando-se como referência as áreas próximas à ocorrência de um caso humano autóctone.

\subsection{Específicos}

- Mapear as áreas com presença de PNHs no perímetro periurbano/urbanizado na região sul de Ribeirão Preto, onde houve o registro do caso humano confirmado;

- Realizar a captura, georreferenciamento, colheita de sangue e marcação (nanochips) dos primatas não humanos;

- Avaliar a soroprevalência da febre amarela por meio da presença de anticorpos neutralizantes anti-YFV pelo Teste de Neutralização por Redução de Placas (PRNT ${ }_{50}$ );

- Avaliar a circulação do vírus da febre amarela pela pesquisa do antígeno NS1-YFV e por RT-qPCR;

- Avaliar o impacto do vírus da febre amarela na população de PNHs; 
MATERIAIS E MÉTOdos 


\section{MATERIAIS E MÉTODOS}

O presente estudo foi conduzido em parceria entre a Secretaria Municipal de Saúde de Ribeirão Preto, por meio do Departamento de Vigilância Ambiental em Saúde (DVAS), a Secretaria de Estado da Saúde de São Paulo, por meio da Superintendência de Controle de Endemias (SUCEN), o Ministério da Saúde, pela Secretaria de Vigilância em Saúde (SVS) e o Laboratório de Virologia Molecular, FMRP-USP, Ribeirão Preto/SP.

Pesquisadores do Laboratório de Virologia Molecular da FMRP/USP/Ribeirão Preto/SP foram responsáveis pelo trabalho de campo (captura dos primatas não humanos e a colheita de sangue), o processamento e o armazenamento das amostras colhidas e, também, pelo desenvolvimento e padronização do teste sorológico PRNT (Plaque Reduction Neutralization Test). As equipes técnicas das entidades parceiras forneceram apoio técnico e parte do material utilizado nas atividades de campo pela equipe.

Tendo em vista as regulamentações brasileiras para a realização do projeto foi obtida a autorização do Instituto Chico Mendes de Biodiversidade - Ministério do Meio Ambiente ICMBio/MMA por meio do Sistema de Autorização e Informação em Biodiversidade (SISBIO): autorização concedida n ${ }^{0}$ 61391-1 (ANEXO A); a aprovação da Comissão de Ética no Uso de Animais (CEUA), sob protocolo 010/2018 (ANEXO B) e aprovação da Instituto Florestal - Secretaria Estadual de Meio Ambiente, Carta COTEC n 367/2018 D62/2018 PM (ANEXO C). Ademais foram solicitadas autorizações à Secretaria Municipal de Saúde e Secretaria Municipal de Meio Ambiente para realizar a captura em áreas públicas do município, as quais também foram concedidas.

\subsection{Caracterização do local de estudo}

O Município de Ribeirão Preto localiza-se na região nordeste do Estado de São Paulo, nas coordenadas $21^{\circ} 10^{\prime} 40.00^{\prime \prime}$ Sul e 4748'36.00" Oeste (Figura 1). O município é cruzado pela Rodovia Anhanguera (SP-330), que liga São Paulo à divisa de Minas Gerais; além disso, é tido como polo industrial e também referência na área da saúde, o que traz ao município alto fluxo de pessoas, diariamente.

Na divisão administrativa da saúde, do Estado de São Paulo, Ribeirão Preto está inserido em um dos três territórios da área de cobertura do Grupo de Vigilância Epidemiológica (GVE) $\mathrm{n}^{\circ}$ XXIV, Aquífero Guarany, juntamente com os municípios de Jardinópolis, Guatapará, 


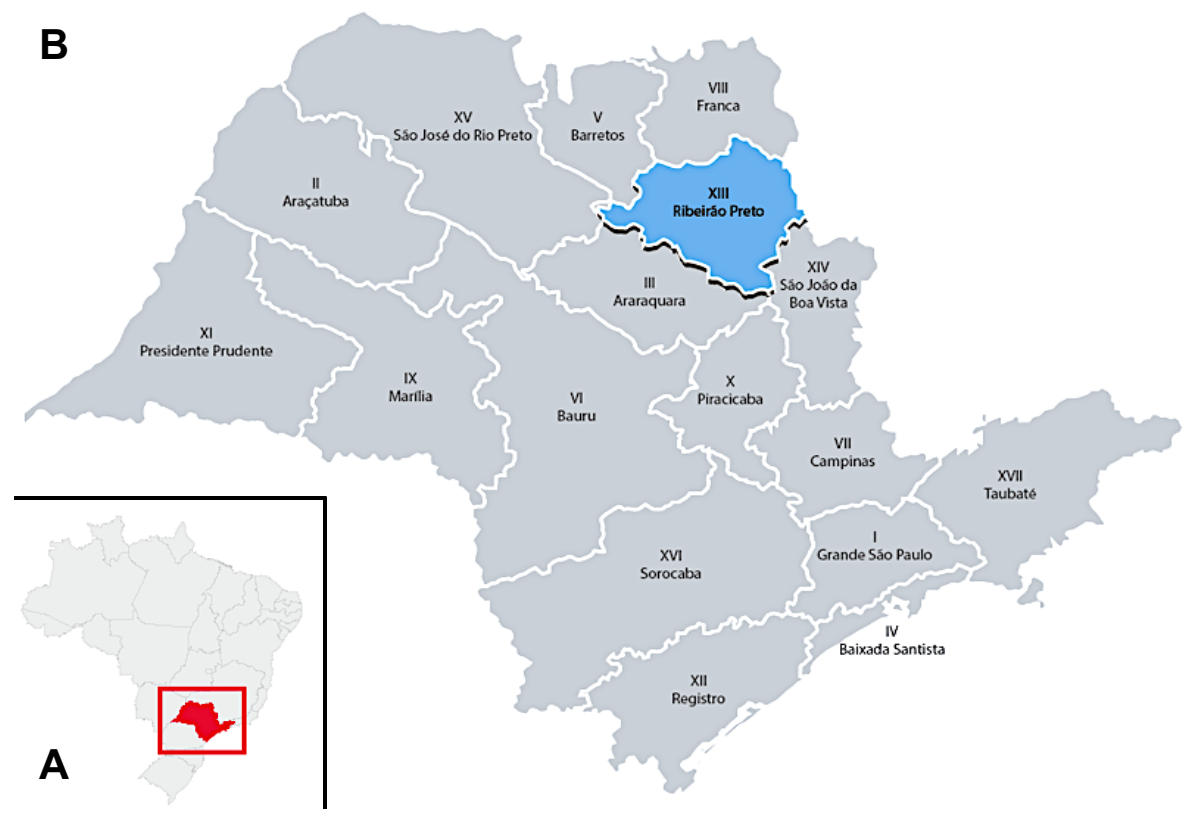

Figura 1. A) Mapa do Brasil com destaque para o Estado de São Paulo em vermelho; B) Mapa do Estado de São Paulo subdividido por regiões de Saúde, destacando-se a região XIII, em azul, onde está localizado o Município de Ribeirão Preto. Fonte: A: https://commons.wikimedia.org/wiki/File:SaoPaulo_MesoMicroMunicip.svg; $\quad$ B: http://nephrp.com.br/neph-drs.html

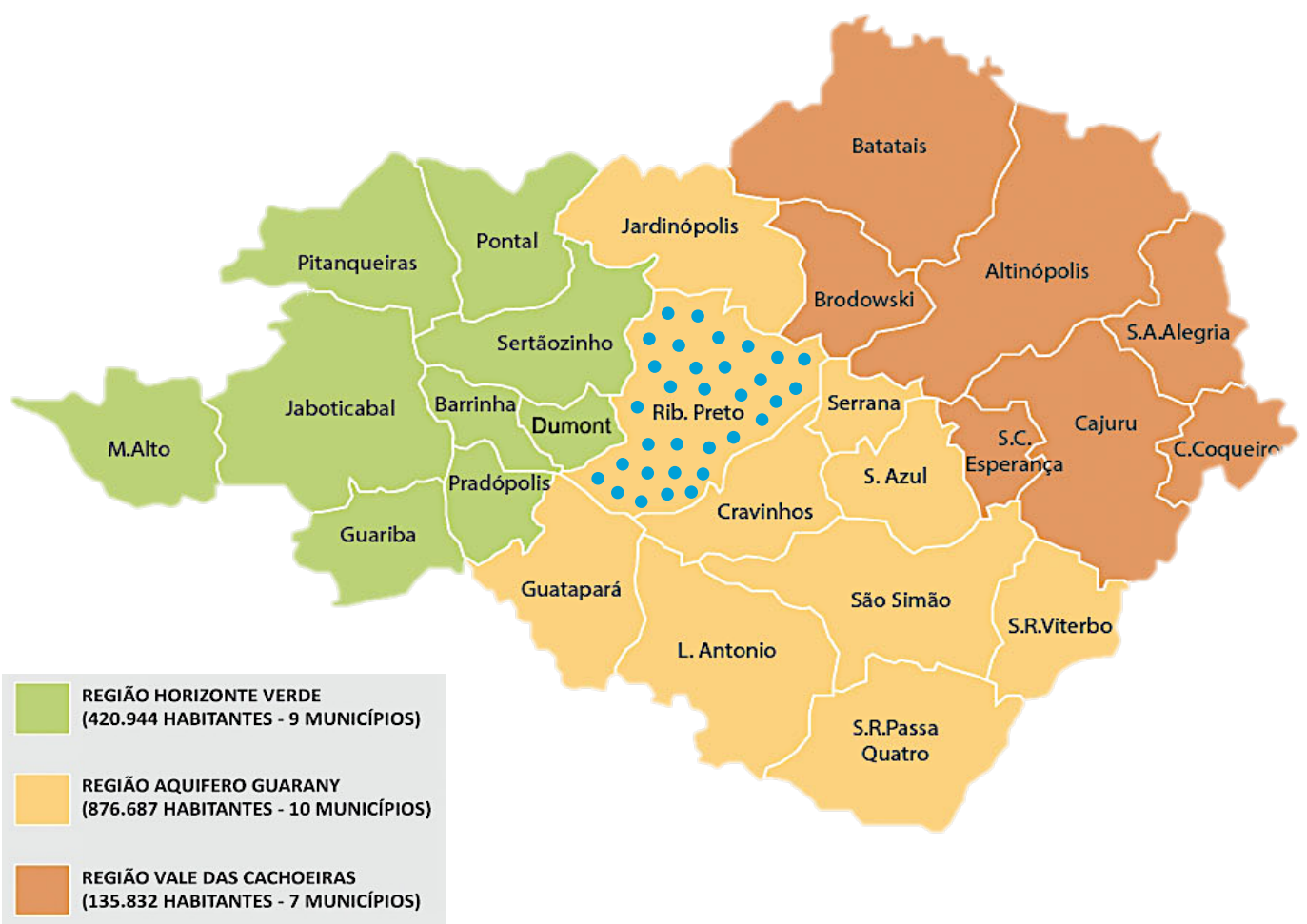

Figura 2. Mapa dos municípios que compõe a Região de Saúde XIII e o GVE XXIV. Área destacada com pontos azuis corresponde ao Município de Ribeirão Preto. Verde: Horizonte Verde; Amarelo: Aquífero Guarani; Vermelho alaranjado: Vale das Cachoeiras. Fonte: http://nephrp.com.br/nephdrs.html. 
Ribeirão Preto está localizado no bioma Cerrado, restando raras áreas de mata natural em seu território. Apesar disso, possui entremeado à área urbana árvores com idades superiores a quatro décadas, compondo o cenário de diversas praças; devido à idade, estas possuem densidade e tamanho consideráveis, abrigando diversas espécies animais, vertebrados e invertebrados. A cidade é "cortada” pelo Ribeirão Preto, rio que dá nome ao município; na periferia, sua extensão é margeada por vegetação ciliar que abriga muito animais, fornecendo habitat apropriado para diversas espécies animais. Além disso, o município possui três grandes reservas de mata, sendo: A) Estação Ecológica de Ribeirão Preto (EERP - Mata de Santa Tereza), localizada na região sudoeste; B) Universidade de São Paulo, localizada na região oeste; e Bosque e Zoológico "Fábio Barreto", localizado na região central do município. A precipitação pluviométrica média anual é de aproximadamente $1422.7 \mathrm{~mm}$, sendo o primeiro trimestre (janeiro, fevereiro e março) o mais chuvoso, com 44,2\% (628.4mm) do total anual. Assim, os meses de janeiro, fevereiro, março, outubro, novembro e dezembro detém, em média, $83,2 \%(1183.2 \mathrm{~mm})$ do total anual de chuva. Aliada a alta precipitação tem-se a elevada temperatura média, atingindo $23,2^{\circ} \mathrm{C}$, podendo chegar à máxima média de $29,1^{\circ} \mathrm{C}(\mathrm{CEPAGRI}$, 2017).

\subsection{Locais de captura dos PNHs}

A estratégia de investigação foi definida a partir dos casos confirmados de febre amarela no Município de Ribeirão Preto entre o final de 2016 e início de 2017. Seis casos, sendo três saguis, dois bugios e um ser humano, foram confirmados na última epidemia (Figura 3).

Os trabalhos de captura e investigação tiveram como foco a região onde o único caso humano autóctone do município foi confirmado, próximo à EERP. Anterior ao projeto, durante o surto, nessa localidade, equipes da SUCEN fizeram a captura de mosquitos vetores silvestres, para a realização do isolamento viral, pelo Instituto Adolfo Lutz de São Paulo (IAL/SP), o qual foi positivo a partir de mosquitos do gênero Haemagogus, elucidando a epidemiologia silvestre.

Devido à extensão do município, à restrição de equipes e às dificuldades de realizar a captura em determinadas regiões, o estudo foi direcionado para a região sul do Município de Ribeirão Preto. Nessa região os locais de captura foram concentrados na área em que o houve o óbito humano confirmado por febre amarela no ano de 2016. Ademais, para que o local fosse escolhido deveria reunir as seguintes características: áreas com alta densidade arbórea, população humana residente ou grande fluxo de pessoas (residentes no município ou não) e 
presença de PNHs. Foram contempladas no estudo cinco áreas distintas, embora fizessem parte do mesmo complexo biótico "Mata de Santa Tereza".

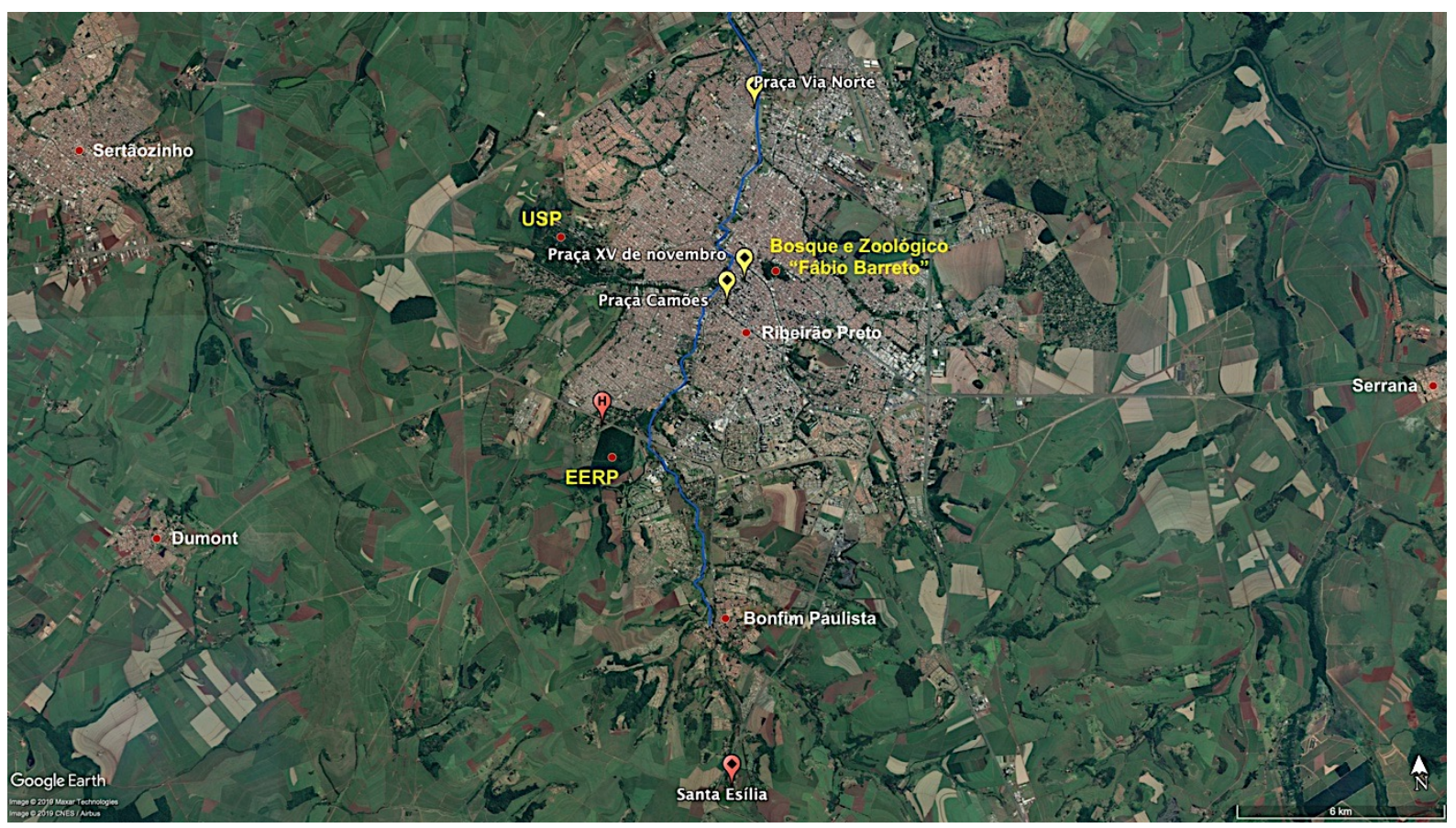

Figura 3. Vista aérea do Município de Ribeirão Preto e região. Linha azul: trecho aquático, rio "Ribeirão Preto", cruzando o município; Ponto vermelho (losango): animais da espécie Alouatta caraya, positivos para febre amarela (FA); Ponto vermelho $(\mathrm{H})$ : caso humano positivo para FA; Pontos amarelos (losango): animais da espécie Callithrix penicillata, positivos para FA. Fonte: Google Earth, 2019.

Os locais foram: Departamento Regional de Saúde (DRS) - XIII/Grupo de Vigilância Epidemiológica (GVE) XXIV, Condomínio Residencial “Quinta da Boa Vista B”, Condomínio Residencial "Quinta da Boa Vista A” (residência da pessoa que veio à óbito por FA), Hospital Santa Tereza de Ribeirão Preto e Estação Ecológica de Ribeirão Preto - "Mata de Santa Tereza", perfazendo um total de 577 ha $\left(5,77 \mathrm{Km}^{2}\right)$ (Figura 4).

Em cada área foi realizada uma visita prévia para a identificação da possível presença de PNHs e se confirmado, solicitou-se a autorização para a realização das atividades de captura. Uma vez autorizada verificou-se os pontos de maior circulação dos animais, conforme as informações obtidas com os moradores e funcionários de cada localidade. Após o reconhecimento das áreas, as armadilhas foram instaladas.

\subsection{Atividades no campo}

A captura de PNH de vida livre, está fundamentada na vigilância ativa, compondo um dos pilares da vigilância de epizootias de febre amarela (BRASIL, 2017e). Caracteriza-se como uma estratégia ímpar na busca de evidências da circulação viral, e também de avaliação do 
impacto do vírus em populações residentes, por meio da avaliação da soroprevalência. Tais achados contribuem para predizer o risco de infecção na população humana e também auxilia na implementação de ações preventivas, no intuito de mitigar o número de acometidos pela doença na população humana, e principalmente, evitar óbitos. Além disso, pode predizer, com base na população de PNHs susceptíveis, qual o risco de uma nova epizootia se processar e em quanto tempo isso poderia acontecer.

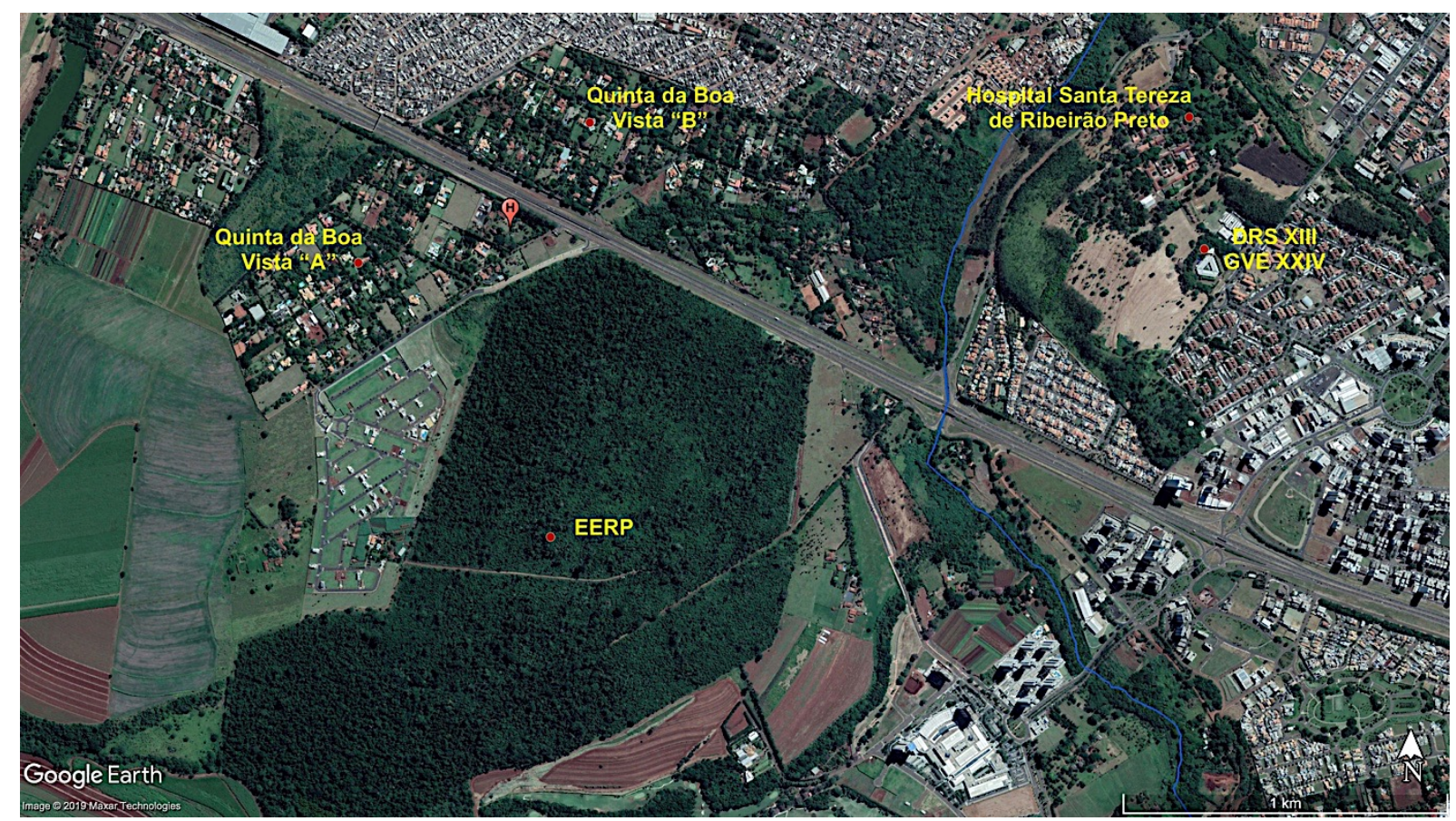

Figura 4. Vista aérea da região sul Município de Ribeirão Preto e os respectivos locais onde as capturas foram realizadas. Linha azul: trecho aquático, rio "Ribeirão Preto"; Ponto vermelho $(\mathrm{H})$ : caso humano positivo para FA; Google Earth, 2019.

Conforme o "Guia de Vigilância de Epizootias em Primatas Não Humanos e Entomologia Aplicada à Vigilância da Febre Amarela" (BRASIL, 2017e) foram seguidas as seguintes condições: permissão dos órgãos ambientais; equipe multidisciplinar devidamente treinada; contato com autoridades locais e proprietários das áreas; georreferenciamento da área (GPS); conhecimento prévio do local; equipamentos de campo e de laboratório; apoio local e uso de EPIs específicos (Figura 5). A equipe de trabalho foi composta por profissionais médicos veterinários, médicos, biomédicos, biólogos, enfermeiros, entre outros.

Têm-se registro de pelo menos três diferentes gêneros de PNH de vida livre no Município de Ribeirão Preto, Callithrix, Sapajus e Alouatta (Figura 6). O primeiro é o mais numeroso e amplamente distribuído dentro perímetro periurbando e urbano, além de estabelecer relação sinantrópica. Portanto, o gênero Callithrix foi a espécie alvo no estudo. Ademais, o gênero Sapajus, embora incomum na área urbana, é frequente na área de reserva da EERP, 
compondo bandos com cerca de 30 indivíduos, também foi incluído no estudo. Na área urbana, na área do Bosque e Zoológico "Fábio Barreto", existem exemplares do gênero Alouatta de vida livre, contudo a captura desses espécimes não foi realizada.

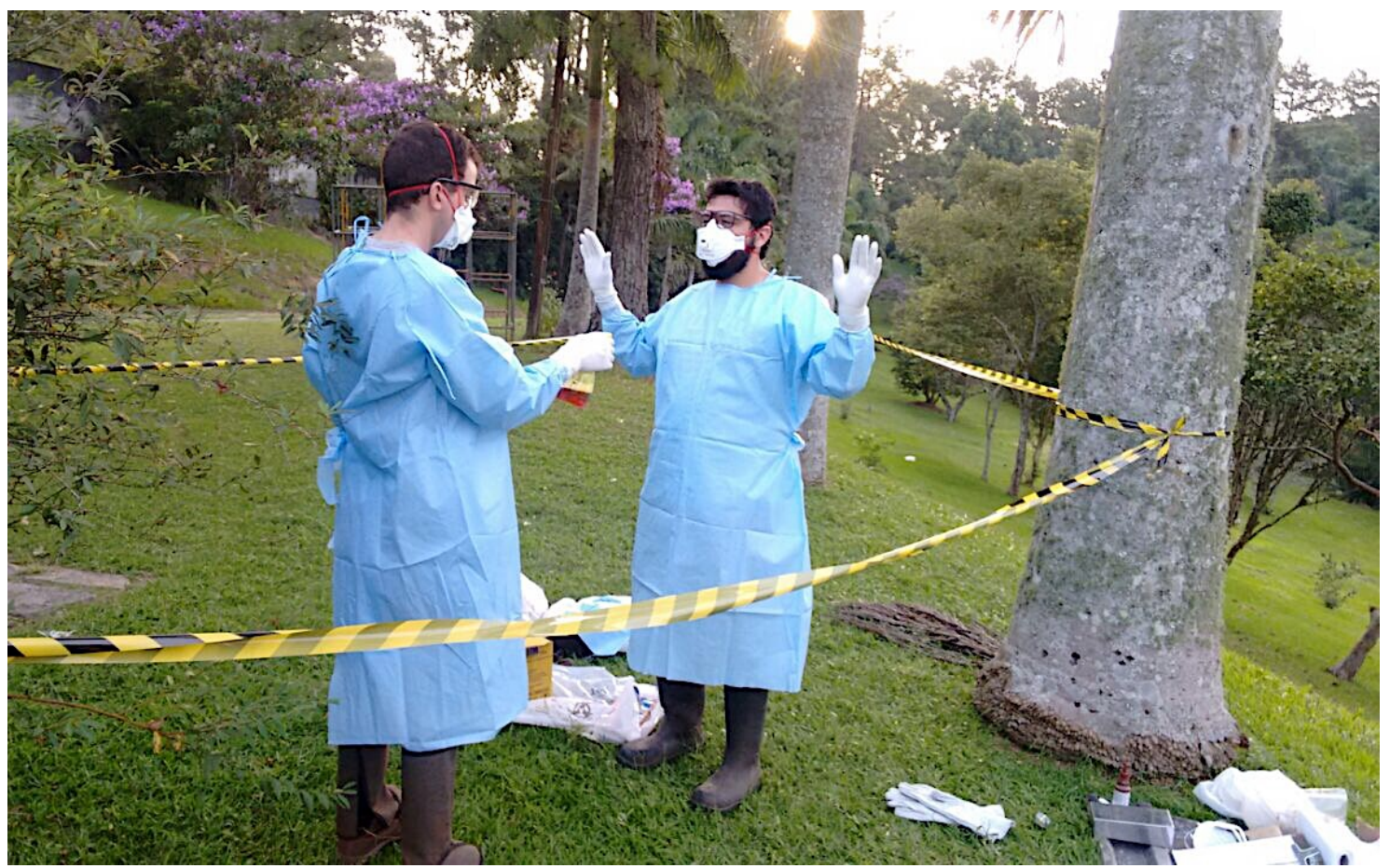

Figura 5. Investigação epidemiológica de epizootia de Febre Amarela, conduzida pelo CVE/SES/SP e SVS/MS no Município de São Roque, São Paulo, durante o surto em 2017. Visualiza-se os equipamentos de proteção individual (EPIs) requeridos para a atividade, como: óculos de proteção, máscara de proteção respirador PFF3/P3, avental de manga longa e cumprido, luvas e botas.
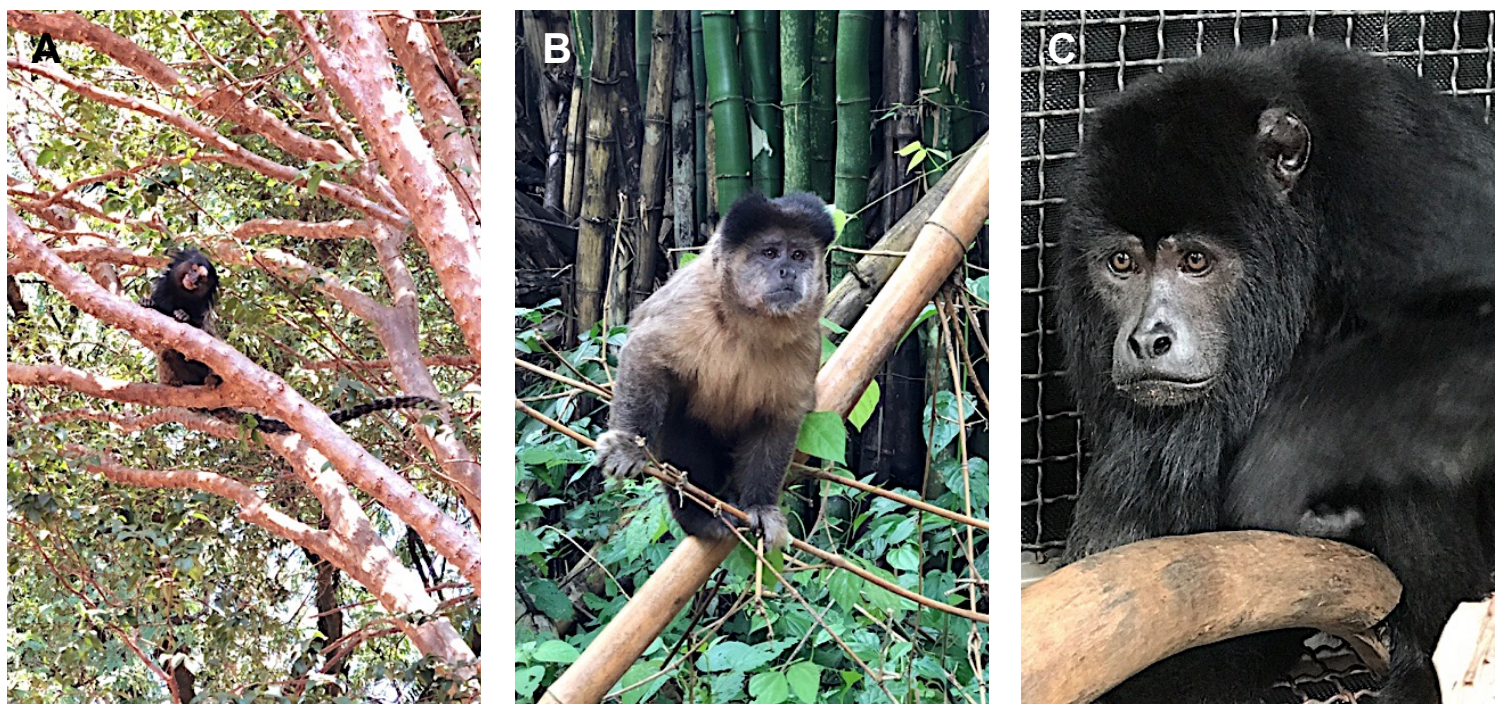

Figura 6. Espécies de primatas não humanos comuns no Município de Ribeirão Preto e região. A) Callithrix penicillata (Sagui de tufos pretos); B) Sapajus nigritus (Macaco-prego); C) Alouatta caraya (Bugio preto).

A partir do levantamento realizado na rotina de trabalho do DVAS, pôde-se estimar as populações de PNHs existentes em diversos pontos do município. Entretanto, na região sul, por 
ser uma área com maior densidade arbórea, o conhecimento sobre a população de calitriquídeos era limitada. A partir do conhecimento prévio sobre a biologia dessas espécies e da informação fornecida pelos moradores e/ou funcionários de cada região, estimou-se o número médio de indivíduos de cada bando. Dessa maneira preconizou-se a captura, de no mínimo 30\% dos indivíduos de cada bando, buscando contemplar a população de adulta e jovem adulta. Apesar disso, filhotes, quando capturados, também foram incluídos.

\subsubsection{Protocolo de captura}

As capturas e a colheita de amostras biológicas foram planejadas de acordo com a espécie alvo e seu respectivo porte físico (pequeno: gêneros Callithrix e Saguinus, variando de 120g a 600g; médio: gêneros Cebus, Sapajus, Saimiri, Aotus e Callicebus, variando de 500g a 4Kg). Para animais de pequeno e médio porte, foram utilizadas armadilhas tipo Tomahawk, tendo, respectivamente, $50 \times 21,5 \times 20 \mathrm{~cm}$ e $90 \times 45 \times 50 \mathrm{~cm}$.

As armadilhas foram colocadas sempre suspensas, fosse em árvores ou sobre muros e outras estruturas artificiais (Figura 7), a fim de manter a segurança dos animais quando capturados e também para facilitar a captura, buscando posicioná-las em locais onde os animais haviam sido avistados anteriormente ou locais considerados "caminhos" ou "rotas" desses animais.
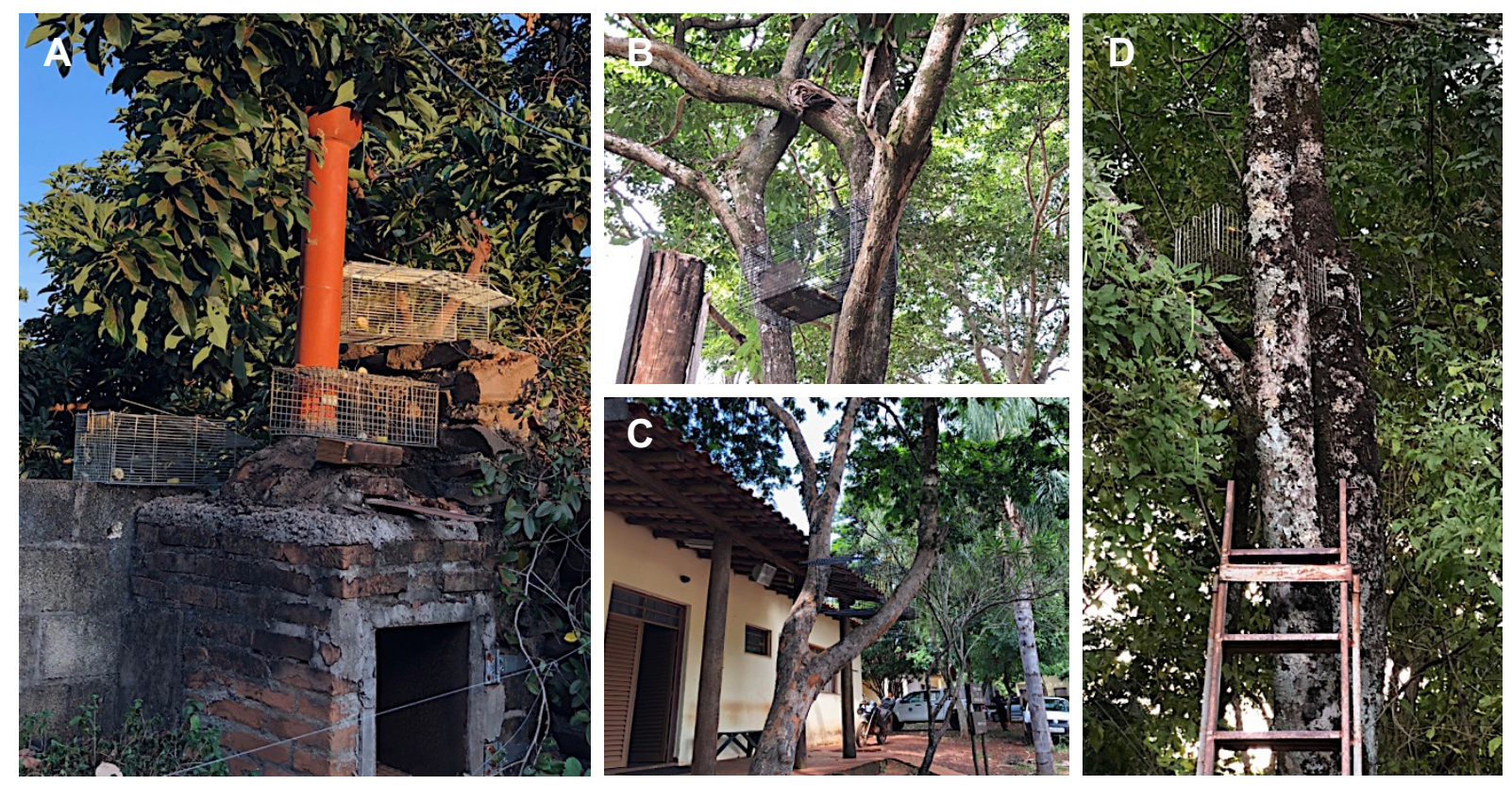

Figura 7. Armadilhas tipo Tomahawk utilizadas durante as capturas. A e D) Condomínio Residencial "Quinta da Boa Vista B", armadilha pequena (50 x 21,5 x $20 \mathrm{~cm}$ ) para captura de saguis, cedidas pela SUCEN/SP; C e D) EERP, armadilha média $(90$ × 45 × $50 \mathrm{~cm})$ para captura de macacos-prego, cedidas pela SVS/MS. 
Para capturar os animais utilizou-se o método de "ceva", colocando-se banana e outras frutas cortadas em pedaços, e uma pasta atrativa à base de banana, paçoca de amendoim, aveia, mel e sardinha.

Os PNHs desses gêneros possuem hábitos diurnos, portanto, as armadilhas eram cevadas e armadas diariamente no início da manhã, entre seis e sete horas, antecipando-se ao horário que animais passavam pelo local. Após armadas, equipes faziam rondas pelos locais onde estavam as armadilhas, de três a quatro vezes durante o dia, a fim de verificar se algum animal havia sido capturado. Quando capturado (Figura 8), a equipe de coleta era acionada e se direcionava para o local. É importante ressaltar que no final do dia, entre cinco e seis horas da tarde, todas as armadilhas eram vistoriadas novamente, desarmadas e fechadas, evitando que algum PNH ficasse preso durante a noite sem conhecimento prévio da equipe.

Esse protocolo garantiu que nenhum PNH ficasse exposto às condições ambientais adversas (baixas temperaturas, chuva, predadores) ocasionado pela captura, o que poderia ocasionar o óbito deste. Da mesma forma as rondas regulares para verificação das armadilhas eram necessárias, pois outros animais, de forma acidental, acabavam sendo capturados (Figura 9). Tão logo eram identificadas espécies diferentes do objetivo, fazia-se a soltura.
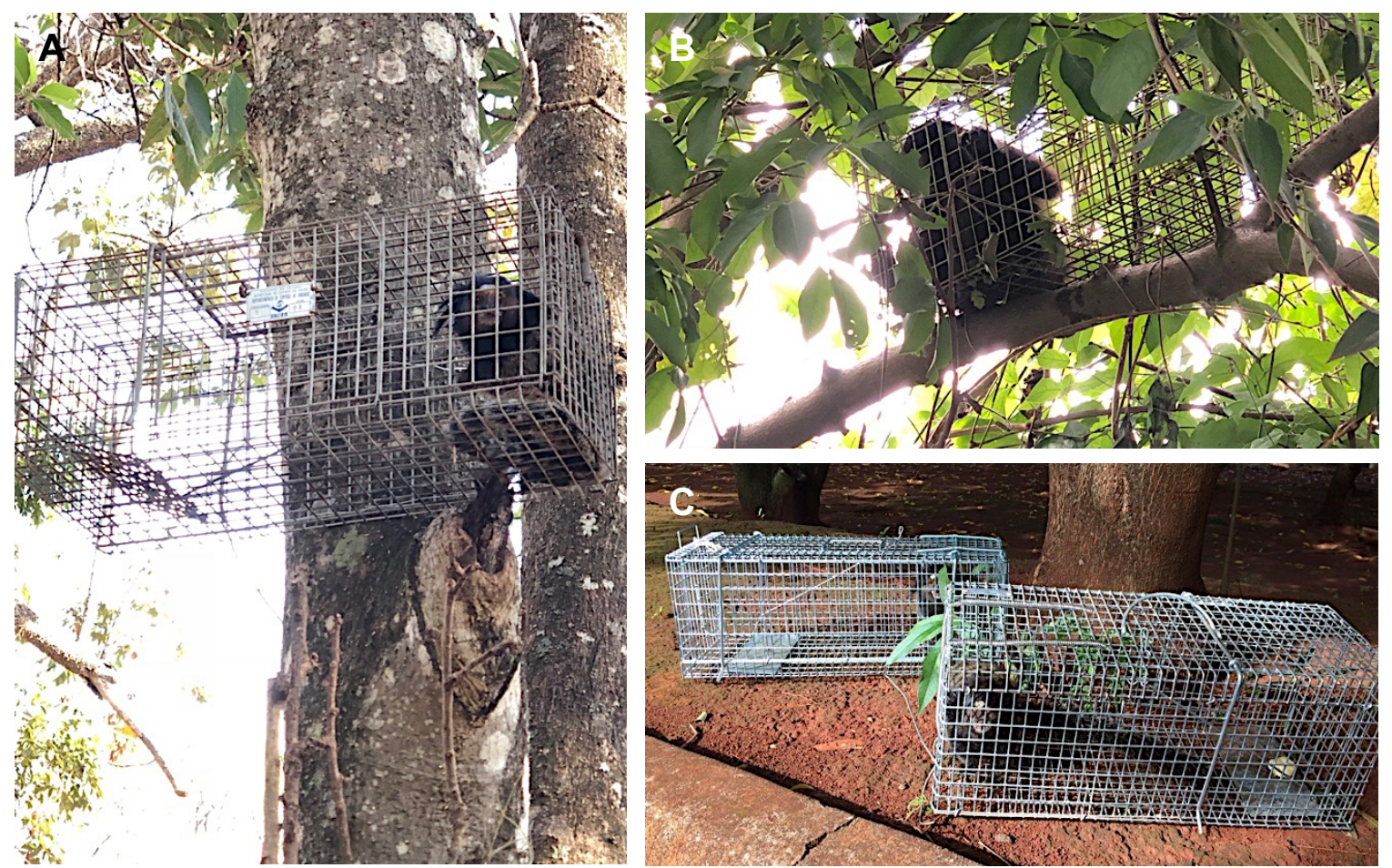

Figura 8. PNHs capturados na região sul do Município de Ribeirão Preto. A e C) PNHs da espécie Callithrix penicillata; B) PNH fêmea da espécie Sapajus nigritus. 
O sucesso das capturas está fundamentado no entendimento do comportamento animal. Além disso, obter informações sobre o local que será trabalhado, principalmente, por meio moradores e funcionários que convivem com esses animais, e que muitas vezes os alimentam; reconhecimento da área e observação da rotina de migração dos bandos.
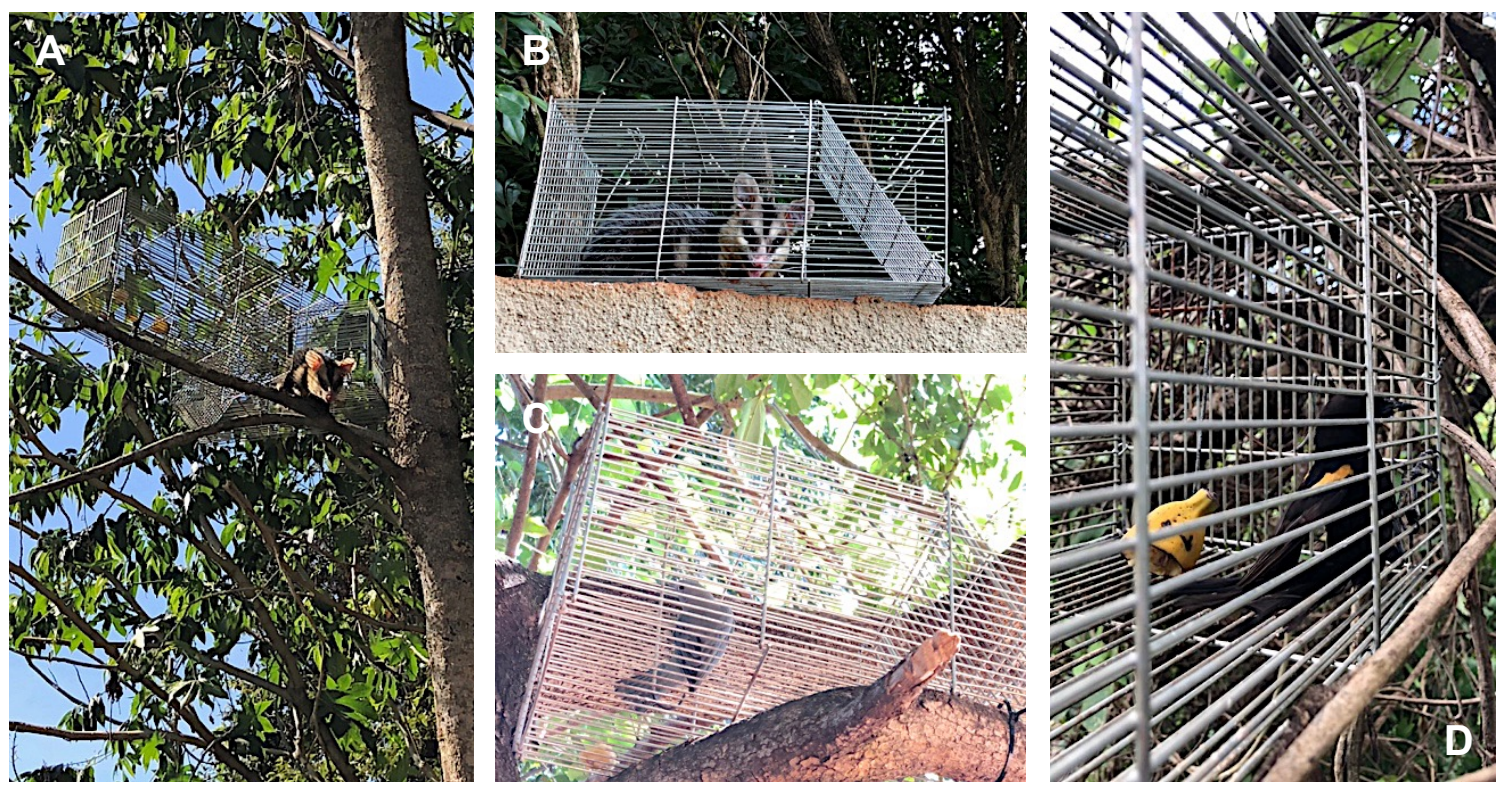

Figura 9. Animais capturados acidentalmente. A e B) Didelphis albiventris (Gambá-de-orelha-branca); C) Tangara sayaca (Sanhaçu-cinzento); D) Icterus pyrrhopterus (Encontro).

\subsubsection{Protocolo anestésico}

O protocolo anestésico utilizado seguiu as diretrizes do Centro Nacional de Primatas (Cenp/SVS/MS) e da Divisão de Vigilância Ambiental em Saúde (CEVS/SES) do Rio Grande do Sul (BRASIL, 2017e). A dose utilizada do Midazolam $(5 \mathrm{mg} / \mathrm{mL})$, medicação préanestésica/sedativa, foi de 0,2 a $0,5 \mathrm{mg} / \mathrm{Kg}$; e do Cloridrato de Cetamina (50mg/mL), anestésico dissociativo, foi de 5 a $15 \mathrm{mg} / \mathrm{Kg}$;

A aplicação foi feita via intramuscular (IM), através da própria armadilha (Figura 10), a fim de minimizar o estresse do animal, pela manipulação, e também evitar que o animal escapasse ao tentar abrir a armadilha para a aplicação do anestésico. Com o auxílio de um limitador de espaço tipo garfo, reduz-se a área disponível na armadilha deslocando o animal para um dos cantos, deixando espaço para a aplicação no local correto (região de bíceps femoral).

No decorrer do procedimento, quando necessário, a fim de garantir a qualidade e segurança do procedimento, tanto para o animal, quanto para o médico veterinário, fez-se o reforço anestésico, utilizando-se metade das doses empregadas na primeira aplicação. 


\subsubsection{Descrição das atividades}

Após a captura, os PNHs foram submetidos ao protocolo anestésico, descrito anteriormente. Enquanto isso, a mesa de procedimentos era preparada, com todos os equipamentos e materiais necessários para a manipulação, colheita de sangue e biometria (Figura 11). Na sequência, a equipe se paramentava com os respectivos EPIs para que pudessem iniciar os procedimentos.

Somente após o animal estar sob efeito anestésico, cerca de 10 a 15 minutos após a aplicação, deu-se início ao o exame físico, a biometria, colheita de material biológico, aplicação do nanochip (AnimallTAG ${ }^{\circledR}$ ) e registro fotográfico (Figuras 12).
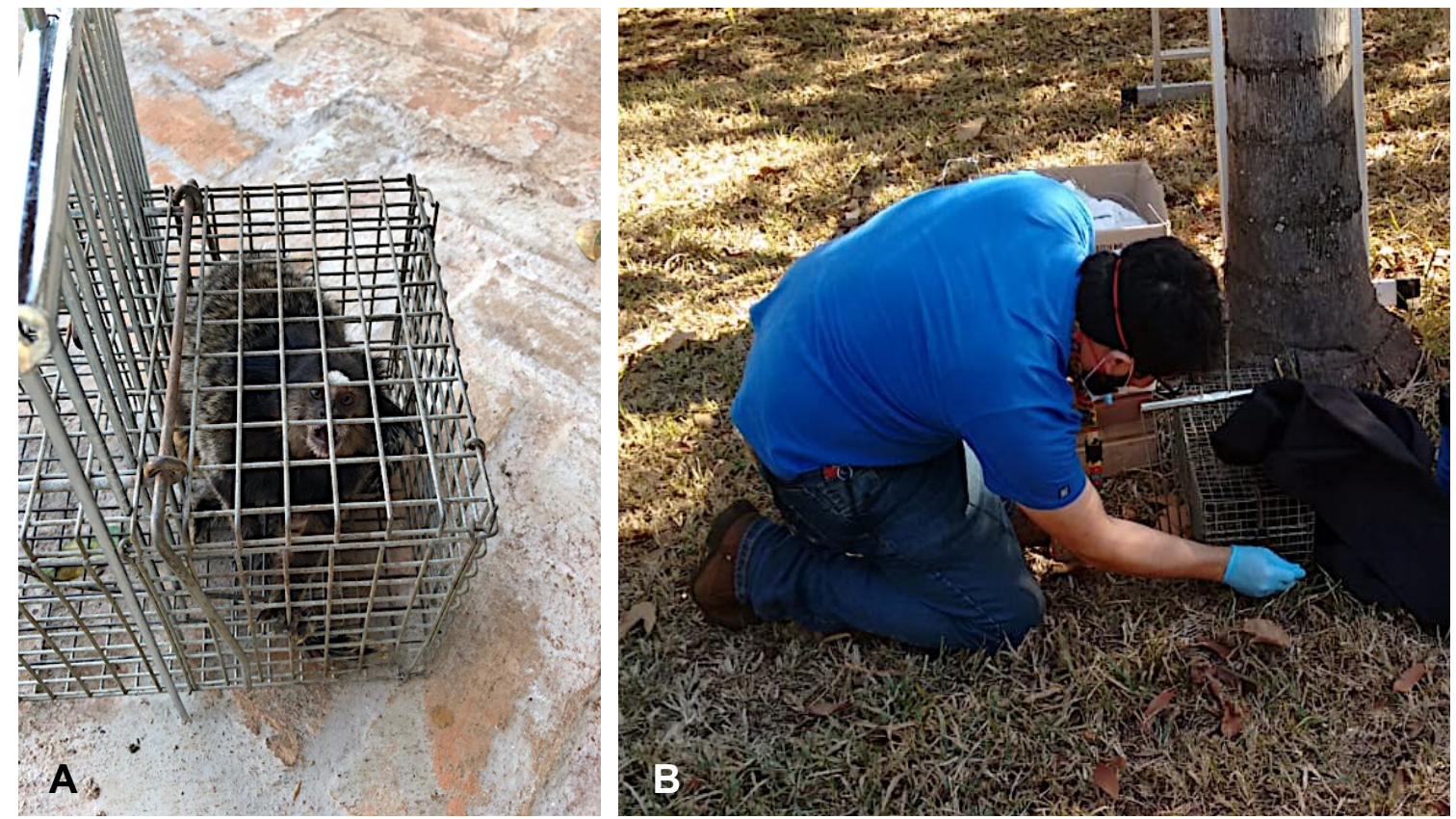

Figura 10. A) Limitador de espaço sendo utilizado para encurralar o animal em um canto da armadilha, facilitando a aplicação da medicação anestésica; B) Aplicação da medicação anestésica através da armadilha, em PNH da espécie C. penicillata.

O presente estudo adotou o uso da "FICHA DE IDENTIFICAÇÃO DE PRIMATAS" (ANEXO) que consta no "Guia de Vigilância de Epizootias em Primatas Não Humanos e Entomologia Aplicada à Vigilância da Febre Amarela" como padrão para a identificação e registro dos animais capturados. Nessa ficha os dados estão agrupados por local, características do local de captura, dados do animal, histórico clínico, material coletado, resultados laboratoriais, observações, investigador e fotos do local e do animal capturado. O uso dessa ficha como padrão permitirá, no futuro, a comparação de dados com outros estudos que tratem da mesma temática. 
a) Exame físico: contemplou a identificação do animal (espécie, sexo, idade), pesagem, observação das cavidades naturais e mucosas aparentes; biometria, aferição da temperatura, colocação de nanochip e avaliação dos sistemas tegumentar, cardíaco, respiratório e gênito-urinário.

b) Coleta e processamento de material biológico: o sangue foi colhido por venopunção da veia femoral, preferencialmente, contudo devido à proximidade anatômica e ao tamanho do animal, no caso dos calitriquídeos, algumas amostras foram colhidas a partir da arterial femoral. Para a manutenção da homeostase é preconizado que se colha entre 1 a $2 \%$ de sangue em relação ao peso vivo. Dessa forma, para animais com até $500 \mathrm{~g}$ o volume de sangue colhido variou de 0,5 a $1 \mathrm{~mL}$ e para animais acima de $1 \mathrm{Kg}$ o volume coletado foi de 3 a $5 \mathrm{~mL}$. Para a punção venosa dos saguis foi utilizada seringa hipodérmica de $1 \mathrm{~mL}$ e agulha $0,45 \mathrm{x}$ $13 \mathrm{~mm}$ e para animais maiores, como macaco prego foi utilizada seringa de 3 ou $5 \mathrm{~mL}$ com agulha 0,70 x $25 \mathrm{~mm}$. Todo o material utilizado para venopunção foi utilizado uma única vez, sendo descartado após o uso. Anterior à punção foi realizada a desinfecção do local com álcool iodado, na proporção de cinco partes de álcool 70\% para uma parte de tintura de iodo $(5: 1)$.

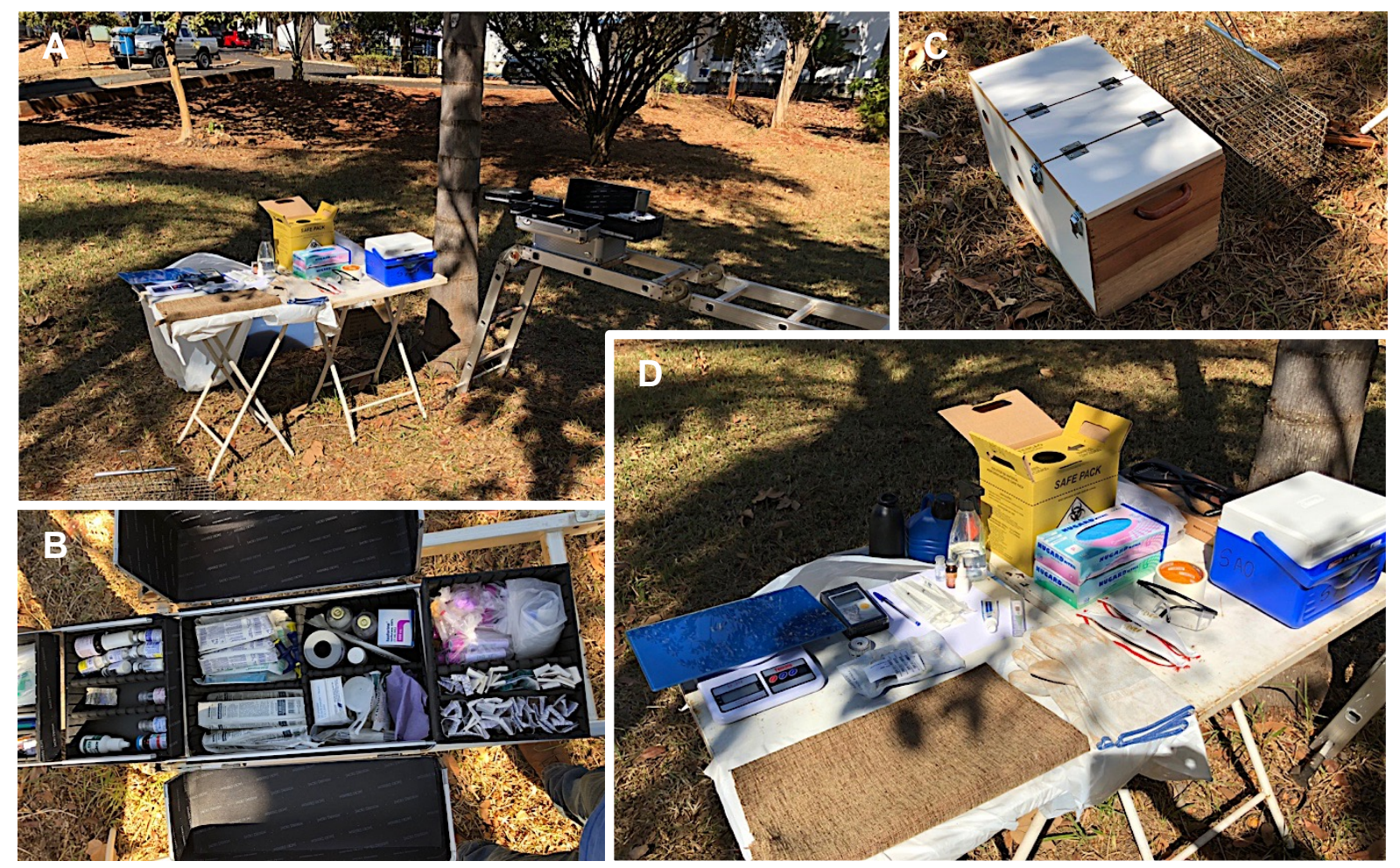

Figura 11. Equipamentos utilizados à campo para a realização da avaliação dos animais e colheita de sangue. A e D) Mesa com todos os equipamentos e insumos necessários para avaliação, biometria e colheita de sangue dos animais e armazenamento/transporte das amostras; B) Caixa de medicação e insumos para colheita de sangue; C) Armadilha para captura de PNHs da espécie C. penicillata, limitador de espaço tipo garfo e caixa de recuperação pós-anestesia. 
c) Acondicionamento e encaminhamento das amostras: após a colheita, de acordo com o volume obtido, separou-se em duas alíquotas, sendo uma colocada em tubo com EDTA e outra em tubo seco ou com gel separador para a obtenção do soro sanguíneo. Até o momento do encaminhamento e ou processamento das amostras, estas foram mantidas refrigeradas entre 2 e $8^{\circ} \mathrm{C}$ em caixa isotérmica com gelo reciclável. Do tubo com EDTA uma pequena alíquota foi separada e encaminhada para o Laboratório de Análises Clínicas Veterinárias (LACVET) onde foram realizados o hemograma e o esfregaço delgado. O restante do sangue foi encaminhado para o Laboratório de Virologia Molecular onde foi centrifugado e separada as frações do sangue total, em plasma e fração celular, e do sangue coagulado, em soro e coágulo. Cada parte foi armazenada em tubo criogênico e armazenado à ultrabaixa temperatura $\left(-70^{\circ} \mathrm{C}\right)$ até o momento do uso. Na impossibilidade de obter volume suficiente para todas alíquotas, de acordo com o estado geral do animal, deu-se preferência a obtenção de plasma ou soro, apenas.
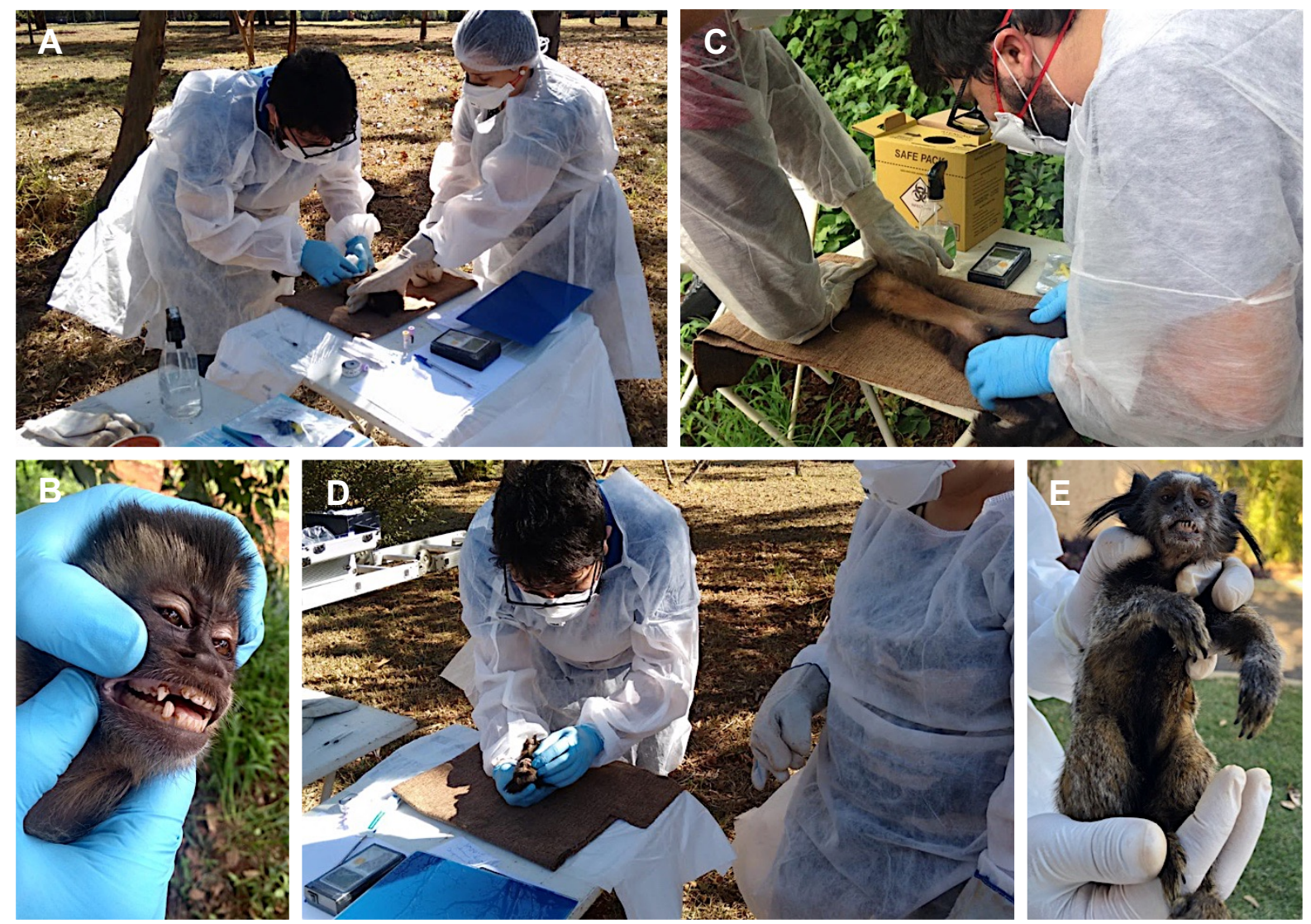

Figura 12. Procedimento de avaliação física, colheita de sangue, e biometria. A) Contenção do PNH para colheita de sangue; B) Avaliação da cavidade oral da fêmea de $S$. nigritus; C) Avaliação da região da venopunção; D) Exame físico; E) C. penicillata senil, captura no Condomínio Residencial Quinta da Boa Vista "B". 


\subsection{Atividades laboratoriais}

\subsubsection{Hemograma e esfregaço delgado}

A partir de uma alíquota de sangue, $30 \mu \mathrm{L}$ com anticoagulante (EDTA), foi realizado o hemograma por contagem automatizada pela máquina ABX Micros ESV60 (Horiba Medical). O diferencial leucocitário foi realizado pela técnica de esfregado delgado em lâmina de vidro, utilizando-se $5 \mu \mathrm{L}$ de sangue para cada lâmina. Os esfregaços foram feitos em duplicatas. Após a confecção, as lâminas foram coradas pela técnica do Panótico Rápido ${ }^{\circledR}$ (LB laborclin) e lidas em microscópio óptico (Nikon Eclipse E200) por médico veterinário especializado em patologia clínica. A técnica do esfregaço delgado, além da contagem diferencial das células e avaliação da sua morfologia, permite avaliar a presença de outros microorganismos, como parasitas, que podem acometer os animais.

\subsubsection{Deteç̧ão de anticorpos neutralizantes anti-YFV nas amostras clínicas de PNH por PRNT (Plaque Reduction Neutralization Test)}

Para a realização do PRNT, adaptou-se o protocolo descrito por Russell et al. (1967). A detecção de anticorpos neutralizantes anti-YFV foi realizada nas amostras de soro e/ou plasma. Uma alíquota de cada amostra, $40 \mu \mathrm{L}$, foi inativada a $56^{\circ} \mathrm{C}$ por $45-60$ minutos e em seguida iniciou-se a diluição seriada (em DMEM sem suplementação). Iniciou-se pela diluição 1:10, finalizando-se na diluição 1:5.120, totalizando 10 diluições. Junto à diluição das amostras foi adicionado um controle do vírus (DMEM e vírus) e um controle negativo na diluição 1:10 (uma amostra conhecidamente negativa para a presença de anticorpos anti-YFV, que também foi inativa $56^{\circ} \mathrm{C}$ por $45-60$ minutos); a amostra utilizada no controle negativo foi uma amostra humana, que não fora infectada ou vacinada contra febre amarela. Optou-se por uma amostra humana devido à ausência de uma amostra de $\mathrm{PNH}$ conhecidamente negativa e à proximidade evolutiva entres as espécies. Uma vez prontas a diluições e os controles, estes foram incubados com uma quantidade fixa de $90 \mathrm{PFU} /$ tubo do YFV por 1 hora a $37^{\circ} \mathrm{C}$. Após essa etapa as amostras foram adicionadas em uma placa de 24 poços contendo $4 \times 10^{5}$ células de Rim de Macaco Verde Africano - VERO (BCRJ 0245; ATCC: CCL-81), de baixa passagem, por poço, plaqueadas no dia anterior, e incubadas por 1 hora a $37^{\circ} \mathrm{C}$ para a adsorção viral. Após essa etapa, o inóculo foi retirado por completo e um overlay (meio semi-sólido constituído de CMC 1,5\% e meio DMEM suplementado com $2 \%$ de antibiótico/antimicótico e 2\% de SFB) foi 
adicionado a cada poço da placa. A adição do meio semi-sólido é necessária para que cada PFU fique restrito ao sítio de infecção, possibilitando a formação e visualização dos plaques. A placa é então mantida em estufa com $5 \%$ de $\mathrm{CO}_{2}$ a $37^{\circ} \mathrm{C}$ até que seja possível a visualização adequada das placas, o que em média leva 5 a 7 dias. Após esse período, revela-se a placa; para isso retirou-se o overlay e adicionou-se uma solução de formol a 10\%, em quantidade suficiente para cobrir $40 \%$ de cada poço, para que as células fossem fixadas. Deixou-se em agitação leve por cerca de 30 minutos. Na sequência retirou-se o formol e repetiu-se essa etapa mais uma vez. É importante que a lavagem seja bem-feita, evitando-se a deposição de "grumos", pois caso haja poderá interferir na visualização dos plaques após corados. Feitas as duas lavagens com formol, adicionou-se a solução de cristal violeta $1 \%$, quantidade suficiente para cobrir o fundo (200 - $300 \mu \mathrm{L}$ ou 3 a 4 gotas) de cada poço, deixando em contato por mais 30 minutos em agitação leve. Uma vez coradas lavou-se em água corrente, para retirar o cristal violeta, e em seguida colocou-se para secar. Após secas, os plaques puderam ser visualizados e contados manualmente com o auxílio de um transiluminador de luz branca.

Nos poços a coloração violeta, oriunda do cristal, representa as células que se mantiveram integras e vivas, sem a infeção do vírus. Já a região do tapete celular que não foi corado, representa o local onde o vírus conseguiu infectar a célula e então replicou em quantidade suficiente para gerar o efeito citopático, tornando-o visível. Tais regiões foram caracterizadas como plaques e, portanto, foram contados para a avaliação da porcentagem de neutralização (Figura 14).

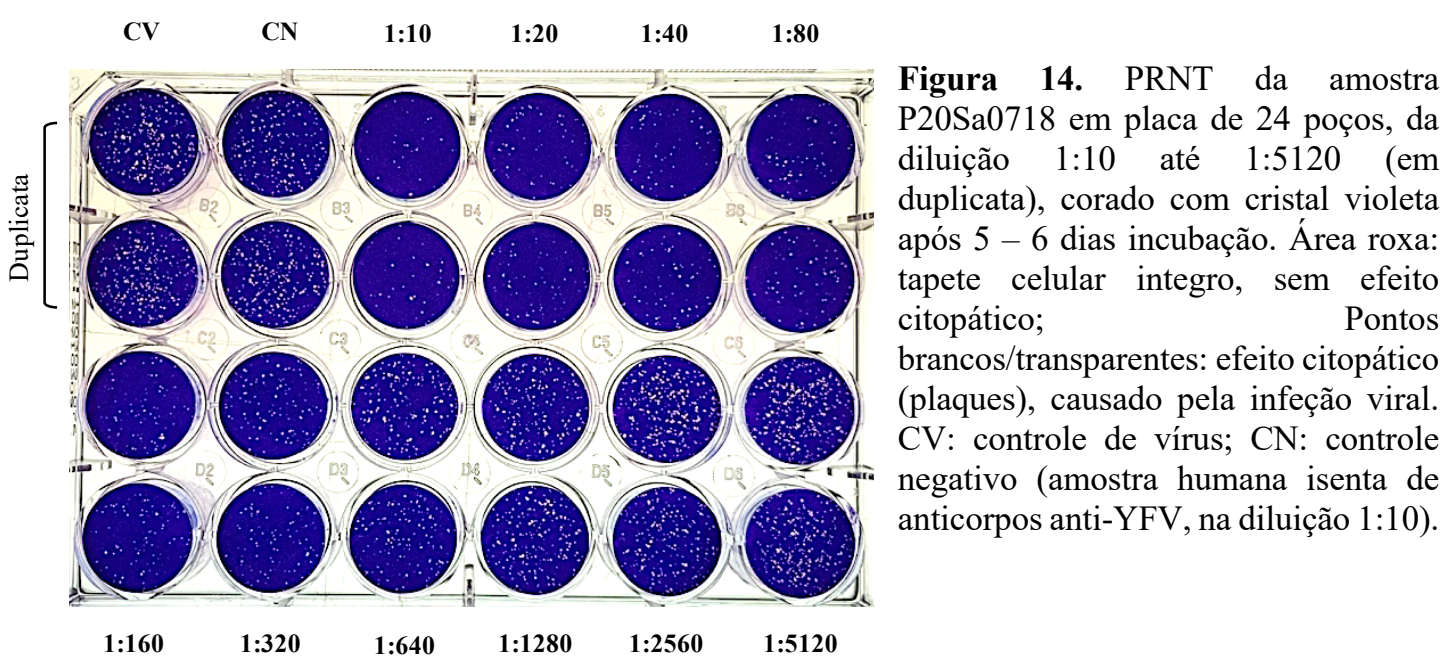

Seguindo as recomendações da Organização Mundial de Saúde (OMS), para que um PNH fosse considerado positivo, o cut off do título de anticorpo foi fixado em 10. As amostras que apresentaram títulos de anticorpos neutralizantes maiores ou iguais a 10 foram consideradas positivas (LANG et al., 1999; NIEDRIG et al., 2008; WHO, 2010; KAY et al., 2011; MELO et 
al., 2011; MONATH et al., 2011; MACHADO et al., 2013; AHUKA-MUNDEKE; STAPLES et al., 2018).

$\mathrm{O}$ valor do $\mathrm{PRNT}_{50}$ foi avaliado conforme o "Guidelines for plaque reduction neutralization testing of human antibodies to dengue viruses" da OMS (WHO, 2007; ROEHRIG, et al., 2008). Dessa forma, o título de anticorpos foi dado pelo valor da última diluição em que foi possível detectar a neutralização maior ou igual a 50\% dos plaques em relação ao controle negativo (CN) (ROEHRIG et al., 2008).

\subsubsection{Cepas YFV utilizadas no PRNT}

Foram utilizadas duas cepas diferentes para a realização dos testes, uma vacinal e outra selvagem. A cepa vacinal 17DD é convencionalmente utilizada em laboratórios para a realização de testes (LANG et al., 1999; MELO et al., 2011), pois é bem padronizada e traz riscos mínimos para quem manipula. A outra cepa utilizada foi a selvagem, JabSPM02 (SICONELLI et al., 2019), isolada no próprio laboratório, de um Alouatta caraya filhote, que veio à óbito durante o surto de FA em 2016, na Município de Jaboticabal/SP. Inicialmente seria utilizada apenas a cepa selvagem, contudo devido à problemas iniciais na padronização e por ser uma cepa recém isolada, estabelecida na $3^{\text {a }}$ passagem em célula VERO para uso, e ainda não totalmente adaptada, optou-se por testar em paralelo a cepa vacinal.

Após realizar uma passagem em células de Aedes albopictus, clone C6/36, e retornar para VERO, estabelecendo-se a $5^{\text {a }}$ passagem desde o isolamento, a cepa começou a apresentar plaques satisfatoriamente, possibilitando a padronização e a sua utilização. Após a padronização do teste com ambas as cepas, verificou-se que havia diferença nos resultados de uma mesma amostra quando testadas com as diferentes cepas. Assim, decidiu-se utilizar ambas as cepas para todas as amostras.

\subsubsection{Deteç̧ão da circulação do vírus da febre amarela na população de primatas não humanos capturados}

A avaliação da possível manutenção da circulação viral na população de PNHs foi feita em duas etapas, triagem e confirmação. Na primeira utilizou-se um teste rápido cromatográfico para a proteína não estrutural - NS1(não disponível comercialmente) e na segunda foi utilizada a RT-qPCR para a confirmação. 


\subsubsection{Detecção de antígeno viral NS1 do vírus da febre amarela}

Utilizou-se o teste rápido imunocromatográfico ASAN Easy Test ${ }^{\circledR}$ Yellow Fever NS1 Ag (Asan Pharm, Seoul, Korea), licenciado para uso em pesquisa. Para a realização do teste foi utilizado $20 \mu \mathrm{L}$ da fração celular, aliquotada do sangue total com EDTA. No local indicado adicionou-se os $20 \mu \mathrm{L}$ do sangue e em seguida 3 gotas $(80-100 \mu \mathrm{L})$ do tampão de corrida. Feito isso, aguardou-se 20 minutos para a leitura. Para que o teste esteja válido, uma banda controle deve aparecer na parte superior do dispositivo. Quando negativo, será visualizado apenas a banda controle, e quando positivo outra banda aparecerá logo abaixo do controle, havendo, portanto, duas bandas (Figura 15). Embora o "kit" seja licenciado para o uso em seres humanos, a proteína viral é a mesma seja no organismo humano ou animal. Apesar disso, para validar o uso, utilizou-se uma amostra positiva (Figura 16) de primata não humano que veio à óbito por febre amarela, confirmado por RT-qPCR e imunohistoquímica (SICONELLI et al., 2019). Após validar, testou-se as amostras dos animais capturados.

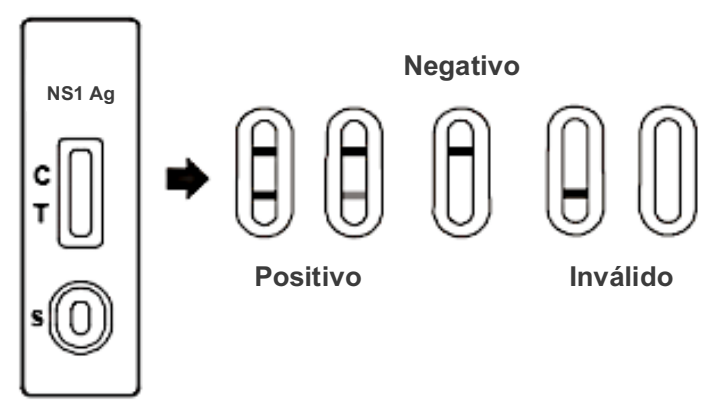

Figura 15. Esquema de um teste rápido para o antígeno NS1 e suas possíveis interpretações. Fonte: http://portuguese.custommono clonalantibody.com/sale3166512-dengue ns1-rapidmedical-home-rapid-urine-drugabuse-test-kit.html

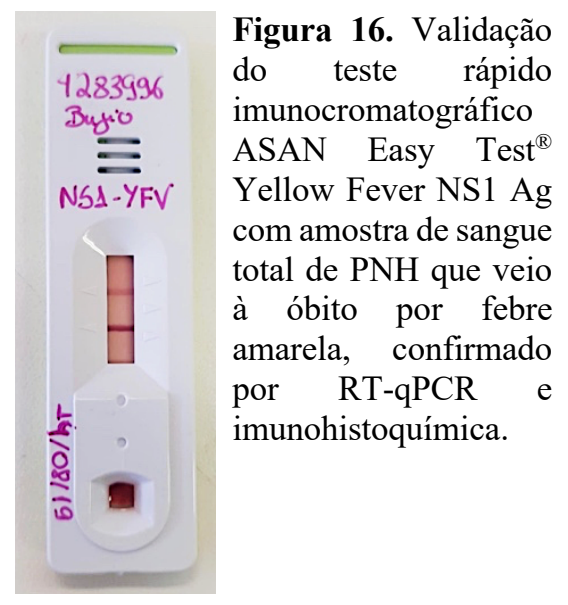

Embora tenha funcionado, optou-se também por realizar o diagnóstico molecular, pela RT-qPCR, independente do resultado, a fim de eliminar qualquer dúvida gerada pelo teste rápido, por ser um teste desenvolvido para utilização em amostras de seres humanos. 


\subsubsection{Diagnóstico molecular para o vírus da febre amarela}

\subsection{Extração do RNA}

Devido ao tipo de amostra disponível, fração celular congelada do sangue total com EDTA, a extração do RNA foi feita conforme protocolo de KIM et al., 2014, com o ácido guanidínico tiocianato-fenol-clorofórmio, com algumas modificações. Para tanto, utilizou-se $300 \mu \mathrm{L}$ de TRI Reagent ${ }^{\mathbb{R}}$ (Sigma-Aldrich, Saint Louis, USA) para $75 \mu \mathrm{L}$ de amostra. A mistura foi agitada em vórtex e na sequência foi incubada por 5 minutos à temperatura ambiente; após, foi adicionado $76 \mu \mathrm{L}$ de clorofórmio, agitando novamente em vórtex, e centrifugou-se a 12.000 x g, $4^{\circ} \mathrm{C}$, por 15 minutos. Após a separação das fases, transferiu-se cuidadosamente a fase aquosa para um novo tubo, com $190 \mu \mathrm{L}$ de isopropanol e homogeneizou-se vagarosamente para que o RNA fosse precipitado. Incubou-se a temperatura ambiente por 10 minutos e procedeuse nova centrifugação a $12.000 \mathrm{x} \mathrm{g}, 4^{\circ} \mathrm{C}$, por 15 minutos. Cuidadosamente, o sobrenadante foi descartado e o pellet (RNA precipitado) foi submetido à duas lavagens com etanol 75\%. Após adicionar o etanol, homogeneizou-se vagarosamente e repetiu-se a centrifugação a $12.000 \mathrm{x} \mathrm{g}$, $4^{\circ} \mathrm{C}$, por 15 minutos. Depois da última lavagem, o sobrenadante foi descartado e o tubo foi deixado aberto com a tampa para baixo para que todo o etanol evaporasse, por cerca de 15 a 30 minutos a temperatura ambiente. Uma vez seco, o RNA foi eluido em água ultrapura e então congelado em ultrabaixa temperatura até o momento do uso.

\subsubsection{2. $R T-q P C R$ para febre amarela silvestre}

A RT-PCR em tempo real utilizou o QuantiTect Virus Kit (QIAGEN, Germantown, EUA). Para a amplificação foram utilizados os primers e sonda listados na tabela 1 .

As reações de amplificações foram realizadas utilizando-se $3 \mu \mathrm{L}$ de RNA, $2 \mu \mathrm{L}$ do reagente QuantiTect Virus Master Mix (QIAGEN ${ }^{\circledR}$, Germantown, EUA), 0,1 $\mu 1$ do reagente QuantiTect Virus RT Mix, 0,25 $\mu$ l dos oligonucleotídeos (10pmol), $0,125 \mu \mathrm{L}$ da sonda (10pmol), e água para completar o volume final de $10 \mu \mathrm{L}$. 
A reação foi executada no aparelho ABI 7500 FastReal-Time PCR System (Applied Biosystems, Foster City, EUA). Na primeira etapa (pré-PCR) a reação de transcrição reversa do RNA (síntese do cDNA) foi feita a $50^{\circ} \mathrm{C}$ por 20 minutos, seguida pela inativação da transcriptase reversa e ativação da DNA polimerase a $95^{\circ} \mathrm{C}$ por cinco minutos. Em seguida, foram feitos 40 ciclos de $95^{\circ} \mathrm{C}$ por 15 segundos para a desnaturação das fitas de cDNA, e $60^{\circ} \mathrm{C}$ por 45 segundos para o anelamento dos primers e extensão das fitas de DNA. A partir da fluorescência emitida pela sonda FAM, o aparelho realizou a quantificação detectando a intensidade da emissão. Os resultados foram normalizados pelo volume de RNA utilizado na reação e foram então calculados para se obter equivalente de PFU/mL.

Os resultados foram analisados como o software 7500 Software v. 2.0.1 (Applied Biosystems, City, EUA), tendo como base o valor de CT (cycle threshold), que corresponde ao número de ciclos em que é atingido o limiar da detecção da fluorescência emitida pelo fluóroforo liberado da sonda durante a reação de PCR em tempo real. Assim, para que a amostras fossem consideradas positivas, estas deveriam apresentar amplificação em duplicata.

Para a quantificação da carga viral, uma curva padrão foi confeccionada a partir do estoque viral previamente quantificado. O RNA viral foi extraído e foram feitas diluições seriadas com fator de 1:10 iniciando em $1,5 \times 10^{6} \mathrm{PFU} / \mathrm{mL}$ e finalizando em $1,5 \times 10^{0} \mathrm{PFU} / \mathrm{mL}$. Os RNAs diluídos para a curva padrão foram adicionados à placa junto às amostras a serem quantificadas.

Tabela 1. Oligonucleotídeos utilizados na detecção do RNA do YFV por RT-PCR em tempo real.

\begin{tabular}{ccc} 
Primer/Sonda & Sequência & Referência \\
\cline { 1 - 2 } Primer Forward - YF.For & 5' GTGACAGCCTTGGCCATT 3' & SICONELLI et al., 2019 \\
\cline { 1 - 2 } Primer Reverse - YF.Rev & 5' AGGCTGGGCCAACAGCCA 3'
\end{tabular}


RESULTADOS 


\section{RESULTADOS}

\subsection{Captura e avaliação física}

De Abril de 2018 a Dezembro de 2018 foram capturados 39 animais na região sul do Município de Ribeirão Preto, Estado de São Paulo (Figura 17), sendo 38 da espécie Callithrix penicillata (Sagui de tufos pretos) e 01 da espécie Sapajus nigritus (Macaco-prego).

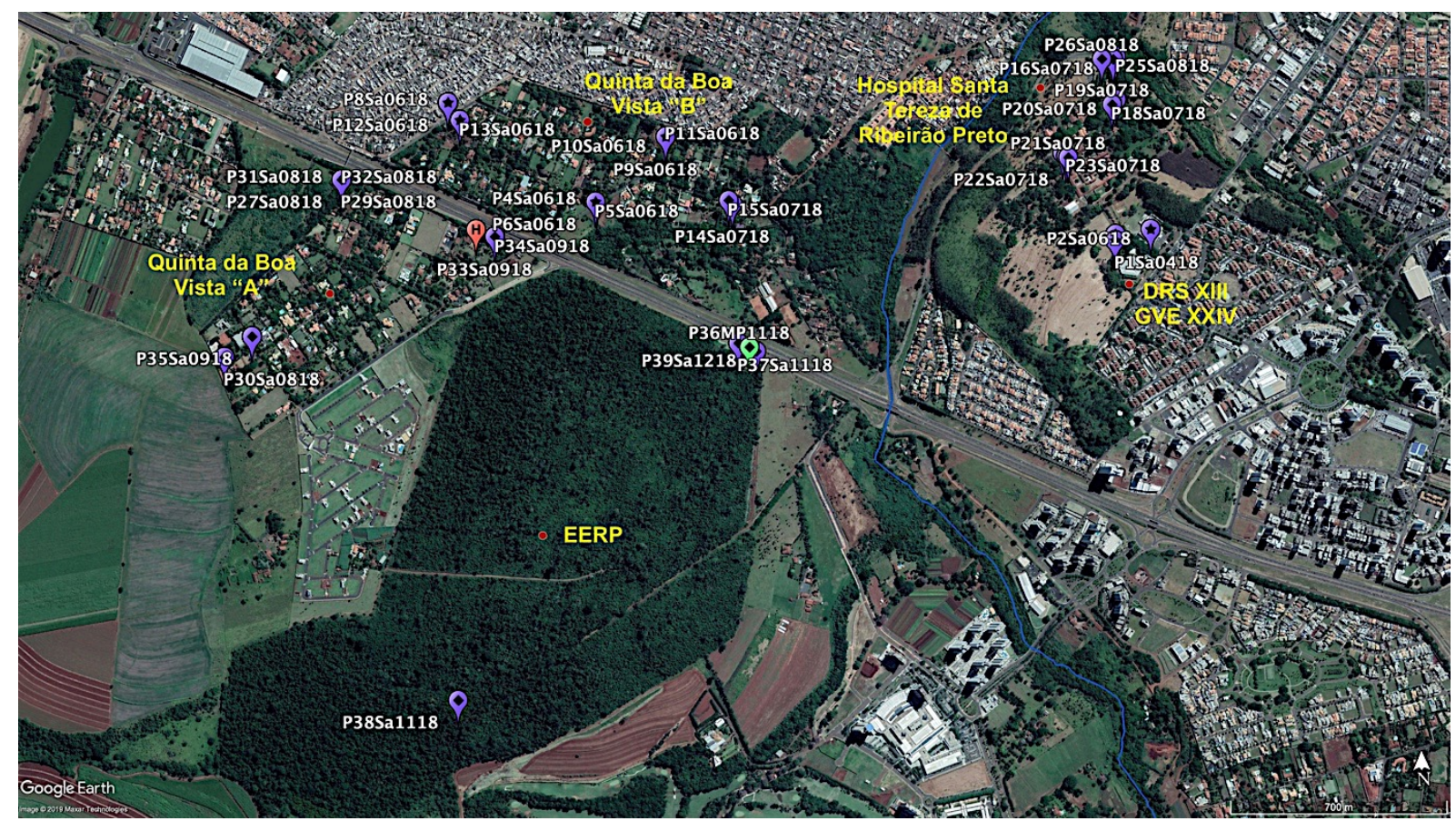

Figura 17. Vista aérea da região sul Município de Ribeirão Preto e os respectivos pontos onde as capturas foram realizadas. Linha azul: trecho aquático, rio "Ribeirão Preto"; Ponto vermelho $(\mathrm{H})$ : caso humano positivo para FA; Ponto Roxo (losango): PNHs da espécie C. penicillata; Ponto verde (losango): PNH da espécie S. nigritus. Google Earth, 2019.

Dos 38 saguis, 55,26\% (21/38) eram fêmeas e 44,74\% (17/38) machos, sendo a maior parte de animais adultos $63,15 \%$ (24/38), jovens adultos $13,25 \%(5 / 38)$ ou senis 7,89 (3/38). Filhotes também foram capturados, representando $15,78 \%$ (6/38) do total de saguis capturados. O único exemplar de macaco-prego foi uma fêmea em transição de idade, filhote para jovem adulto.

$\mathrm{Na}$ área de estudo foi possível identificar a presença de pelo menos 13 bandos distintos, cujo número de indivíduos variou de 3 a 10. Contudo, foi identificado um bando com mais de 15 indivíduos. Durante esse período houve a recaptura de alguns indivíduos, porém sempre no mesmo local onde haviam sido capturados anteriormente. No período estudado não houve migração de indivíduos por territórios de outros bandos. 
Após a captura e anestesia todos os animais passaram por avaliação física, seguindo o roteiro da "FICHA DE IDENTIFICAÇÃO DE PRIMATAS". Todos os animais apresentaram boa condição física, com escore corporal entre 2 e 4 (escala de 0 a 5 , sendo 0 = extremamente magro e 5 = obeso). Excluindo-se os filhotes, a média de peso dos saguis de tufos preto (jovens adultos, adultos e senis) foi de 372,8 gramas. Embora alguns animais tenham apresentado alguma alteração em sistema tegumentar, como alopecia, hiperqueratose, cicatrizes, perda de partes do corpo (amputação parcial de membro pélvico, dígitos e cauda), não foi identificada nenhuma alteração nos demais sistemas avaliados.

Na palpação, de 14 fêmeas (C. penicillata) em idade reprodutiva, pelo menos 8 (57\%) apresentaram aumento de volume na região abdominal e/ou presença de leite nas glândulas mamárias, sugerindo-se possível prenhes e/ou a presença de filhotes lactantes no grupo.

\subsection{Hemograma e achados clínico patológicos}

Todos os animais estudados foram de vida livre e, portanto, sem nenhum conhecimento prévio sobre o histórico clínico desses animais. Por ações antrópicas, o habitat natural dessas espécies foi degradado e modificado, impondo maior pressão sobre esses animais que estão se aproximado cada vez mais do ser humano, buscando abrigo e alimento. A migração desses animais e, também, dos seres humanos rumo à mesma direção expõe ambos ao risco do desenvolvimento de doenças. Diante disso, além do exame físico é importante que a avaliação do estado geral de saúde desses animais seja complementada com o hemograma, podendo ser associado, com resultados de exames específicos ou de achados clínicos. Essa avaliação ajuda no entendimento de como essa espécie está se adaptando às mudanças e também se podem portar algum patógeno e assim oferecer algum risco à saúde da população humana.

O hemograma foi realizado em 36 dos 39 animais capturados. O resultado do hemograma referentes aos PNHs (35 animais) da espécie $C$. penicillata foram: hemácias: $6,73 \times 10^{6} / \mu \mathrm{L} \pm$ 1,23; hemoglobina: $14,36 \mathrm{~g} / \mathrm{dL} \pm 2,43$; hematócrito: $44,11 \% \pm 7,55$; $\mathrm{VCM}: 65,79 \mathrm{fL} \pm 2,92$; HCM: $21,4 \mathrm{pg} \pm 1,1 ; \mathrm{CHCM}: 32,59 \mathrm{~g} / \mathrm{dL} \pm 0,80$; leucócitos totais: $8,4 \times 10^{3} / \mu \mathrm{L} \pm 2,77$; neutrófilos segmentados: $52,5 \% \pm 18,85$; neutrófilos bastonetes: 0 ; eosinófilos: $2 \% \pm 2,11$; basófilos: $1,08 \% \pm 1,55$; linfócitos: $41,73 \% \pm 18,83$; monócitos: $2,44 \% \pm 1,70$; plaquetas: $428 \times 10^{3} / \mu \mathrm{L} \pm 150$; e proteína plasmática total 6,32 $\pm 0,46 \mathrm{~g} / \mathrm{dL}$ (Tabela 2). De acordo com os valores de referência para animais de vida livre do gênero Callithrix (VERONA; PISSINATI et al., 2014), 80\% (28/35) apresentaram anemia; 31,42\% (11/35) aumento e 22,85\% (8/35) diminuição do hematócrito. Já na série branca 46,82\% (16/35) apresentaram leucopenia, e 
embora não se tenha verificado leucocitose, $48,57 \%$ (17/35) mostraram linfocitose e $8,57 \%$ (3/35) linfopenia; 11,42\% (4/35) apresentaram neutrofilia e 48,57\% (17/35) neutropenia.

Tabela 2. Parâmetros hematológicos de primatas não humanos, da espécie Callithrix penicillata, de vida livre capturados em área urbanizada do Município de Ribeirão Preto/SP.

\begin{tabular}{ccccc} 
& \multicolumn{2}{c}{ Intervalo } & Média & Desvio Padrão \\
\cline { 2 - 3 } & Mínimo & Máximo & & \\
\hline Hemácias $\left(\times 10^{6} / \mu \mathrm{L}\right)$ & 4,23 & 9,1 & 6,73 & 1,23 \\
\hline Hemoglobina $(\mathrm{g} / \mathrm{dL})$ & 8,9 & 20 & 14,36 & 2,43 \\
\hline Hematócrito $(\%)$ & 28,2 & 58,6 & 44,11 & 7,55 \\
\hline VCM $(\mathrm{fL})$ & 62 & 76 & 65,79 & 2,92 \\
\hline HCM $(\mathrm{pg})$ & 19,6 & 25,1 & 21,4 & 1,1 \\
\hline CHCM $(\mathrm{g} / \mathrm{dL})$ & 30,5 & 34,1 & 32,59 & 0,8 \\
\hline Leucócitos & 4.200 & 13.500 & 8.400 & $2.779,30$ \\
\hline Neutrófilos segmentados $(\%)$ & 20 & 91 & 52,5 & 18,85 \\
\hline Neutrófilos segmentados $(\mu \mathrm{L})$ & 966 & 12194 & 4.477 & $2.531,89$ \\
\hline Neutrófilos bastonetes $(\%)$ & 0 & 0 & 0 & 0 \\
\hline Neutrófilos bastonetes $(\mu \mathrm{L})$ & 0 & 0 & 0 & 0 \\
\hline Eosinófilos $(\%)$ & 0 & 10 & 2 & 2,11 \\
\hline Eosinófilos $(\mu \mathrm{L})$ & 58 & 630 & 169,38 & 153,64 \\
\hline Basófilos $(\mu \mathrm{L})$ & 0 & 6 & 1,088 & 1,55 \\
\hline Basófilos $(\mu \mathrm{L})$ & 52 & 405 & 98,79 & 129,74 \\
\hline Linfócitos $(\%)$ & 6 & 78 & 41,73 & 18,83 \\
\hline Linfócitos $(\mu \mathrm{L})$ & 804 & 9.126 & 3.439 & $1.893,61$ \\
\hline Monócitos $(\%)$ & 0 & 9 & 2,44 & 1,7 \\
\hline Monócitos $(\mu \mathrm{L})$ & 0 & 1080 & 207,58 & 191,41 \\
\hline Plaquetas $(\mu \mathrm{L})$ & 119.000 & 827.000 & 428.265 & 150.564 \\
\hline Proteína Plasmática Total $(\mathrm{g} / \mathrm{dL})$ & 5,6 & 7,2 & 6,32 & 0,46 \\
\hline & & & &
\end{tabular}

Apesar disso, para que se avalie adequadamente os valores, deve-se considerar a faixa etária, o ambiente, a disponibilidade de alimento, a espécie, captura, metodologia de leitura, além da condição clínica do animal. Esses fatores podem influenciar diretamente na intepretação. Estudos para a avaliação hematológica em animais de vida livre são um desafio, devido às dificuldades, desde captura até a coleta, o que contribui com a escassez na literatura de valores hematológicos de referência confiáveis para animais selvagens.

Os valores do hemograma referente a fêmea da espécie $S$. nigritus foram: hemácias: 3,81 $\times 10^{6} / \mu \mathrm{L}$; hemoglobina: 9,5g/dL; hematócrito: 27,2\%; VCM: 72 fL; HCM: 25,1 pg; CHCM: $35,1 \mathrm{~g} / \mathrm{dL}$; leucócitos totais: $13,5 \times 10^{3} / \mu \mathrm{L}$; neutrófilos segmentados: $74 \%$; neutrófilos bastonetes: 0 ; eosinófilos: 0; basófilos: 0; linfócitos: 23\%; monócitos: 3\%; plaquetas: $475 \times 10^{3} / \mu \mathrm{L}$. A proteína plasmática total foi de $6,32 \pm 0,46 \mathrm{~g} / \mathrm{dL}$. Esse animal apresentou 
anemia, com elevação no hematócrito (indicativo de desidratação), sem leucocitose, porém com neutrofilia e linfopenia.

\subsubsection{Achados clínico patológicos}

Durante a contagem diferencial de células leucocitárias em esfregaço delgado foi identificada a presença de microfilárias (Figura 18) em 6 PNHs adultos da espécie $C$. penicillata. Diante dos achados, em parceria com o Laboratório de Enfermidades Parasitárias (LabEPar), da Faculdade de Ciências Agrárias e Veterinárias de Jaboticabal (FCAV/Unesp), foram encaminhadas as lâminas dos animais positivos, para a presença de microfilária, e uma alíquota de sangue para a identificação morfológica e molecular, respectivamente. Pela avaliação morfológica concluiu-se que as microfilárias pertenciam ao morfogrupo Mansonella (Tetrapetalonema) (BAIN et al., 2015). Após a extração do DNA, PCR e Sequenciamento, as microfilárias foram confirmadas como Mansonella sp. As técnicas e os primers utilizados para a identificação molecular foram padronizados pelo LabEPar e pelo Laboratório de Epidemiologia Molecular, também da FCAV/Unesp. Assim, por fazerem parte de outro projeto e ainda não ter sido publicado, não foram descritos.
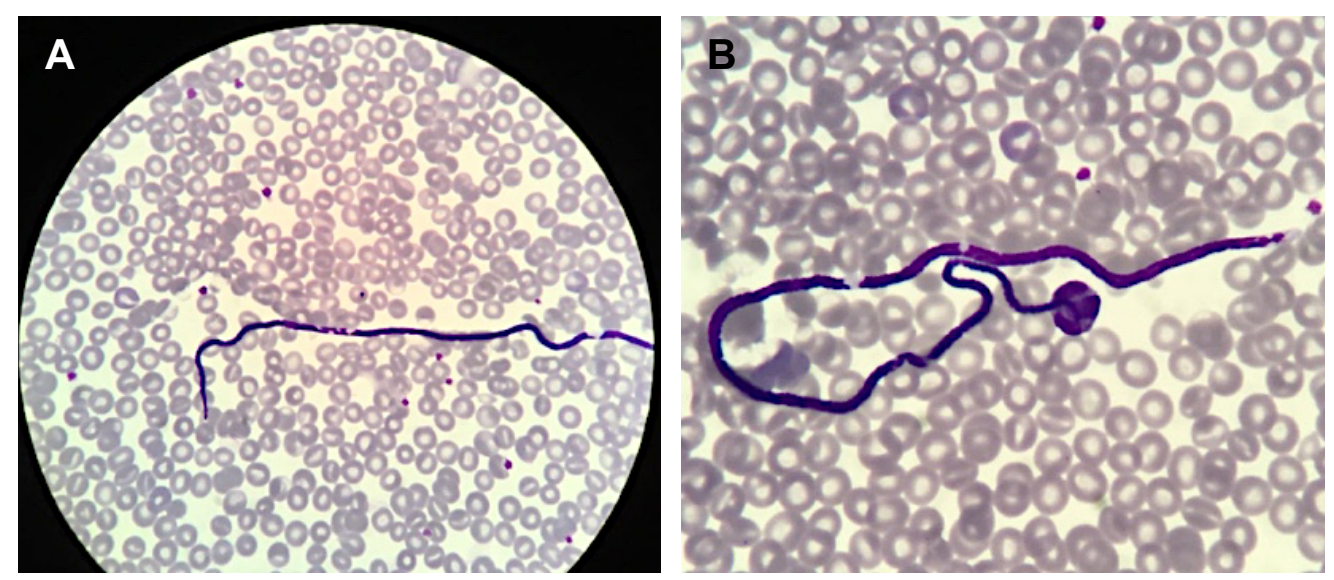

Figura 18. Microfilárias do morfogrupo Mansonella em sangue de PNH (C. penicillata) adulto, coradas por Panótico Rápido ${ }^{\mathbb{R}}$. A) parte posterior da microfilária, em aumento de 40x;

B) Microfilária em aumento de 100x, em imersão.

\subsection{PRNT}

Todas as 39 amostras foram submetidas ao PRNT para a detecção de anticorpos antiYFV. O PRNT é o teste padrão-ouro para a detecção de anticorpos neutralizantes, $\operatorname{IgM}$ e IgG, contra vírus do gênero Flavivirus, mostrando elevada especificidade. Além disso, é uma técnica 
que melhor relaciona a presença de anticorpos e a proteção contra o vírus que se está testando (MELO et al., 2011; MACHADO et al., 2013). Para a realização dos testes foi utilizado tanto o plasma (31 amostras), quanto o soro (8 amostras).

No PRNT $_{50}$, foi utilizada a cepa selvagem JabSPM02 (isolada em nosso laboratório de um PNH, que veio à óbito pelo YFV na epizootia 2016, no Município de Jaboticabal) na avaliação de todas as amostras dos PNHs capturados. Destes, 12,82\% (5/39) dos animais foram negativos, não apresentando anticorpos neutralizantes detectáveis na técnica. Dos positivos, em ordem crescente de títulos neutralizantes, 33,34\% (13/39) apresentaram título igual a 10, $25,64 \%(10 / 39)$ igual a $20,5,12 \%(2 / 39)$ igual a $40,10,26 \%(4 / 39)$ igual a 80 e $12,82 \%(5 / 39)$ igual a 160 (Tabela 3 ). Diferentemente, no $\mathrm{PRNT}_{50}$ feito com a cepa vacinal $17 \mathrm{DD}$, nenhum dos animais capturados apresentaram anticorpos neutralizantes, portanto, sendo todos negativos (Figura 19). Para tanto, por ser a cepa circulante na atual epidemia, o trabalho considerou os resultados gerados pela cepa do vírus da febre amarela selvagem, JabSPM02.
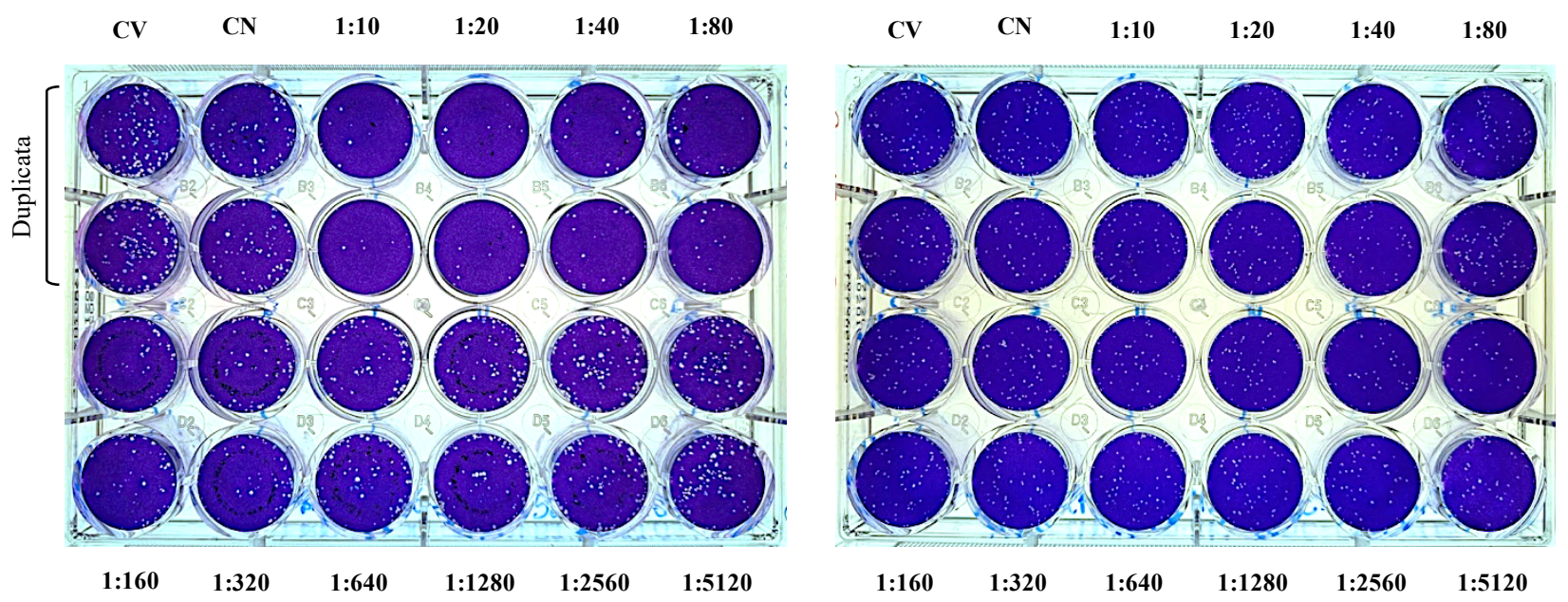

Figura 19. Diferença entre $\mathrm{PRNT}_{50}$ da amostra P36MP0918, com diluição seriada (fator 2) de 1:10 até 1:5.120 (em duplicata) utilizando as diferentes cepas do vírus da febre amarela. Na primeira placa (à esquerda) foi utilizada a cepa selvagem JabSPM02 e nota-se a redução $\geq 50 \%$ no número de plaques (neutralização) até a diluição 1:160. Já na segunda placa (à direita) utilizou-se a cepa vacinal 17DD, não sendo possível identificar a neutralização em nenhuma das diluições. O mesmo resultado foi observado nas outras amostras dos PNHs testadas com o vírus selvagem (JabSPM02) e vacinal (17DD). CV: controle de vírus; CN: controle negativo (amostra humana isenta de anticorpos anti-YFV, na diluição 1:10).

\subsection{Detecção do antígeno NS1 para o vírus da febre amarela}

A manutenção da circulação do vírus da febre amarela não foi detectada em nenhum dos animais capturados durante o período estudado. Na triagem feita a partir do teste rápido imunocromatográfico ASAN Easy Test ${ }^{\circledR}$ Yellow Fever NS1 Ag (Asan Pharm, Seoul, Korea), 
todos os testes estavam válidos, porém nenhum animal apresentou a presença de da proteína viral NS1 no sangue (Tabela 3 e Figura 20).
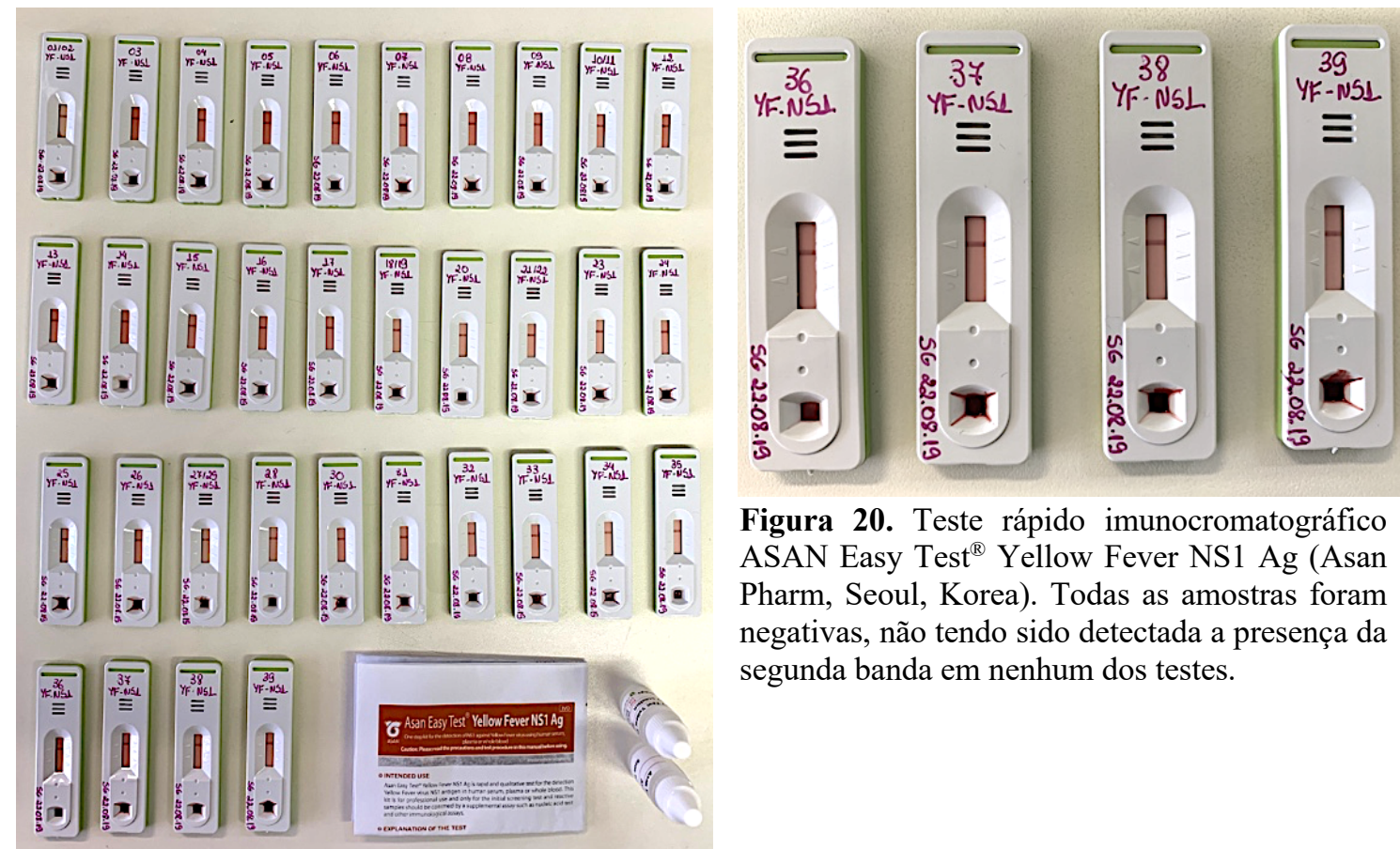

Figura 20. Teste rápido imunocromatográfico ASAN Easy Test ${ }^{\circledR}$ Yellow Fever NS1 Ag (Asan Pharm, Seoul, Korea). Todas as amostras foram negativas, não tendo sido detectada a presença da segunda banda em nenhum dos testes.

\subsection{RT-qPCR para o vírus da febre amarela}

Embora não se tenha detectado a presença do antígeno viral, por meio do teste rápido NS1-YFV, em nenhuma das amostras dos PNHs, realizou-se a RT-qPCR, a fim de descartar uma possível circulação do YFV na região estudada.

A RT-qPCR foi negativa para todas as amostras testadas (Tabela 3). 
Tabela 3. Resultados do PRNT 50 (expresso em títulos de acordo com a diluição), NS1 - YFV (ASAN) e YFV RT-qPCR das amostras de PNHs capturados na região sul de Ribeirão Preto, entre abril e dezembro de 2018.

\begin{tabular}{|c|c|c|c|c|c|c|c|c|c|}
\hline Local & ID & Sexo & Idade & Espécie & Fluido & $\begin{array}{l}\text { PRNT }_{50} \\
\text { (17DD) }\end{array}$ & $\begin{array}{c}\text { PRNT }_{50} \\
\text { (JabSPM02) } \\
\end{array}$ & $\begin{array}{l}\text { NS1 - YFV } \\
\text { (ASAN)* }\end{array}$ & $\begin{array}{c}\text { YFV } \\
\text { RT-qPCR* }\end{array}$ \\
\hline \multirow{3}{*}{$\begin{array}{l}\text { DRS/ } \\
\text { GVE }\end{array}$} & $\mathrm{P} 1 \mathrm{Sa} 0418$ & M & A & C. penicillata & Plasma & 0 & 10 & NEG & NEG \\
\hline & $\mathrm{P} 2 \mathrm{Sa} 0618$ & M & A & C. penicillata & Plasma & 0 & 10 & NEG & NEG \\
\hline & P3Sa0618 & $\mathrm{F}$ & $\mathrm{F}$ & C. penicillata & Plasma & 0 & 0 & NEG & NEG \\
\hline \multirow{12}{*}{$\begin{array}{c}\text { Quinta } \\
\text { da Boa } \\
\text { Vista } \\
\text { "B" }\end{array}$} & $\mathrm{P} 4 \mathrm{Sa} 0618$ & $\mathrm{~F}$ & A & C. penicillata & Plasma & 0 & 20 & NEG & NEG \\
\hline & P5Sa0618 & $\mathrm{F}$ & $\mathrm{F}$ & C. penicillata & Plasma & 0 & 160 & NEG & NEG \\
\hline & P6Sa0618 & $\mathrm{F}$ & A & C. penicillata & Plasma & 0 & 10 & NEG & NEG \\
\hline & P7Sa0618 & M & $\mathrm{J}$ & C. penicillata & Plasma & 0 & 20 & NEG & NEG \\
\hline & P8Sa0618 & $\mathrm{F}$ & $\mathrm{S}$ & C. penicillata & Plasma & 0 & 80 & NEG & NEG \\
\hline & P9Sa0618 & M & A & C. penicillata & Plasma & 0 & 10 & NEG & NEG \\
\hline & $\mathrm{P} 10 \mathrm{Sa} 0618$ & M & $\mathrm{F}$ & C. penicillata & Plasma & 0 & 0 & NEG & NEG \\
\hline & P11Sa0618 & $\mathrm{F}$ & $\mathrm{F}$ & C. penicillata & Plasma & 0 & 20 & NEG & NEG \\
\hline & P12Sa0618 & $\mathrm{F}$ & $\mathrm{F}$ & C. penicillata & Plasma & 0 & 0 & NEG & NEG \\
\hline & P13Sa0618 & $\mathrm{F}$ & A & C. penicillata & Plasma & 0 & 20 & NEG & NEG \\
\hline & P14Sa0718 & $\mathrm{F}$ & A & C. penicillata & Plasma & 0 & 10 & NEG & NEG \\
\hline & P15Sa0718 & M & A & C. penicillata & Plasma & 0 & 10 & NEG & NEG \\
\hline \multirow{11}{*}{$\begin{array}{c}\text { Hospital } \\
\text { Santa } \\
\text { Tereza } \\
\text { de } \\
\text { Ribeirão } \\
\text { Preto }\end{array}$} & P16Sa0718 & $\mathrm{F}$ & A & C. penicillata & Plasma & 0 & 20 & NEG & NEG \\
\hline & $\mathrm{P} 17 \mathrm{Sa} 0718$ & M & A & C. penicillata & Plasma & 0 & 10 & NEG & NEG \\
\hline & P18Sa0718 & $\mathrm{F}$ & $\mathrm{S}$ & C. penicillata & Plasma & 0 & 10 & NEG & NEG \\
\hline & P19Sa0718 & M & A & C. penicillata & Plasma & 0 & 10 & NEG & NEG \\
\hline & P20Sa0718 & M & $\mathrm{A}$ & C. penicillata & Plasma & 0 & 160 & NEG & NEG \\
\hline & $\mathrm{P} 21 \mathrm{Sa} 0718$ & $\mathrm{~F}$ & A & C. penicillata & Plasma & 0 & 20 & NEG & NEG \\
\hline & $\mathrm{P} 22 \mathrm{Sa} 0718$ & $\mathrm{~F}$ & $\mathrm{~A}$ & C. penicillata & Plasma & 0 & 20 & NEG & NEG \\
\hline & P23Sa0718 & M & A & C. penicillata & Plasma & 0 & 10 & NEG & NEG \\
\hline & $\mathrm{P} 24 \mathrm{Sa} 0718$ & $\mathrm{~F}$ & A & C. penicillata & Soro & 0 & 10 & NEG & NEG \\
\hline & $\mathrm{P} 25 \mathrm{Sa} 0818$ & $\mathrm{~F}$ & $\mathrm{~J}$ & C. penicillata & Plasma & 0 & 10 & NEG & NEG \\
\hline & $\mathrm{P} 26 \mathrm{Sa} 0818$ & $\mathrm{~F}$ & A & C. penicillata & Soro & 0 & 40 & NEG & NEG \\
\hline \multirow{9}{*}{$\begin{array}{c}\text { Quinta } \\
\text { da Boa } \\
\text { Vista } \\
\text { "A"A" }\end{array}$} & P27Sa0818 & $\mathrm{F}$ & A & C. penicillata & Plasma & 0 & 20 & NEG & NEG \\
\hline & P28Sa0818 & M & A & C. penicillata & Plasma & 0 & 160 & NEG & NEG \\
\hline & P29Sa0818 & $\mathrm{F}$ & $\mathrm{J}$ & C. penicillata & Plasma & 0 & 20 & NEG & NEG \\
\hline & $\mathrm{P} 30 \mathrm{Sa} 0818$ & M & A & C. penicillata & Soro & 0 & 0 & NEG & NEG \\
\hline & $\mathrm{P} 31 \mathrm{Sa} 0818$ & M & $\mathrm{F}$ & C. penicillata & Soro & 0 & 160 & NEG & NEG \\
\hline & P32Sa0818 & $\mathrm{F}$ & $\mathrm{J}$ & C. penicillata & Plasma & 0 & 80 & NEG & NEG \\
\hline & P33Sa0918 & M & A & C. penicillata & Plasma & 0 & 80 & NEG & NEG \\
\hline & P34Sa0918 & M & A & C. penicillata & Soro & 0 & 40 & NEG & NEG \\
\hline & $\mathrm{P} 35 \mathrm{Sa} 0918$ & $\mathrm{~F}$ & A & C. penicillata & Plasma & 0 & 10 & NEG & NEG \\
\hline \multirow{4}{*}{$\begin{array}{c}\text { EERP - } \\
\text { Mata de } \\
\text { Santa } \\
\text { Tereza }\end{array}$} & P36MP0918 & $\mathrm{F}$ & $\mathrm{J}$ & S. nigritus & Soro & 0 & 80 & NEG & NEG \\
\hline & P37Sa1118 & $\mathrm{F}$ & $\mathrm{A}$ & C. penicillata & Soro & 0 & 0 & NEG & NEG \\
\hline & P38Sa1118 & $\mathrm{M}$ & $\mathrm{S}$ & C. penicillata & Plasma & 0 & 160 & NEG & NEG \\
\hline & P39Sa1118 & M & $\mathrm{J}$ & C. penicillata & Soro & 0 & 20 & NEG & NEG \\
\hline
\end{tabular}

ID: identificação do animal; Sexo - M: macho; F: fêmea; Idade - F: filhote; J: jovem adulto; A: adulto; S: senil; NEG: negativo; *para a realização do teste NS1 e RT-qPCR foi utilizado a fração celular do sangue com EDTA. 


\section{DISCUSSÃo}




\section{DISCUSSÃO}

A vigilância de epizootias é um dos pilares do Programa de Vigilância, Prevenção e Controle da Febre Amarela no Brasil (BRASIL, 2017e), cujo objetivo é a deteç̧ão precoce da atividade viral em áreas endêmicas e, principalmente, em áreas sem registro prévio da circulação do vírus da febre amarela. Embora seja uma estratégia essencial, pois a detecção do vírus em populações de PNHs prediz o surgimento de casos em seres humanos (STRODE et al., 1951; ARAUJO et al., 2011; MORENO et al., 2013; SICONELLI et al., 2019), subsidiando o desenvolvimento de ações de prevenção e controle, a falta de sensibilidade do serviço de vigilância em períodos de surto, combinada à demora no diagnóstico, tem feito vítimas em todo o território nacional, principalmente em áreas sem recomendação de vacinação (ALMEIDA et al., 2014).

De julho de 2016 a dezembro de 2018 o Brasil viveu a pior epidemia de febre amarela silvestre que se tem registro, 2.156 casos humanos confirmados, destes 746 vieram a óbito, e pelo menos 14.513 epizootias notificadas, sendo confirmadas laboratorialmente cerca de 1.525 (BRASIL, 2017c,d; 2018). Destas, aproximadamente 700 foram do Estado de São Paulo. A região Sudeste foi responsável por mais de $90 \%$ de todos os casos notificados e confirmados no país durante esse período (BRASIL, 2017c,d; 2018). Registros de surtos anteriores já mostravam a dispersão contínua do vírus no sentido leste-sul do país, alcançando áreas onde desde a década de 30 não se tinha registros da circulação do YFV (VASCONCELOS, 2010; POSSAS et al., 2018), sendo portanto, questão de tempo até que o YFV alcançasse áreas com alta densidade populacional, como a região metropolitana de Campinas, Grande São Paulo e baixada santista, além de outras capitais localizadas na costa leste do país, cuja população apresentava baixo ou quase nulo índices de cobertura vacinal. Equipes da Saúde do Estado de São Paulo acompanharam a dispersão do vírus na tentativa de estimar quanto tempo levaria para alcançar esses centros e assim instituir medidas preventivas, contudo, devido à ausência de informação de algumas regiões, o YFV chegou antes do previsto, causando mortes. Essa situação deixou clara a fragilidade do sistema de saúde brasileiro, no que tange o contingenciamento de emergências sanitárias. Assim que o YFV alcançou a região de mata atlântica, perdeu-se o controle sobre qual a direção o vírus continuaria avançando. Desde o registro do vírus na capital, em outubro 2017 (SÃO PAULO, 2017), muitos bandos de bugios foram dizimados (FIORAVANTI, 2018) e de acordo com o Boletim Epidemiológico de junho de 2019, do Ministério da Saúde, a transmissão tem se mantido ativa em toda área leste do Estado de São Paulo (SÃO PAULO, 2019) e tem avançado rumo ao sul, nos Estados do Paraná 
e de Santa Catarina, onde outras dezenas de PNHs e também seres humanos têm sido diagnosticados com o vírus (BRASIL, 2019b,c).

Embora até o momento não tenha sido detectado o vírus em populações do vetor urbano, Ae. aegypti, a pressão de infecção foi grande, elevando o risco de uma possível volta do ciclo urbano (COUTO-LIMA et al., 2017). Recentemente foi isolado pela primeira vez o vírus da febre amarela a partir do vetor Ae. albopictus, considerado secundário na transmissão da dengue, que fora coletado em área e transmissão ativa (LAMBRECHTS et al., 2010; MEDEIROS et al., 2018; SICONELLI et al., 2019). Apesar de não ter sido provado laboratorialmente a sua capacidade de transmissão para o YFV, evidências encontradas no campo durante a epidemia de 2017 sugerem que esse vetor pode estar relacionado com transmissão, e ser, possivelmente, o elo entre a área urbana e rural. A presença de PNHs positivos em áreas estritamente urbanas (CUNHA et al., 2019; SICONELLI et al., 2019), como nos Municípios de Ribeirão Preto e Campinas, demonstram a mudança do padrão epidemiológico desse vírus, de modo que a presença de vetores zoofílicos, porém não estritos como o Ae. albopictus, em praças com grandes formações arbóreas, sugere a transmissão do YFV por esse vetor, principalmente quando pesquisas entomológicas feitas por órgão estaduais de saúde não encontram vetores silvestres, como Haemagogus e Sabethes.

A vigilância de epizootias está fundamentada na vigilância passiva, ou seja, na espera de que a informação chegue até o serviço de saúde, por meio de notificação ou denúncia (BRASIL, 2017e). Entretanto, esse modelo tem se mostrado falho uma vez que o objetivo primordial é fazer a detecção precoce desse vírus, de forma a identificá-lo antes que este atinja proporções epizoóticas e consequentemente epidêmicas. Por isso, faz-se necessário a revisão do modelo de vigilância a ser praticado pelo serviço de saúde, particularmente na situação epidemiológica que estamos vivendo, já que a população da principal espécie sentinela (Alouatta sp.) sofreu uma drástica redução, sendo dizimada em muitos locais da região sudeste. A vigilância ativa, embora demande equipe técnica especializada e, portanto, mais cara, mantém-se como o próprio nome sugere "ativa", com equipes buscando periodicamente sinais da circulação viral, procurando por PNHs mortos em áreas de matas, que muitas vezes antecedem áreas urbanas, realizando a captura de PNHs e também de outras espécies, para que o sangue seja amostrado e submetido à vigilância virológica e sorológica. É, portanto, mais assertiva quando o objetivo é detectar o vírus antes que atinja áreas urbanas e para que se busque melhor entendimento epidemiológico acerca do vírus.

Sob esta perspectiva é que o presente estudo foi realizado, embasado na vigilância ativa para avaliar qual foi o impacto do YFV na população de PNHs da região sul do Município de 
Ribeirão Preto. Área onde fora confirmado um óbito humano, em dezembro de 2016, e que, mais tarde, houve o isolamento viral a partir de mosquitos do gênero Haemagogus coletados no local (CUNHA et al., 2019).

Para que as capturas tivessem êxito foi necessário realizar o planejamento das atividades a cada etapa. A partir do caso humano, em conjunto com a equipe técnica do Departamento de Vigilância Ambiental em Saúde, da Secretaria Municipal de Saúde de Ribeirão Preto, foram definidas as regiões onde seriam feitas as buscas pela presença de PNHs, as capturas e os locais em que as armadilhas seriam instaladas. Foram definidos sete locais de captura, denominados também de etapas, todos localizados dentro de áreas particulares, sob jurisdição municipal ou estadual e embora o projeto tivesse a licença do ICMBio/MMA para realizar as capturas, deveria haver a autorização mútua dos respectivos locais. Após definidas as áreas, a equipe responsável foi até cada local, conversou com o responsável, a fim de sensibilizá-lo sobre a necessidade do trabalho e assim, solicitar a autorização. As capturas aconteceram em cinco locais, dos sete que haviam sido previamente planejados, devido à recusa na autorização e por motivos de segurança para a equipe e para os animais. A população predominante na região é de saguis de tufos preto (Callithrix penicillata) com média de 5 indivíduos/bando. Contudo, na Estação Ecológica de Ribeirão Preto (Mata de Santa Tereza) há também dois bandos bem definidos de macacos-prego (Sapajus nigritus), com cerca de 15 a 30 indivíduos cada. Dentro de cada área, foram definidas estações de captura onde as armadilhas foram instaladas, 3 a 4 armadilhas por local, buscando cobrir paralelamente a maior área possível, contemplando os possíveis bandos ali presentes, conforme as informações que eram obtidas dos moradores. Com essa estratégia, foi possível avaliar se havia migração dos bandos interterritórios, uma vez que após capturados os animais era marcados, via aplicação de nanochips. De acordo com as evidências coletadas por meio da observação visual dos bandos e também durante as capturas, não se constatou a migração desses PNHs em diferentes territórios, ficando cada bando restrito à sua área específica. O menor e o maior território estimado foi, respectivamente, 3,74 ha $\left(37.409 \mathrm{~m}^{2}\right)$ e 21,5 ha $\left(215.450 \mathrm{~m}^{2}\right)$, perímetro semelhante ao registrado no guia "Primatas do Brasil - Guia de Campo" (REIS et al., 2015), que cita áreas variando de 2,5 a 18,5 ha/bando, o que mostra a capacidade de adaptação desses animais nos mais diferentes ambientes, como os das cidades. Constatou-se ainda que cada bando possuía uma rotina de migração, percorrendo sempre os mesmos trajetos e em horários quase que fixos; cada etapa demorou de 4 semanas a 12 semanas, dependendo da área e de quão habituado os animais estavam com os seres humanos. Com exceção dos animais da área de mata ou dos locais onde os animais não tinham contato direto com seres humanos, os saguis possuíam comportamento sinantrópico e muitos 
deles estavam praticamente domesticados. Situação essa confirmada pela captura facilitada nesses locais, onde houve, inclusive, a recaptura de alguns exemplares, na mesma etapa, o que não se viu nas áreas onde os animais eram mais selvagens. Após a captura e coleta de sangue, essas amostras foram submetidas a testes sorológicos e virológicos a fim de detectar se os animais daquela região haviam tido contato com o vírus em algum momento da vida e se ainda, de forma silenciosa o vírus se mantivera circulando, mesmo que em baixas cargas virais. Cabe ressaltar que todos os procedimentos seguiram o Guia de Vigilância de Epizootias em Primatas Não Humanos e Entomologia Aplicada à Vigilância da Febre Amarela (BRASIL, 2017e).

Estudos soroepidemiológicos para verificar a prevalência da febre amarela em PNHs são escassos. Autores como Oliveira-Filho et al. (2018) e Moreira-Soto et al. (2018) estudaram bugios (Alouatta sp.), macacos-prego (Cebus sp. e Sapajus sp.) e saguis (Callithrix sp.) das regiões Nordeste e Centro-Oeste do país. O sangue desses animais foi submetido à vírus neutralização para YFV, resultando respectivamente, 1/49 macaco-prego positivo pelo $\mathrm{PRNT}_{90}$ e 0/207 pelo PRNT 50 . Situação semelhante foi encontrada por Morales et al. (2017) na Argentina, onde 4/108 bugios apresentaram títulos muito baixos, de 10 e 20 no PRNT $_{90}$; o que é esperado ao se aumentar a especificidade, pois nesse teste apenas serão positivos aqueles animais que apresentaram redução de pelo menos $90 \%$ dos plaques, o que evidencia o poder de neutralização dos anticorpos presentes no soro (ROEHRIG et al., 2008). Lima et al. (2010) pela técnica do ELISA avaliaram o soro de 570 animais da espécie Alouatta caraya, oriundos do Estado de São Paulo (área da Hidrelétrica Porto Primavera). Todos foram negativos para IgG. Outro estudo realizado por Laroque et al. (2014) ao pesquisar YFV em 131 amostras de macacos-prego, sendo 31 de vida livre e 100 de cativeiro, encontrou apenas dois PNHs de cativeiro com título de 20 na IH (Inibição da Hemaglutinação). No presente estudo foi encontrado 87,18\% (34/39) de soropositividade nas espécies Callithrix penicillata e Sapajus nigritus, com títulos variando de 10 a 160 . É recomendado que seja utilizado o PRNT $_{90}$ em áreas onde se tem a circulação de vírus pertencentes a mesma família, como DENV e ZIKV, principalmente (WHO, 2007; ROEHRIG et al., 2008), elevando-se a especificidade, contudo, reduz-se significativamente a sensibilidade de detecção, o que não é desejável. Para tanto, optou-se por aplicar o PRNT $_{50}$ (KATO et al., 2013), que apresenta sensibilidade adequada para o objetivo desse projeto. Foram encontrados $28,2 \%$ de animais com altos títulos de anticorpo, de 40 a 160, o que sugere que esses animais tiveram contato específico com o YFV.

Embora títulos maiores ou iguais a 10 tenham sido considerados positivos e diversos trabalhos mostrarem que indivíduos (PNHs e seres humanos) com esse título de anticorpo estão protegidos contra a infecção pelo YFV (MASON et al., 1973; LANG et al., 1999; NIEDRIG et 
al., 2008; WHO, 2010; KAY et al., 2011; MELO et al., 2011; MONATH et al., 2011; MACHADO et al., 2013; AHUKA-MUNDEKE; STAPLES et al., 2018), não se pode descartar a possibilidade de reação cruzada com outros Flavivirus (Dengue, Zika, febre do Nilo Ocidental, Ilhéus, encefalite de Saint Louis, entre outros) (STETTLER et al., 2016; MOREIRASOTO et al., 2018; OLIVEIRA-FILHO et al., 2018). Oliveira-Filho et al. (2018), também encontraram positividade no $\mathrm{PRNT}_{90}$ de 4,08\% (2/49) para o ZIKV, 2,04\% (1/49) para DENV1 e 4, 14,29\% (7/49) para DENV-2 e 3, 8,16\% (4/49) para ILHV 2,08\% (1/49) para SLEV. Já Moreira-Soto et al. (2018), pelo $\mathrm{PRNT}_{50}$, pesquisaram a soropositividade contra vírus da família Flaviviridae e encontraram 2,9\% (6/207) de positividade para ZIKV, com títulos de 40, dos quais 2 reagiram para DENV, com título de 40 e 160. Os dois PNHs positivos para YFV encontrados por Laroque et al. (2014) também reagiram contra os ILHV, ROCV e SLEV, que apresentou títulos de 80 . Nesse mesmo estudo diversos animais apresentaram reatividade cruzada quando testados com mais de um vírus da mesma família. De 108 bugios, Morales et al. (2017) verificaram que em pelos 57 PNHs tiveram reatividade cruzada entre os vírus DENV1 e 3, SLEV, WNV, ILHV e BSQV. Essa possibilidade torna-se mais factível, ao analisar a população de PNHs estudada, que se localiza em área urbanizada e que o Município de Ribeirão Preto vem, ao longo dos anos, sofrendo com epidemias de Zika e principalmente Dengue, que é recorrente todos os anos. Apesar disso, por restrições técnicas e de logística, o PRNT para outros flavivirus, DENV-1 e 2 e ZIKV, não foi realizado.

Outro ponto importante a ser considerado dentro da técnica do PRNT e que pode interferir, sobremaneira, nos resultados é a cepa viral utilizada. Diversos trabalhos tem utilizado a cepa vacinal 17D/17DD (LANG et al., 1999; NIEDRIG et al., 1999; NIEDRIG et al., 2008; MELO et al., 2011; MONATH, et al., 2011; MORALES et al., 2017; MOREIRA-SOTO et al., 2018), o que faz sentido quando o objetivo é avaliar a resposta imune humoral a partir da vacinação em determinadas populações. Contudo, um dos problemas na comparação dos dados aqui obtidos é que mesmo trabalhos epidemiológicos que visam detectar a soropositividade a partir da infecção natural tem utilizado a cepa vacinal. Nós, além da cepa vacinal, utilizamos a cepa selvagem com resultados díspares entre elas. Embora a cepa 17D/17DD seja mais estável, disponível e traga maior segurança ao manipulador, o seu uso pode trazer resultados equivocados, devendo-se primar pelo uso de uma cepa selvagem recente, quando o objetivo for verificar a soroprevalência em amostras de campo. Nesse estudo o PRNT $_{50}$ foi feito com as duas cepas, em paralelo, para cada uma das amostras, resultando em valores bastante curiosos. Enquanto $87,18 \%$ dos animais foram positivos com o uso da cepa selvagem, JabSPM02, possivelmente uma representação bastante fidedigna da cepa circulante recentemente em nossa 
região, o mesmo não aconteceu com a cepa vacinal, $17 \mathrm{DD}$, de modo que nenhum animal apresentou neutralização contra essa cepa. Desde o seu isolamento, em 1927, a cepa ASIBI passou por diversos tipos de cultivo o que culminou com mutações e consequentemente na sua atenuação (STAPLES et al., 2018). Embora a cepa JabSPM02 não tenha sido completamente sequenciada, a porção disponível é referente a região estrutural do genoma, e ela é idêntica à região correspondente do vírus isolado e sequenciado completamente no Estado do Espírito Santo em 2017 (BONALDO et al., 2017; SICONELLI et al., 2019). Desde a cepa ASIBI, o YFV acumulou muitas mutações ao longo da sua evolução, principalmente ao se comparar a cepa 17D/17DD e a cepa selvagem, que circulou na última epidemia. É muito provável que a distância filogenética entre os dois vírus seja significativa (BONALDO et al., 2017). Entretanto, uma análise mais aprofundada é necessária para que se pontuem quais as diferenças, principalmente em porções codificadoras de proteínas estruturais, que ajudem a entender o que foi visto no presente estudo. Apesar da divergência genética, não se alterou a capacidade de neutralização dos anticorpos, produzidos a partir da cepa 17DD, que foi confirmado ao avaliar uma amostra de pessoa primo-vacinada, após 120 dias da vacinação (Comissão de Ética e Pesquisa - CEP: 2.914.563). Foram identificados anticorpos neutralizantes para ambos os vírus, com títulos idênticos, 40. Assim, animais infectados naturalmente parecem possuir alguma diferença em seus anticorpos, que não reconhecem a partícula viral da cepa vacinal. O mesmo parece ser verdade para seres humanos, também infectados naturalmente, pois em uma amostra do paciente que veio à óbito pelo YFV selvagem em 2016 (FABRO et al., 2019), da mesma região onde os PNHs foram capturados, quando submetido à vírus neutralização por ambos os vírus, houve neutralização apenas da cepa selvagem, alcançando título de 80 .

Apesar dos gêneros Alouatta, Sapajus/Cebus e Callithrix estarem envolvidos com maior frequência na epidemiologia da FA, estes apresentam diferentes graus de susceptibilidade ao YFV, sendo os gêneros Alouatta e Callithrix os mais susceptíveis (LAEMMERT, 1944; KINDLOVITS et al., 2009; POSSAS et al., 2018). Destaca-se o primeiro por ser considerada espécie sentinela para as autoridades de saúde e cursar com o desenvolvimento da doença clínica, assim como nos seres humanos (VASCONCELOS, 2003); já os Sapajus/Cebus são considerados resistentes ao desenvolvimento da doença, mas não à infecção, sendo considerados "reservatórios" (DAVIS et al., 1929; DAVIS, 1930; STRODE, 1951; BENSABATH et al., 1966; OTT-JOSLIN, 1986; ALMEIDA et al., 2012; HANLEY et al., 2013; MORENO et al., 2011; 2013; MASCHERETTI et al., 2013; BRASIL, 2017e; CUNHA et al., 2019). A concepção de que saguis são tão susceptíveis quanto os bugios deve ser reavaliada, pois embora esses animais estejam sendo notificados durante as epidemias em 
quantidades semelhantes ou superiores ao gênero Alouatta, estudos tem mostrado que a positividade para o YFV nesses animais é muito menor ou quase nula, quando avaliados pela RT-qPCR e imunohistoquímica (MORENO et al., 2011; CUNHA et al., 2019). Dados esses que corroboram o presente estudo, pois a maior parte dos animais apresentou resultados positivos na sorologia contra o YFV e negativos quando submetidos a procura do antígeno NS1 e RT-qPCR. Esses dados demonstram que os saguis são infectados pelo YFV, porém não desenvolvem doença clássica, conforme os bugios, apresentando baixa carga viral (CUNHA et al., 2019), possivelmente não vindo a óbito pelo vírus e não representando um fator muito importante na manutenção das epizootias.

O resultado desse trabalho traz dados que ajudam a entender o novo perfil epidemiológico do YFV que se estabeleceu no país. Contudo, levanta uma preocupação sobre como acontecerá a detecção precoce desse vírus numa próxima epidemia, prevista para acontecer em 5 ou 7 anos (VASCONCELOS, 2010; SOUZA, 2013). Como discutido, bugios são considerados animais sentinelas, pois apresentam alta susceptibilidade à infecção pelo YFV, o que leva a alta taxa de letalidade na população. Desde a epidemia de 2008/2009 tem-se registrado a morte de centenas de PNHs dessa espécie, tanto na região sul, quando região sudeste, reduzindo-se os índices populacionais dessa espécie e, portanto, perdendo-se população sentinela (ALMEIDA et al., 2012; FIALHO et al., 2012; FIORAVANTI, 2018). Embora a população de saguis seja abundante e esteja disseminada em diversos municípios, ocasionando problemas à população humana, devido ao descontrole populacional, o presente estudo mostrou que esses animais se infectam, porém não adoecem e tampouco vem à óbito por causa do YFV. Com isso, a sensibilidade da vigilância passiva reduz significativamente, uma vez que essa espécie não morre pela infecção, além de apresentar baixa carga viral (CUNHA et al., 2019), o que torna o diagnóstico mais difícil. Entretanto, como mais de $85 \%$ destes animais apresentam títulos de anticorpos neutralizantes contra o YFV, pode-se caracterizar uma imunidade de rebanho. Isso significa que o alto número de indivíduos "imunizados" naturalmente protegerá esta região contra uma nova epizootia de FA nos próximos anos, até que a população de PNHs seja renovada com indivíduos suscetíveis, em proporção suficiente para possibilitar a infecção e assim causar uma epizootia. Deve-se considerar também que para que isso aconteça, estes animais precisam desenvolver uma viremia alta o suficiente para amplificar o vírus e mantê-lo circulante na população. Ao avalia-los clinicamente, exame físico e hemograma, esses animais apresentaram condição clínica satisfatória (VERONA; PISSINATI et al., 2014; THRALL et al., 2015), mostrando que apesar de viverem em um ambiente totalmente modificado pelo ser humano, tem se adaptado adequadamente e prosperado. 
Situação que é confirmada, pela presença de fêmeas prenhes nos bandos. Em alguns PNHs foi identificada a presença de microfilárias no sangue periférico, contudo, por não ser o objetivo do estudo, não se aprofundou nessa análise, contudo, mas buscamos parcerias na tentativa de descobrir qual a significância desse achado, tanto para a população de PNHs, quanto humana.

Assim, por estarem em contato direto com a população humana, nos grandes centros urbanos, esses animais representam um risco à saúde de ambos, elevando-se inclusive o risco da reurbanização do YFV, além de proporcionar condições ótimas para que outros arbovírus e patógenos circulem nessa população. Dessa forma a vigilância de epizootias, do Programa de Vigilância, Prevenção e Controle da Febre Amarela no Brasil, deve ser revisado para que seja adequado a nova realidade epidemiológica. 
Conclusões 


\section{CONCLUSÕES}

A presença de anticorpos neutralizantes em primatas não humanos em área urbanizada da região sul do município confirma a ocorrência prévia da circulação autóctone do vírus da febre amarela no local, corroborando a detecção dos casos positivos em primatas não humanos e do caso humano de 2016. A ausência de detecção viral nos PNHs capturados demonstra a inexistência da manutenção da circulação viral nos dias atuais.

Embora a espécie Callithrix penicillata seja susceptível à infeção pelo vírus da febre amarela, esta não adoece da mesma forma e nem na mesma proporção que se evidencia em primatas do gênero Alouatta sp. e, portanto, não podem ser considerados animais sentinelas.

Assim, em face a esse novo padrão epidemiológico a vigilância passiva de epizootias deve ser questionada e revisada, pois a sensibilidade de detecção desta estratégia pode não ser suficiente para o desencadeamento das medidas de prevenção e controle em tempo oportuno.

A substituição das populações sentinelas, gênero Alouatta, por não sentinelas, Sapajus/Cebus e Callithrix, em especial a última que está totalmente urbanizada, aliado ao tipo de vigilância praticado, fará com que a detecção fique prejudicada, possibilitando que o vírus circule de forma silenciosa, expondo a população humana ao risco. Portanto, a presença de calitriquídeos no ambiente urbano, em contato direto com a população humana, eleva o risco da transmissão de zoonoses, como a febre amarela. Além disso, esse cenário cria uma condição ideal para uma possível reurbanização desse vírus, desde que esses animais mantenham a viremia alta e prolongada. 


\section{REFERÊNCIAS}




\section{REFERÊNCIAS}

AHUKA-MUNDEKE, S.; CASEY, R. M.; HARRIS, J. B.; DIXON, M. G.; NSELE, P. M.; KIZITO, G. M.; UMUTESI, G.; LAVEN, J.; PALUKU, G.; GUEYE, A. S.; HYDE, T. B.; SHERIA, G. K. M.; MUYEMBE-TANFUM, J. J.; STAPLES, J. E. Immunogenicity of Fractional-Dose Vaccine during a Yellow Fever Outbreak — Preliminary Report. The New England Journal of Medicine, 2018. DOI: 10.1056/NEJMoa1710430

AlMEIDA, M. A. B.; SANTOS, E.; CARDOSO, J. C.; FONSECA, D. F.; NOLL, C. A.; SILVEIRA, V. R.; MAEDA, A. Y.; SOUZA, R. P.; KANAMURA, C.; BRASIL, R. A. Yellow Fever Outbreak Affecting Alouatta Populations in Southern Brazil (Rio Grande do Sul State), 2008-2009. American Journal of Primatology, v. 74, p. 68-76, 2012.

ALMEIDA, M. A. B.; CARDOSO, J. C.; SANTOS, E.; FONSECA, D. F.; CRUZ, L. L.; FARACO, F. J. C.; BERCINI, M. A.; VETTORELlO, K. C.; PORTO, M. A.; MOHRDIECK, R.; RANIERI, T. M. S.; SCHERMANN, M. T.; SPERB, A. F.; PAZ, F. Z.; NUNES, Z. M. A.; ROMANO, A. P. M.; COSTA, Z. G.; GOMES, S. L.; FLANNERY, B. Surveillance for yellow fever virus in non-human primates in southern Brazil, 2001-2011: a tool for prioritizing human populations for vaccination. PLoS Neglected Tropical Diseases, v. 8, n. 3, e2741, 2014. Disponível em: <https://doi.org/10.1371/journal.pntd.0002741>

ARAUJO, F. A. A.; RAMOS, D. G.; SANTOS, A. L.; PASSOS, P. H. O.; ELKHOURY, A. N. S. M.; COSTA, Z. G. A.; LEAL, A. G.; ROMANO, A. P. M. Epizootias em primatas não humanos durante reemergência do vírus da febre amarela no Brasil, 2007 a 2009. Epidemiologia e Serviços de Saúde, v. 20, n. 4, p. 527-536, 2011.

BAIN, O.; MUTAFCHIEV, Y.; JUNKER, K.; GUERRERO, R.; MARTIN, C.; LEFOULON, E.; UNI, S. Review of the genus Mansonella Faust, 1929 sensu lato (Nematoda: Onchocercidae), with descriptions of a new subgenus and a new subspecies. Zootaxa, v. 3918, n. 2, p. 151-193, 2015.

BENSABATH, G.; SHOPE, R. E.; ANDRADE, A. H. B.; SOUZA, A. P. Recuperación de vírus amarílico procedente de un mono centinela, en las cercanias de Belém, Brasil. Boletín de la Oficina Sanitaria Panamericana, v. 60, p. 187-92, 1966. 
BONALDO, M. C.; GÓMEZ, M. M.; SANTOS, A. A. C.; ABREU, F. V. S.; FERREIRA-DEBRITO, A.; MIRANDA, R. M.; CASTRO, M. G.; LOURENÇO-DE-OLIVEIRA, R. Genome analysis of yellow fever virus of the ongoing outbreak in Brazil reveals polymorphisms. Memórias do Instituto Oswaldo Cruz, v. 112, n. 6, p. 447-451, 2017.

BRASIL. Ministério da Saúde. Fundação Nacional da Saúde. Manual de Vigilância Epidemiológica da Febre Amarela. Brasília: Ministério da Saúde, 1999.

BRASIL. Ministério da Saúde. Secretaria de Vigilância em Saúde. Guia de vigilância epidemiológica. Brasília: Ministério da Saúde, 2005a. p. 307-324.

BRASIL. Ministério da Saúde. Secretaria de Vigilância em Saúde. Manual de vigilância de epizootias em primatas não-humanos. Brasília: Ministério da Saúde, 2005b.

BRASIL. Ministério da Saúde. Biblioteca Virtual de Saúde. Febre Amarela. Profissionais da Saúde. 2008a. Disponível em: <http://bvsms.saude.gov.br/bvs/febreamarela/profissionais. php> Acesso em: 20 jan. 2017.

BRASIL. Ministério da Saúde. Boletim diário do dia 14 de março de 2008. Situação da Febre Amarela Silvestre no Brasil, 2007 e 2008. 2008b.

BRASIL. Ministério da Saúde. Secretaria de Vigilância em Saúde. Departamento de Vigilância Epidemiológica. Coordenação Geral de Doenças Transmissíveis. Áreas com recomendação de vacina contra a febre amarela no Brasil 2008 e 2009. Brasília: Fundação Nacional de Saúde, 2008c.

BRASIL. Ministério da Saúde. Secretaria de Vigilância em Saúde. Febre amarela silvestre, Brasil, 2009: boletim de atualização - dezembro/2009: Emergências em Saúde Pública de Importância Nacional (ESPIN) de febre amarela Silvestre em São Paulo e no Rio Grande do Sul e a situação epidemiológica atual no Brasil (2008/2009). Brasília: Ministério da Saúde, 2009. 
BRASIL. Ministério da Saúde. Secretaria de Vigilância em Saúde. Departamento de Imunização. Regiões de recomendação de vacina contra Febre Amarela 2014. 2014.

BRASIL. Ministério da Saúde. Secretaria de Vigilância em Saúde. Coordenação-Geral de Desenvolvimento da Epidemiologia em Serviços. Guia de Vigilância em Saúde. Brasília: Ministério da Saúde, 2016a. p. 399-416.

BRASIL. Ministério da Saúde. Secretaria de Vigilância em Saúde. Febre Amarela. Situação Epidemiológica/ Dados. 2016b. Disponível em: $<$ http://portalsaude.saude.gov.br/index.php/situacao-epidemiologica-dadosfebreamarela $>$. Acesso em: 10 dez. 2016.

BRASIL. Ministério da Saúde. Secretaria de Vigilância em Saúde. Departamento de Vigilância das Doenças Transmissíveis. Nota Informativa n0 02/2017 - Orientação para profissionais de saúde sobre febre amarela silvestre. Brasília: Ministério da Saúde, 2017a.

BRASIL. Ministério da Saúde. Secretaria de Vigilância em Saúde. Departamento de Vigilância das Doenças Transmissíveis. Febre Amarela: Brasil adota dose única da vacina por recomendação da OMS. 2017b. Disponível em: $<$ http://portalsaude.saude.gov.br/index.php/cidadao/principal/agencia-saude/28003-febreamarela-brasil-adota-dose-unica-da-vacina-por-recomendacao-da-oms $>$. Acesso em: 06 abril. 2017.

BRASIL. Ministério da Saúde. Secretaria de Vigilância em Saúde. Centro de Operações de Emegências em Saúde Pública sobre Febre Amarela (COES). Informe no 43/2017 Monitoramento dos casos e óbitos de Febre Amarela no Brasil. Brasília: Ministério da Saúde, 2017c.

BRASIL. Ministério da Saúde. Secretaria de Vigilância em Saúde. Departamento de Vigilância das Doenças Transmissíveis. Informe n⿳0 01 - 2017/2018 - Monitoramento do Período Sazonal da Febre Amarela, Brasil - 2017/2018. Brasília: Ministério da Saúde, 2017d.

BRASIL. Ministério da Saúde. Secretaria de Vigilância em Saúde. Departamento de Vigilâncias das Doenças Transmissíveis. Guia de Vigilância de Epizootias em Primatas Não 
Humanos e Entomologia Aplicada à Vigilância da Febre Amarela. 2. Ed. Brasília: Ministério da Saúde, 2017e.

BRASIL. Ministério da Saúde. Secretaria de Vigilância em Saúde. Departamento de Vigilância das Doenças Transmissíveis. Informe n⿳0 01 - 2018/2019 - Monitoramento do Período Sazonal da Febre Amarela, Brasil - 2018/2019. Brasília: Ministério da Saúde, 2018a.

BRASIL. Ministério da Saúde. Secretaria de Vigilância em Saúde. Departamento de Vigilância das Doenças Transmissíveis. Informe n⿳0 02 - 2018/2019 - Monitoramento do Período Sazonal da Febre Amarela, Brasil - 2018/2019 Brasília: Ministério da Saúde, 2018b.

BRASIL. Ministério da Saúde. Secretaria de Vigilância em Saúde. Coordenação-Geral de Desenvolvimento da Epidemiologia em Serviços. Guia de Vigilância em Saúde. 3. Ed. Brasília: Ministério da Saúde, 2019a. p. 363-388.

BRASIL. Ministério da Saúde. Secretaria de Vigilância em Saúde. Departamento de Vigilância das Doenças Transmissíveis. Informe $\mathbf{n}^{\mathbf{0}} 10$ - 2018/2019 - Monitoramento do Período Sazonal da Febre Amarela, Brasil - 2018/2019. Brasília: Ministério da Saúde, 2019b.

BRASIL. Ministério da Saúde. Secretaria de Vigilância em Saúde. Departamento de Vigilância das Doenças Transmissíveis. Informe n⿳ 18 - 2019 - Monitoramento de Febre Amarela, Brasil - 2019. Brasília: Ministério da Saúde, 2019c.

CEPAGRI. Centro de Pesquisas Meteorológicas e Climáticas Aplicadas a Agricultura UNICAMP. Campinas, 2017. Disponível em: <http://www.cpa.unicamp.br/outrasinformacoes/clima_muni_490.html>. Acesso em: 18 jun. 2017.

CHAMBERS, T. J.; HAHN, C. S.; GALLER, R.; RICE, C. M. Flavivirus genome organization, expression, and replication. Annual Review of Microbiology, v. 44, p. 649-688, 1990.

COIMBRA, T. L.; SOUZA, R. P.; MORENO, E. S. Febre Amarela: Epizootias e casos humanos no Estado de São Paulo, 2008. Anais da $21^{\circ}$ Reunião Anual do Instituto Biológico. São Paulo: INSTITUTO BIOLÓGICO, 2008. p. 3-6. 
CONSOLI, R. A. G. B; LOURENÇO-DE-OLIVEIRA, R. Principais mosquitos de importância sanitária no Brasil. Rio de Janeiro: Fiocruz, 1998.

COSTA, Z. G. A.; OLIVEIRA, R. C.; TUBOI, S. H.; SILVA, M. M.; VASCONCELOS, P. F. C. Redefinição das áreas de risco para febre amarela silvestre no Brasil. Revista da Sociedade Brasileira de Medicina Tropical, n. 35, supl. I, p. 84, 2002.

COUTO-LIMA, D.; MADEC, Y.; BERSOT, M. I.; CAMPOS, S. S.; MOTTA, M. A.; SANTOS, F. B.; VAZEILLE, M.; VASCONCELOS, P. F. C.; LOURENÇO-DE-OLIVEIRA, R.; FAILLOUX, A. B. Potential risk of re-emergence of urban transmission of Yellow Fever virus in Brazil facilitated by competente Aedes populations. Scientific Reports, v. 7, e4848, 2017.

CUNHA, M. S.; COSTA, A. C.; FERNANDES, N. C. C. A.; GUERRA, J. M.; SANTOS, F. C. P.; NOGUEIRA, J. S.; D’AGOSTINO, L. G.; KOMNINAKIS, S. V.; WITKIN, S. S.; RESSIO, R. A.; MAEDA, A. Y.; VASAMI, F. G. S.; KAIGAWA, U. M. A.; AZEVEDO, L. S.; FACIOLI, P. A. S.; MACEDO, F. L. L.; SABINO, E. C.; LEAL, E.; SOUZA, R. P. Epizootics due to Yellow Fever Virus in São Paulo State, Brazil: viral dissemination to new áreas (20162017). Scientific Reports, v. 9, e5474, 2019.

DAVIS, N. C.; SHANNON, R. C. Studies on South American yellow fever. III. Transmission of the virus to Brazilian monkeys. Preliminary observations. The Journal of Experimental Medicine, v. 50, p. 81-85, 1929.

DAVIS, N. C. Susceptibility of Capuchin (Cebus) monkeys to yellow fever virus. American Journal of Epidemiology, v. 11, p. 321-334, 1930.

FABRO, A. T.; ENGELMAN, G. G.; FERREIRA, N. N.; VELLONI, J. M. F.; ESPÓSITO, D. L. A.; FONSECA, B. A. L.; BRUNALDI, M. O. Yellow Fever-Induced Acute Lung Injury. American Journal of Respiratory and Critical Care Medicine, v. 200, n. 2, p. 250-252, 2019.

FIALHO, M. S.; PRINTES, R. C.; ALMEIDA, M. A. B.; LAROQUE, P. O.; SANTOS, E.; JERUSALINSKY, L. Avaliação do impacto da epizootia de Febre Amarela sobre as populações 
de primatas não humanos nas unidades de conservação do Rio Grande do Sul, Brasil. Biotemas, v. 25 , p. 217-225, 2012.

FIORAVANTI, C. The monkey alarm. Pesquisa FAPESP, v. 263, p. 1-9, 2018.

GOOGLE EARTH. Google, 2019. Disponível em: <https://www.google.com.br/intl/ptPT/earth/>. Acesso em: 28 ago.. 2019.

HANLEY, K. A.; MONATH, T. P.; WEAVER, S. C.; ROSSI, S. L.; RICHMAN, R. L.; VASILAKIS, N. Fever versus fever: the role of host and vector susceptibility and interspecific competition in shaping the current and future distribution of the sylvatic cycles of dengue vírus and yellow fever virus. Infection, Genetics and Evolution, v. 19, p. 292-311, 2013.

HOLZMANN, I. I.; AGOSTINI, J.; ARETA, H.; FERREYRA, P.; BELDOMENICO, M.; DI BITETTI. Impact of Yellow Fever Outbreaks on Two Howler Monkey Species (Alouatta guariba clamitans and A. caraya) in Misiones, Argentina. American Journal of Primatology, v. 72, p. 475-480, 2010.

KATO, F.; ISHIDA, Y.; KAWAGISHI, T.; KOBAYASHI, T.; HISHIKI, T.; MIURA, T.; IGARASHI, T. Natural infection of cynomolgus monkeys with dengue virus occurs in epidemic cycles in the Philippines. Journal of General Virology, v. 94, p. 2202-2207, 2013.

KAY, A.; CHEN, L. H.; SISTI, M.; MONATH, T. P. Short report: yellow fever vaccine seroconversion in travelers. American Journal of Tropical Medicine and Hygiene, v. 85, n. 4, p. 748-749, 2011.

KINDLOVITS, L. M; KINDLOVITS, A. Febre amarela: clínica e terapêutica em primatas tropicais. 2. ed. Rio de Janeiro: L. F. Livros, 2009. p. 190-191.

KIM, J.H.; JIN, H. O.; PARK, J. A.; CHANG, Y. H.; HONG, Y. J.; LEE, J. K. Comparison of three different kits for extraction of high-quality RNA from frozen blood. SpringerPlus, v. 3, p. 76, 2014. 
KUNO, G. Serodiagnosis of flaviviral infections and vaccinations in humans. In: CHAMBER, T. J.; MONATH, T. P. (Eds.), Advances in Virus Research, v. 61. Elsevier, California, USA, 2003. p. 3-65.

LAEMMERT, H. W. Susceptibility of marmosets to different strains of yellow fever virus. American Journal of Tropical Medicine, v. 24, p. 7181, 1944.

LAMBRECHTS, L.; SCOTT, T. W.; GUBLER, D. J. Consequences of the Expanding Global Distribution of Aedes albopictus for Dengue Virus Transmission. PLoS Neglected Tropical Diseases, v. 4, n. 5, e646, 2010.

LANG, J.; ZUCKERMAN, J.; CLARKE, P.; BARRETT, P.; KIRKPATRICK, C.; BLONDEAU, C. Comparison of the immunogenicity and safety of two 17D yellow fever vaccines. American Journal of Tropical Medicine and Hygiene, v. 60, n. 6, p. 1045-1050, 1999.

LAROQUE, P. O.; VALENÇA-MONTENEGRO, M. M.; FERREIRA, D. R.; CHIANG, J. O.; CORDEIRO, M. T.; VASCONCElOS, P. F. C.; SILVA, J. C. Epidemiologic survey for arbovirus in galician capuchin monkeys (Cebus flavius) free living in Paraíba and captive capuchin monkey ((2014).) from northeast Brazil. Pesquisa Veterinária Brasileira, v. 34, p. $462-468,2014$.

LIMA, M. A.; ROMANO-LIEBER, N. S.; DUARTE, A. M. R. C. Circulation of antibodies against yellow fever virus in a simian population in the area of Porto Primavera Hydroelectric Plant, São Paulo, Brazil. Revista do Instituto de Medicina Tropical de São Paulo, São Paulo, v. 52, n. 1, 2010.

MACHADO, V. W.; VASCONCElOS, P. F.; SILVA, E. V. P.; SANTOS, J. B. Serologic assessment of yellow fever immunity in the rural population of a yellow fever-endemic area in Central Brazil. Revista da Sociedade Brasileira de Medicina Tropical, v. 46, n. 2, p. 166$171,2013$.

MAEDA, A.; MAEDA, J. Review of diagnostic plaque reduction neutralization tests for flavivirus infection. The Veterinary Journal, v. 195, p. 33-40, 2013. 
MARKOFF L. Yellow fever outbreak in Sudan. The New England Journal of Medicine, v. 368, p.689-69, 2013.

MASCHERETTI, M.; TENGAN, C. H.; SATO, H. K.; SUZUKI, A.; SOUZA, R. P.; MAEDA, M.; BRASIL, R.; PEREIRA, M.; TUBAKI, R. M.; WANDERLEY, D. M. V.; FORTALEZA, C. M. C. B.; RIBEIRO, A. F. Febre amarela silvestre: reemergência de transmissão no estado de São Paulo, Brasil, 2009. Revista de Saúde Pública, v. 47, n. 5, p. 881-889, 2013. Disponível em: <http://dx.doi.org/10.1590/S00348910.2013047004341>.

MASON, R. A.; TAURASO, N. M.; SPERTZEL, R. O.; GINN, R. K. Yellow fever vaccine: direct challenge of monkeys given graded doses of 17D vaccine. Journal of Applied Microbiology, v. 23, n. 5, p. 908-913, 1973.

MEDEIROS, A. S.; COSTA, D. M. P.; BRANCO, M. S. D.; SOUSA, D. M. C.; MONTEIRO, J. D.; GALVÃO, S. P. M.; AZEVEDO, P. R. M.; FERNANDES. J. V.; JERONIMO, S. M. B.; ARAÚJO, J. M. G. Dengue virus in Aedes aegypti and Aedes albopictus in urban areas in the state of Rio Grande do Norte, Brazil: Importance of virological and entomological surveillance. PLoS ONE, v. 13, n. 3, e0194108, 2018.

MELO, A. B.; SILVA, M. P. C.; MAGALHÃES, M. C. F.; GIL, L. H. V. G.; CARVALHO, E. M. F.; BRAGA-NETO, U. M.; BERTANI, G. R.; MARQUES-JUNIOR, E. T. A.; CORDEIRO, M. T. Description of a prospective 17DD yellow fever vaccine cohort in Recife, Brazil. American Journal of Tropical Medicine and Hygiene, v. 85, n. 4, 739-747, 2011.

MONATH, T. P.; BRINKER, K. R.; CHANDLER, F. W.; KEMP, G. E.; CROPP, C. B. Pathophysiologic correlations in a rhesus monkey model of yellow fever: with special observations on the acute necrosis of B cell areas of lymphoid tissues. American Journal of Tropical Medicine and Hygiene, v. 30, p. 431-443, 1981.

MONATH, T. P. Yellow fever: an update. Lancet Infect Diseases, v. 1, n. 1, p. 11-20, 2001. 
MONATH, T. P.; FOWLER, E.; JOHNSON, C. T.; BALSER, J.; MORIN, M. J.; SISTI, M.; TRENT, D. W. An inactivated cell culture vaccine against yellow fever. The New England Journal of Medicine, v. 364, p. 1326-1333, 2011.

MONATH, T. P.; VASCONCELOS, P. F. C. Yellow fever. Journal of Clinical Virology, v. 64, p. 160-173, 2015. Disponível em: <http://dx.doi.org/10.1016/j.jcv.2014.08.030>.

MORALES, M. A.; FABBRI, C. M.; ZUNINO, G. E.; KOWALEWSKI, M. M.; LUPPO, V. C.; ENRÍA, D. A.; LEVIS, S. C.; CALDERÓN, G. E. Detection of the mosquito-borne flaviviruses, West Nile, Dengue, Saint Louis Encephalitis, Ilheus, Bussuquara, and Yellow Fever in free-ranging black howlers (Alouatta caraya) of Northeastern Argentina. PLoS Neglected Tropical Diseases, v. 11, n. 2, p. e0005351, 2017.

MOREIRA-SOTO, A.; CARNEIRO, I. O.; FISCHER, C.; FELDMANN, M.; KÜMMERER, B. M.; SILVA, N. S.; SANTOS, U. G.; SOUZA, B. F. C. D.; LIBORIO, F. A.; VALENÇAMONTENEGRO, M. M.; LAROQUE, P. O.; FONTOURA, F. R.; OLIVEIRA, A. V. D.; DROSTEN, C.; LAMBALLERIE, X.; FRANKE, C. R.; DREXLER, J. F. Limited Evidence for Infection of Urban and Peri-urban Nonhuman Primates with Zika and Chikungunya Viruses in Brazil. mSphere (American Society for Microbiology), v. 3, n. 1, e00523-17, 2018.

MORENO, E. S.; ROCCO, I. M.; BERGO, E. S.; BRASIL, R. A.; SICILIANO, M. M.; SUZUKI, A.; SILVEIRA, V. R.; BISORDI, I.; SOUZA, R. P.; YELLOW FEVER WORKING GROUP. Reemergence of yellow fever: detection of transmission in the State of São Paulo, Brazil, 2008. Revista da Sociedade Brasileira de Medicina Tropical, v. 44, n. 3, p. 290-296, 2011.

MORENO, E. S.; SPINOLA, R.; TENGAN, C. H.; BRASIL, R. A.; SICILIANO, M. M.; COIMBRA, T. L. M.; SILVEIRA, V. R.; ROCCO, I. M.; BISORDI, I.; SOUZA, R. P.; PETRELLA, S.; PEREIRA, L. E.; MAEDA, A. Y.; SILVA, F. G.; SUZUKI, A. Yellow fever epizootics in non-human primates, São Paulo State, Brazil, 2008-2009. Revista do Instituto de Medicina Tropical de São Paulo, v. 55, n. 1, p. 45-50, 2013.

NIEDRIG, M.; LADEMANN, M.; EMMERICH, P.; LAFRENZ, M. Assessment of IgG antibodies against yellow fever virus after vaccination with 17D by different assays: 
neutralization test, haemagglutination inhibition test, immunofluorescence assay and ELISA. Tropical Medicine \& International Health, v. 4, p. 867-871, 1999.

NIEDRIG, M.; KÜRSTEINER, O.; HERZOG, C.; SONNENBERG, K. Evaluation of an Indirect Immunofluorescence Assay for Detection of Immunoglobulin $\mathrm{M}(\mathrm{IgM})$ and $\operatorname{IgG}$ Antibodies against Yellow Fever Virus. Clinical and Vaccine Immunology, v. 15, n. 2, p. $177-181,2008$.

NORRIS, D. E. Mosquito-borne diseases as a consequence of land use change. EcoHealth, v.1, n.1, p. 19-24, 2004. Disponível em: <http://dx.doi.org/10.1007/s10393-004-0008-7>

OIE. World Organization for animal health. One Health. 2017. Disponível em: $<$ http://www.oie.int/en/for-the-media/onehealth/>. Acesso em: 23 jan. 2017.

OLIVEIRA-FILHO, E. F.; OLIVEIRA, R. A. S.; FERREIRA, D. R. A.; LAROQUE, P. O.; PENA, L. J.; VALENÇA-MONTENEGRO, M. M.; MOTA, R. A.; GIL, L. H. V. G. Seroprevalence of selected flaviviruses in free-living and captive capuchin monkeys in the state of Pernambuco, Brazil. Transboundary and Emerging Diseases, p. 1-4, 2018.

OTT-JOSLIN, J. E. Viral diseases in nonhuman primates. In: Fowler M. Zoo and wild animal medicine. Philadelphia: W.B. Saunders, 1986. p. 674-97.

PAHO. Organización Panamericana de la Salud. Alerta Epidemiológica Fiebre amarilla - 9 de enero de 2017. 2017.

PESSOA, F. Odes de Ricardo Reis. Fernando Pessoa. (Notas de João Gaspar Simões e Luiz de Montalvor.) Lisboa: Ática, 1946 (imp.1994), p. 148. Disponível em: $<$ http://arquivopessoa.net/textos/503>. Acesso em: 20 ago. 2019.

PINHEIRO, F. P.; TRAVASSOS DA ROSA, A. P. A.; MORAES, M. A.; ALMEIDA NETO, J. C.; CAMARGO, S.; FILGUEIRAS, F. P. An epidemic of yellow fever in Central Brazil, 1972-1973. I. Epidemiological studies. The American Journal of Tropical Medicine and Hygiene, v. 27, n.1, pt. 1, p. 125-132, 1978. 
PIERSON, T. C.; DIAMOND, M. S. Flavivirus. In: FIELDS, B. N.; KNIPE, D. M.; HOWLEY, P. M. FIELDS Virology. 6 (Ed). Philadelphia: LIPPINCOTT WILLIAMS \& WILKINS, 2013, cap. 26

POSSAS, C.; LOURENÇO-DE-OLIVEIRA, R.; TAUIL, P. L.; PINHEIRO, F. P.; PISSINATTI, A.; CUNHA, R. V.; FREIRE, M.; MARTINS, R. M.; HOMMA, A. Yellow fever outbreak in Brazil: the puzzle of rapid viral spread and challenges for immunisation. Memórias do Instituto Oswaldo Cruz, v. 113, n. 10, e180278, 2018.

REIS, N. R.; PERACCHI, A. L.; BATISTA, C. B.; ROSA, G. L. M. Primatas do Brasil Guia de Campo. 1 (Ed). Rio de Janeiro: Technical Books Editora, 2015.

RIBEIRO, M.; ANTUNES, C. M. F. Febre amarela: estudo de um surto. Revista da Sociedade Brasileira de Medicina Tropical, v. 42, n. 5, p. 523-531, 2009.

RICE, C. M.; LENCHES, E. M.; EDDY, S. R.; SHIN, S. H.; STRAUSS, J. H. Nucleotide sequence of yellow fever virus: implications for flavivirus gene expression and evolution. Science, v. 229, p. 726-733, 1985.

ROEHRIG, J. T.; HOMBACH, J.; BARRETT, A. D. T.; Guidelines for plaque-reduction neutralization testing of human antibodies to dengue viruses. Viral Immunology, v. 21, n. 2, p. 123-132, 2008.

RUSSELL, P. K.; NISALAK, A.; SUKHAVACHANA, P.; VIVONA, S. A plaque reduction test for dengue virus neutralizing antibodies. The Journal of Immunology, v. 99, p. 285-290, 1967.

SAAD, L. C.; BARATA, R. B. Surtos de febre amarela no estado de São Paulo, 2000-2010. Epidemiologia e Serviços de Saúde, Brasília, v. 25, n. 3, p. 531-540, 2016.

SÃO PAULO (Estado). Secretaria de Estado de Saúde. Centro de Vigilância Epidemiológica Professor Alexandre Vranjac. Coordenadoria de Controle de Doenças. Divisão de Zoonoses. Casos de febre amarela silvestre em residentes do Estado de São Paulo, 2007-2008 BEPA. São Paulo, 2008. v. 5, n. 55, 12 p. 
SÃO PAULO (Estado). Secretaria de Estado de Saúde. Centro de Vigilância Epidemiológica Professor Alexandre Vranjac. Coordenadoria de Controle de Doenças. Divisão de Zoonoses. Febre Amarela Silvestre no Estado de São Paulo, 2009 - BEPA. São Paulo, 2009. v. 6, n. 63.

SÃO PAULO (Estado). Secretaria de Estado de Saúde. Centro de Vigilância Epidemiológica Professor Alexandre Vranjac. Coordenadoria de Controle de Doenças. Divisão de Zoonoses. Nota sobre Febre Amarela - SP intensifica prevenção contra a febre amarela. São Paulo, 2016. Disponível em: <http://www.saude.sp.gov.br/cve-centro-de-vigilancia-epidemiologicaprof.-alexandre-vranjac/areas-de-vigilancia/doencas-de-transmissao-por-vetores-e-zoonoses/ agravos/febre-amarela/nota-sobre-febre-amarela> Acesso em: 20 jan. 2017

SÃO PAULO (Estado). Secretaria de Estado de Saúde. Centro de Vigilância Epidemiológica Professor Alexandre Vranjac. Coordenadoria de Controle de Doenças. RECOMENDAÇÕES PARA VACINAÇÃO DE FEBRE AMARELA. São Paulo, 2016b. Disponível em: $<$ http://www.saude.sp.gov.br/resources/cve-centro-de-vigilancia-epidemiologica/areas-devigilancia/doencas-de-transmissao-por-vetores-e-zoonoses/doc/famarela/famarela16_ recomendacoes_vacinacao.pdf $>$ Acesso em: 03 fev. 2017

SÃO PAULO (Estado). Secretaria de Estado de Saúde. Centro de Vigilância Epidemiológica Professor Alexandre Vranjac. Coordenadoria de Controle de Doenças. Divisão de Zoonoses. BOLETIM EPIDEMIOLÓGICO FEBRE AMARELA, 2017 - 20/10/2017. São Paulo, 2017. Disponível em: < http://www.saude.sp.gov.br/resources/cve-centro-de-vigilanciaepidemiologica/areas-de-vigilancia/doencas-de-transmissao-por-vetores-ezoonoses/doc/famarela/fa17_201017boletim_epidemiologico.pdf> Acesso em: 01 set. 2019

SÃO PAULO (Estado). Secretaria de Estado de Saúde. Centro de Vigilância Epidemiológica Professor Alexandre Vranjac. Coordenadoria de Controle de Doenças. Divisão de Zoonoses. BOLETIM EPIDEMIOLÓGICO FEBRE AMARELA, 2019 - 27/08/2019. São Paulo, 2019. Disponível em: <http://www.saude.sp.gov.br/resources/cve-centro-de-vigilanciaepidemiologica/areas-de-vigilancia/doencas-de-transmissao-por-vetores-ezoonoses/doc/famarela/2019/fa19_boletim_epid_2708.pdf> Acesso em: 01 set. 2019 
SICONELLI, M. J. L.; ESPOSITO, D. L. A.; MORAIS, N. C.; RIBEIRO, J. M.; PERLES, L.; DiAS, M. A.; CARVAlho, A. A. B.; Werther, K.; FERNANDES, N. C. C. A.; IGLEZIAS, S. D.; BÜRGER, K. P.; FONSECA, B. A. L. The Importance of Coordinated Actions in Preventing the Spread of Yellow Fever to Human Populations: The Experience from the 2016-2017 Yellow Fever Outbreak in the Northeastern Region of São Paulo State. Canadian Journal of Infectious Diseases and Medical Microbiology, v. 2019, Article ID 9464768, 2019. Disponível em: < https://doi.org/10.1155/2019/9464768>

SOUZA, R. P.; PETRElla, S.; COIMBRA, T. L. M.; MAEDA, A. Y.; ROCCO, I. M.; BISORDI, I.; SILVEIRA, V. R.; PEREIRA, L. E.; SUZUKI, A.; SILVA, S. J. S.; SILVA, F. G.; SALVADOR, F. S.; TUBAKI, R. M.; MENEZES, R. T.; PEREIRA, M.; BERGO, E. S.; HOFFMANN, R. C.; SPINOLA, R. M. F.; TENGAN, C. H.; SICILIANO, M. M. Isolation of yellow fever virus (YFV) from naturally infectied Haemagogus (Conopostegus) leucocelaenus (DIPTERA, CULICIDAE) in São Paulo State, Brazil, 2009. Revista do Instituto de Medicina Tropical de São Paulo, v. 53, p. 133-139, 2011.

SOUZA, R. P. Filogeografia da Febre Amarela na América do Sul, 2013. 136 f. Tese (Doutorado em Ciências) - Faculdade de Saúde Pública, Universidade de São Paulo, São Paulo, 2013.

STAPLES, J. E.; MONATH, T. P.; GERSHMAN, M. D.; BARRETT, A. D. T. Yellow Fever Vaccines. In: PlOTKIN, S. A; ORENSTEIN, W. A.; OFFIT, P. A.; EDWARDS, K. M. Plotkin's VACCINES. 7 (Ed). Philadelphia: ELSEVIER, 2018, cap. 63.

STETTLER, K.; BELTRAMELLO, M.; ESPINOSA, D. A.; GRAHAM, V.; CASSOTTA, A.; BIANCHI, S.; VANZETTA, F.; MINOLA, A.; JACONI, S.; MELE, F.; FOGLIERINI, M.; PEDOTTI, M.; SIMONElli, L.; DOWALl, S.; ATKINSON, B.; PERCIVALlE, E.; SIMMONS, C. P.; VARANI, L.; BLUM, J.; BALDANTI, F.; CAMERONI, E.; HEWSON, R.; HARRIS, E.; LANZAVECCHIA, A.; SALLUSTO, F.; CORTI, D. Specificity, cross-reactivity, and function of antibodies elicited by Zika virus infection. Science, v. 353, p. 823- 826, 2016.

STRODE, G. K. Yellow Fever. New York: McGraw-Hill Book Company, 1951. 
THRALL, M. A.; WEISER, G.; ALLISON, R. W.; CAMPBELL, T. W. Hematologia e Bioquímica Clínica Veterinária. 2 (Ed). São Paulo: Roca, 2015.

TIGERTT, W. D.; BERGE, T. O.; GOCHENOUR, W. S.; GLEISER, C. A.; EVELAND, W. C.; BRUEGGE, C. V.; SMETANA, H. F. Experimental yellow fever. Transactions of the New York Academy of Science, v. 22, p. 323-333, 1960.

VASCONCELOS, P. F. C.; COSTA, Z. G.; TRAVASSOS DA ROSA, E. S.; LUNA, E.; RODRIGUES, S. G.; BARROS, V. L. R. S.; DIAS, J. P.; MONTEIRO, H. A. O.; OLIVA, O. F. P.; VASCONCELOS, H. B.; OLIVEIRA, R. C.; SOUSA, M. R. S.; BARBOSA DA SILVA, J.; CRUZ, A. C. R.; MARTINS, E. C.; TRAVASSOS DA ROSA, J. F. S. An epidemic of jungle Yellow fever in Brazil, 2000. Implications of climatic alterations in disease spread. Journal of Medical Virology, v. 65, p. 598-604, 2001. Disponível em: $<$ http://dx.doi.org/10.3201/eid0703.010338>.

VASCONCELOS, P. F. C. Febre amarela: reflexões sobre a doença, as perspectivas para o século XXI e o risco da reurbanização. Revista Brasileira de Epidemiologia, v. 5, p. 244-258, 2002. Disponível em: <http://dx.doi.org/10.1590/S1415-790X2002000300004>.

VASCONCELOS, P. F. C. Febre Amarela. Revista da Sociedade Brasileira de Medicina Tropical, v. 36, n. 2, p. 275-293, 2003.

VASCONCELOS, P. F. C. Yellow Fever in Brazil: thoughts and hypotheses on the emergence in previously free areas. Revista de Saúde Pública, v. 44, n. 6, p. 1144-1149, 2010.

VERONA, C. E.; PISSINATTI, A. Primates - Primatas do Novo Mundo (Sagui, Macaco-prego, Macaco-aranha, Bugio e Muriqui). In: CUBAS, Z. S.; SILVA, J. C. R.; CATÃO-DIAS, J. L. Tratado de animais selvagens. 2 (Ed). São Paulo: Roca, 2014. v.1, cap. 34.

ZANOTTO, P. M.; GAO, G. F.; GRITSUN, T.; MARIN, M. S.; JIANG, W. R.; VENUGOPAL, K.; REID, H. W.; GOULD, E. A. An arbovirus cline across the northern hemisphere. Virology, v. 210, p. 152-159, 1995. 
WORLD HEALTH ORGANIZATION. Guidelines for plaque reduction neutralization testing of human antibodies to dengue viruses. Immunization, Vaccines and Biologicals. Geneva, 2007.

WORLD HEALTH ORGANIZATION. Recommendations to Assure the Quality, Safety and Efficacy of Live Attenuated Yellow Fever Vaccines. Report. Geneva, 2010. (WHO technical report series). 
APÊNDICES 
APÊNDICE A - Tabela de informações gerais sobre os primatas não humanos capturados entre abril e dezembro de 2018 , no Município de Ribeirão Preto.

\begin{tabular}{|c|c|c|c|c|c|c|c|c|c|c|}
\hline \multirow{2}{*}{ Amostra } & \multirow{2}{*}{$\mathrm{n}^{0}$ de ID do chip } & \multirow{2}{*}{ Espécie } & \multirow{2}{*}{$\begin{array}{l}\text { Data da } \\
\text { colheita }\end{array}$} & \multirow{2}{*}{ Sexo } & \multirow{2}{*}{ Idade } & \multirow{2}{*}{ Peso (g) } & \multirow{2}{*}{ Local } & \multirow{2}{*}{ Endereço } & \multicolumn{2}{|c|}{ Coordenadas } \\
\hline & & & & & & & & & Sul & Oeste \\
\hline $\mathrm{P} 1 \mathrm{Sa} 0418$ & 934000011110833 & Callithrix penicillata & $15 / 04 / 2018$ & $\mathrm{M}$ & A & 430 & DRS/GVE - Ribeirão Preto & Avenida Independência, 4770 - João Rossi & $21^{\circ} 12^{\prime} 44.00^{\prime \prime}$ & $47^{\circ} 49^{\prime} 42.62^{\prime \prime}$ \\
\hline $\mathrm{P} 2 \mathrm{Sa} 0618$ & 963008000941200 & Callithrix penicillata & $11 / 06 / 2018$ & $\mathrm{M}$ & A & 375 & DRS/GVE - Ribeirão Preto & Avenida Independência, 4770 - João Rossi & $21^{\circ} 12^{\prime} 42.85^{\prime \prime}$ & $47^{\circ} 49^{\prime} 38.51^{\prime \prime}$ \\
\hline P3Sa0618 & 963008000939627 & Callithrix penicillata & $11 / 06 / 2018$ & $\mathrm{~F}$ & $\mathrm{~F}$ & 175 & DRS/GVE - Ribeirão Preto & Avenida Independência, 4770 - João Rossi & $21^{\circ} 12^{\prime} 43.32^{\prime \prime}$ & $47^{\circ} 49^{\prime} 42.55^{\prime \prime}$ \\
\hline $\mathrm{P} 4 \mathrm{Sa} 0618$ & 963008000942042 & Callithrix penicillata & $18 / 06 / 2018$ & $\mathrm{~F}$ & A & 375 & Quinta da Boa Vista "B" & Rod. Pref. Antônio Duarte Nogueira, Km 318 & $21^{\circ} 12^{\prime} 38.68^{\prime \prime}$ & $47^{\circ} 50^{\prime} 41.94 "$ \\
\hline P5Sa0618 & 963008000939652 & Callithrix penicillata & $18 / 06 / 2018$ & $\mathrm{~F}$ & $\mathrm{~F}$ & 140 & Quinta da Boa Vista "B" & Rod. Pref. Antônio Duarte Nogueira, Km 318 & $21^{\circ} 12^{\prime} 38.70^{\prime \prime}$ & $47^{\circ} 50^{\prime} 41.96^{\prime \prime}$ \\
\hline P6Sa0618 & 963008000941330 & Callithrix penicillata & $19 / 06 / 2018$ & $\mathrm{~F}$ & A & 425 & Quinta da Boa Vista "B" & Rod. Pref. Antônio Duarte Nogueira, Km 318 & $21^{\circ} 12^{\prime} 38.76^{\prime \prime}$ & $47^{\circ} 50^{\prime} 41.92^{\prime \prime}$ \\
\hline $\mathrm{P} 7 \mathrm{Sa} 0618$ & 963008000939611 & Callithrix penicillata & $19 / 06 / 2018$ & $\mathrm{M}$ & $\mathrm{J}$ & 325 & Quinta da Boa Vista "B" & Rod. Pref. Antônio Duarte Nogueira, Km 318 & $21^{\circ} 12^{\prime} 38.75^{\prime \prime}$ & $47^{\circ} 50^{\prime} 41.87^{\prime \prime}$ \\
\hline P8Sa0618 & 963008000941426 & Callithrix penicillata & $20 / 06 / 2018$ & $\mathrm{~F}$ & $\mathrm{~S}$ & 375 & Quinta da Boa Vista "B" & Rod. Pref. Antônio Duarte Nogueira, Km 318 & $21^{\circ} 12^{\prime 2} 28.15^{\prime \prime}$ & $47^{\circ} 50^{\prime} 58.36^{\prime \prime}$ \\
\hline P9Sa0618 & 963008000941186 & Callithrix penicillata & $25 / 06 / 2018$ & $\mathrm{M}$ & A & 515 & Quinta da Boa Vista "B" & Rod. Pref. Antônio Duarte Nogueira, Km 318 & $21^{\circ} 12^{\prime} 31.91^{\prime \prime}$ & $47^{\circ} 50^{\prime} 33.77^{\prime \prime}$ \\
\hline P11Sa0618 & 963008000941681 & Callithrix penicillata & $25 / 06 / 2018$ & $\mathrm{~F}$ & $\mathrm{~F}$ & 160 & Quinta da Boa Vista "B" & Rod. Pref. Antônio Duarte Nogueira, Km 318 & $21^{\circ} 12^{\prime} 31.91^{\prime \prime}$ & $47^{\circ} 50^{\prime} 33.77^{\prime \prime}$ \\
\hline $\mathrm{P} 12 \mathrm{Sa} 0618$ & 963008000939633 & Callithrix penicillata & $27 / 06 / 2018$ & $\mathrm{~F}$ & $\mathrm{~F}$ & 205 & Quinta da Boa Vista "B" & Rod. Pref. Antônio Duarte Nogueira, Km 318 & $21^{\circ} 12^{\prime} 28.19^{\prime \prime}$ & $47^{\circ} 50^{\prime} 58.36^{\prime \prime}$ \\
\hline $\mathrm{P} 13 \mathrm{Sa} 0618$ & 963008000941780 & Callithrix penicillata & $27 / 06 / 2018$ & $\mathrm{~F}$ & A & 470 & Quinta da Boa Vista "B" & Rod. Pref. Antônio Duarte Nogueira, Km 318 & $21^{\circ} 12^{\prime} 30.00^{\prime \prime}$ & $47^{\circ} 50^{\prime} 57.06^{\prime \prime}$ \\
\hline $\mathrm{P} 14 \mathrm{Sa} 0718$ & 963008000941307 & Callithrix penicillata & $03 / 07 / 2018$ & $\mathrm{~F}$ & A & 359 & Quinta da Boa Vista "B" & Rod. Pref. Antônio Duarte Nogueira, Km 318 & $21^{\circ} 12^{\prime} 39.12^{\prime \prime}$ & $47^{\circ} 50^{\prime} 26.27^{\prime \prime}$ \\
\hline $\mathrm{P} 15 \mathrm{Sa} 0718$ & 963008000939246 & Callithrix penicillata & $03 / 07 / 2018$ & $\mathrm{M}$ & A & 340 & Quinta da Boa Vista "B" & Rod. Pref. Antônio Duarte Nogueira, Km 318 & $21^{\circ} 12^{\prime} 38.73^{\prime \prime}$ & $47^{\circ} 50^{\prime} 26.70^{\prime \prime}$ \\
\hline $\mathrm{P} 16 \mathrm{Sa} 0718$ & 963008000938858 & Callithrix penicillata & $26 / 07 / 2018$ & $\mathrm{~F}$ & A & 501 & Hospital "Santa Tereza" & Av. Adelmo Perdizza, 495 - Alto da Boa Vista & $21^{\circ} 12^{\prime} 24.38^{\prime \prime}$ & $47^{\circ} 49^{\prime} 42.10^{\prime \prime}$ \\
\hline $\mathrm{P} 17 \mathrm{Sa} 0718$ & 963008000938877 & Callithrix penicillata & $26 / 07 / 2018$ & $\mathrm{M}$ & A & 295 & Hospital "Santa Tereza" & Av. Adelmo Perdizza, 495 - Alto da Boa Vista & $21^{\circ} 12^{\prime} 34.46^{\prime \prime}$ & $47^{\circ} 49^{\prime} 48.28^{\prime \prime}$ \\
\hline $\mathrm{P} 18 \mathrm{Sa} 0718$ & 963008000939234 & Callithrix penicillata & $27 / 07 / 2018$ & $\mathrm{~F}$ & $\mathrm{~S}$ & 367 & Hospital "Santa Tereza" & Av. Adelmo Perdizza, 495 - Alto da Boa Vista & $21^{\circ} 12^{\prime} 29.27^{\prime \prime}$ & $47^{\circ} 49^{\prime} 42.43^{\prime \prime}$ \\
\hline P19Sa0718 & 963008000939428 & Callithrix penicillata & $28 / 07 / 2018$ & $\mathrm{M}$ & A & 450 & Hospital "Santa Tereza" & Av. Adelmo Perdizza, 495 - Alto da Boa Vista & $21^{\circ} 12^{\prime 2} 29.31^{\prime \prime}$ & $47^{\circ} 49^{\prime} 42.43^{\prime \prime}$ \\
\hline $\mathrm{P} 22 \mathrm{Sa} 0718$ & 963008000941219 & Callithrix penicillata & $29 / 07 / 2018$ & $\mathrm{~F}$ & A & 350 & Hospital "Santa Tereza" & Av. Adelmo Perdizza, 495 - Alto da Boa Vista & $21^{\circ} 12^{\prime} 34.98^{\prime \prime}$ & $47^{\circ} 49^{\prime} 47.67^{\prime \prime}$ \\
\hline $\mathrm{P} 23 \mathrm{Sa} 0718$ & 963008000941443 & Callithrix penicillata & 29/07/2018 & $\mathrm{M}$ & A & 347 & Hospital "Santa Tereza" & Av. Adelmo Perdizza, 495 - Alto da Boa Vista & $21^{\circ} 12^{\prime} 34.83^{\prime \prime}$ & $47^{\circ} 49^{\prime} 47.90^{\prime \prime}$ \\
\hline $\mathrm{P} 24 \mathrm{Sa} 0718$ & 963008000939385 & Callithrix penicillata & $29 / 07 / 2018$ & $\mathrm{~F}$ & A & 341 & Hospital "Santa Tereza" & Av. Adelmo Perdizza, 495 - Alto da Boa Vista & $21^{\circ} 12^{\prime} 34.46^{\prime \prime}$ & $47^{\circ} 49^{\prime} 48.29^{\prime \prime}$ \\
\hline P25Sa0818 & 963008000939523 & Callithrix penicillata & $01 / 08 / 2018$ & $\mathrm{~F}$ & $\mathrm{~J}$ & 265 & Hospital "Santa Tereza" & Av. Adelmo Perdizza, 495 - Alto da Boa Vista & $21^{\circ} 12^{\prime 2} 24.07^{\prime \prime}$ & $47^{\circ} 49^{\prime} 41.75^{\prime \prime}$ \\
\hline $\mathrm{P} 26 \mathrm{Sa} 0818$ & 963008000941750 & Callithrix penicillata & $06 / 08 / 2018$ & $\mathrm{~F}$ & A & 502 & Hospital "Santa Tereza" & Av. Adelmo Perdizza, 495 - Alto da Boa Vista & $21^{\circ} 12^{\prime} 24.32^{\prime \prime}$ & $47^{\circ} 49^{\prime} 43.39^{\prime \prime}$ \\
\hline $\mathrm{P} 27 \mathrm{Sa} 0818$ & 963008000940538 & Callithrix penicillata & $16 / 08 / 2018$ & $\mathrm{~F}$ & A & 422 & Quinta da Boa Vista "A" & Rod. Pref. Antônio Duarte Nogueira, Km 318 & $21^{\circ} 12^{\prime} 36.06^{\prime \prime}$ & $47^{\circ} 51^{\prime} 10.64^{\prime \prime}$ \\
\hline $\mathrm{P} 28 \mathrm{Sa} 0818$ & 963008000940496 & Callithrix penicillata & 171 & $\mathrm{M}$ & A & 401 & Quinta da Boa Vista "A" & Rod. Pref. Antônio Duarte Nogueira, Km 318 & $21^{\circ} 12^{\prime} 36.23^{\prime \prime}$ & $47^{\circ} 51^{\prime} 10.75^{\prime \prime}$ \\
\hline $\mathrm{P} 29 \mathrm{Sa} 0818$ & 963008000940525 & Callithrix penicillata & $18 / 08 / 2018$ & $\mathrm{~F}$ & $\mathrm{~J}$ & 258 & Quinta da Boa Vista "A" & Rod. Pref. Antônio Duarte Nogueira, Km 318 & $21^{\circ} 12^{\prime} 36.04^{\prime \prime}$ & $47^{\circ} 51^{\prime} 10.70^{\prime \prime}$ \\
\hline $\mathrm{P} 30 \mathrm{Sa} 0818$ & 963008000940458 & Callithrix penicillata & $27 / 08 / 2018$ & $\mathrm{M}$ & A & 377 & Quinta da Boa Vista "A" & Rod. Pref. Antônio Duarte Nogueira, Km 318 & $21^{\circ} 12^{\prime} 54.64^{\prime \prime}$ & $47^{\circ} 51^{\prime} 24.23 "$ \\
\hline P31Sa0818 & 963008000940509 & Callithrix penicillata & $30 / 08 / 2018$ & $\mathrm{M}$ & $\mathrm{F}$ & 208 & Quinta da Boa Vista "A" & Rod. Pref. Antônio Duarte Nogueira, Km 318 & $21^{\circ} 12^{\prime} 36.07^{\prime \prime}$ & $47^{\circ} 51^{\prime} 10.64^{\prime \prime}$ \\
\hline $\mathrm{P} 32 \mathrm{Sa} 0818$ & 963008000940480 & Callithrix penicillata & $30 / 08 / 2018$ & $\mathrm{~F}$ & $\mathrm{~J}$ & 214 & Quinta da Boa Vista "A" & Rod. Pref. Antônio Duarte Nogueira, Km 318 & $21^{\circ} 12^{\prime} 36.09^{\prime \prime}$ & $47^{\circ} 51^{\prime} 10.65^{\prime \prime}$ \\
\hline $\mathrm{P} 33 \mathrm{Sa} 0918$ & 963008000940494 & Callithrix penicillata & $11 / 09 / 2018$ & $\mathrm{M}$ & A & 377 & Quinta da Boa Vista "A" & Rod. Pref. Antônio Duarte Nogueira, Km 318 & $21^{\circ} 12^{\prime} 42.28^{\prime \prime}$ & $47^{\circ} 50^{\prime} 53.52^{\prime \prime}$ \\
\hline $\mathrm{P} 34 \mathrm{Sa} 0918$ & 963008000940515 & Callithrix penicillata & & $\mathrm{M}$ & A & 404 & Quinta da Boa Vista "A" & Rod. Pref. Antônio Duarte Nogueira, Km 318 & $21^{\circ} 12^{\prime} 42.30^{\prime \prime}$ & $47^{\circ} 50^{\prime} 53.47^{\prime \prime}$ \\
\hline P35Sa0918 & 963008000940523 & Callithrix penicillata & $13 / 09 / 2018$ & $\mathrm{~F}$ & A & 374 & Quinta da Boa Vista "A" & Rod. Pref. Antônio Duarte Nogueira, Km 318 & $21^{\circ} 12^{\prime} 52.51^{\prime \prime}$ & $47^{\circ} 51^{\prime 2} 21.07^{\prime \prime}$ \\
\hline P36MP0918 & 963008000940467 & Sapajus nigritus & $12 / 11 / 2018$ & $\mathrm{~F}$ & $\mathrm{~J}$ & 1.416 & Est. Ecológica de Ribeirão Preto & Rod. Pref. Antônio Duarte Nogueira, Km 317 & $21^{\circ} 12^{\prime} 54.56^{\prime \prime}$ & $47^{\circ} 50^{\prime} 24.64^{\prime \prime}$ \\
\hline P37Sa1118 & 963008000940501 & Callithrix penicillata & $18 / 11 / 2018$ & $\mathrm{~F}$ & A & 369 & Est. Ecológica de Ribeirão Preto & Rod. Pref. Antônio Duarte Nogueira, Km 317 & $21^{\circ} 12^{\prime} 54.12^{\prime \prime}$ & $47^{\circ} 50^{\prime} 25.90^{\prime \prime}$ \\
\hline P38Sa1118 & 963008000940536 & Callithrix penicillata & $26 / 11 / 2018$ & M & $\mathrm{S}$ & 430 & Est. Ecológica de Ribeirão Preto & Rod. Pref. Antônio Duarte Nogueira, Km 317 & $21^{\circ} 13^{\prime} 31.40^{\prime \prime}$ & $47^{\circ} 50^{\prime} 58.50^{\prime \prime}$ \\
\hline P39Sa1118 & 963008000940472 & Callithrix penicillata & $10 / 12 / 2018$ & M & $\mathrm{J}$ & 250 & Est. Ecológica de Ribeirão Preto & Rod. Pref. Antônio Duarte Nogueira, Km 317 & $21^{\circ} 12^{\prime} 55.03^{\prime \prime}$ & $47^{\circ} 50^{\prime} 23.87^{\prime \prime}$ \\
\hline
\end{tabular}

ID: identificação do animal; Sexo - M: macho; F: fêmea; Idade - F: filhote; J: jovem adulto; A: adulto; S: senil; as amostras dos animais. 
APÊNDICE B - Tabela dos parâmetros hematológicos dos primatas não humanos capturados entre abril e dezembro de 2018

\begin{tabular}{|c|c|c|c|c|c|c|c|c|c|c|c|c|c|c|c|c|c|c|c|}
\hline & $\mathbf{P} 4$ * & P5 & P6* & P7 & P8* & P9* & P10 & P11 & P12 & P13 & P14 & P15* & P16 & P17 & P18 & P19 & $\mathbf{P 2 0}$ & $\mathbf{P 2 1}$ & $\mathbf{P 2 2}$ \\
\hline Hemácias $\left(\times 10^{6} / \mu \mathrm{L}\right)$ & 7,27 & 5,87 & 7,32 & 6,99 & 6,52 & 8,78 & 5,07 & 6,37 & 7,55 & 7,49 & 6,59 & 7,45 & 5,93 & 7,26 & 6,64 & 9,1 & 8,03 & 7,16 & 6,51 \\
\hline Hemoglobina (g/dL) & 15,2 & 12,1 & 15,6 & 14,5 & 13,9 & 17,3 & 10,8 & 13,6 & 15,8 & 15 & 13,9 & 14,9 & 13,2 & 15,6 & 13,5 & 20 & 17,7 & 15,2 & 13,3 \\
\hline Hematócrito (\%) & 48,4 & 37,4 & 48,4 & 43,2 & 43,6 & 56,5 & 33,8 & 43,1 & 49,1 & 46,1 & 42,3 & 46,9 & 39,4 & 47,9 & 41,4 & 58,6 & 52,9 & 44,4 & 40,7 \\
\hline $\mathrm{VCM}$ (fL) & 67 & 64 & 66 & 62 & 67 & 64 & 67 & 68 & 65 & 62 & 64 & 63 & 67 & 66 & 62 & 64 & 66 & 62 & 62 \\
\hline $\mathrm{HCM}(\mathrm{pg})$ & 20,9 & 20,6 & 21,3 & 20,8 & 21,4 & 19,6 & 21,2 & 21,3 & 21 & 20,1 & 21,1 & 20 & 22,3 & 21,5 & 20,3 & 21,9 & 22 & 21,3 & 20,5 \\
\hline CHCM (g/dL) & 31,4 & 32,4 & 32,2 & 33,6 & 32 & 30,5 & 31,9 & 31,6 & 32,3 & 32,6 & 32,8 & 31,8 & 33,6 & 32,6 & 32,7 & 34,1 & 33,4 & 34,3 & 32,8 \\
\hline Leucócitos & 6000 & 5900 & 11700 & 5800 & 4800 & 12000 & 8500 & 5100 & 9800 & 9200 & 10400 & 13100 & 6100 & 6400 & 13300 & 6200 & 9900 & 4200 & 8100 \\
\hline Neutrófilos segmentados (\%) & 72 & 31 & 20 & 45 & 72 & 41 & 68 & 56 & 23 & 49 & 47 & 49 & 29 & 34 & 55 & 65 & 53 & 23 & 43 \\
\hline Neutrófilos segmentados $(\mu \mathrm{L})$ & 4320 & 1829 & 2340 & 2610 & 3456 & 4920 & 5780 & 2856 & 2254 & 4508 & 4888 & 6419 & 1769 & 2176 & 7315 & 4030 & 5247 & 966 & 3483 \\
\hline Neutrófilos bastonetes (\%) & 0 & 0 & 0 & 0 & 0 & 0 & 0 & 0 & 0 & 0 & 0 & 0 & 0 & 0 & 0 & 0 & 0 & 0 & 0 \\
\hline Neutrófilos bastonetes $(\mu \mathrm{L})$ & 0 & 0 & 0 & 0 & 0 & 0 & 0 & 0 & 0 & 0 & 0 & 0 & 0 & 0 & 0 & 0 & 0 & 0 & 0 \\
\hline Eosinófilos (\%) & 1 & 2 & 1 & 1 & 2 & 1 & 1 & 4 & 3 & 1 & 2 & 3 & 2 & 1 & 0 & 0 & 1 & 0 & 3 \\
\hline Eosinófilos $(\mu \mathrm{L})$ & 60 & 118 & 117 & 58 & 96 & 120 & 85 & 204 & 294 & 92 & 208 & 393 & 122 & 64 & 0 & 0 & 99 & 0 & 243 \\
\hline Basófilos $(\mu \mathrm{L})$ & 4 & 1 & 0 & 0 & 0 & 0 & 0 & 0 & 1 & 0 & 0 & 3 & 0 & 0 & 1 & 1 & 4 & 3 & 0 \\
\hline Basófilos $(\mu \mathrm{L})$ & 240 & 59 & 0 & 0 & 0 & 0 & 0 & 0 & 98 & 0 & 0 & 393 & 0 & 0 & 133 & 62 & 396 & 126 & 0 \\
\hline Linfócitos (\%) & 22 & 64 & 78 & 49 & 22 & 49 & 28 & 36 & 71 & 48 & 49 & 40 & 66 & 62 & 43 & 31 & 39 & 72 & 49 \\
\hline Linfócitos $(\mu \mathrm{L})$ & 1320 & 3776 & 9126 & 2842 & 1056 & 5880 & 2380 & 1836 & 6958 & 4416 & 5096 & 5240 & 4026 & 3968 & 5719 & 1922 & 3861 & 3024 & 3969 \\
\hline Monócitos (\%) & 1 & 2 & 1 & 5 & 3 & 9 & 3 & 2 & 2 & 2 & 1 & 5 & 3 & 3 & 1 & 3 & 3 & 2 & 5 \\
\hline Monócitos $(\mu \mathrm{L})$ & 60 & 118 & 117 & 290 & 144 & 1080 & 255 & 102 & 196 & 184 & 104 & 655 & 183 & 192 & 133 & 186 & 297 & 84 & 405 \\
\hline Plaquetas $(\mu \mathrm{L})$ & 119.000 & 511.000 & 246.000 & 315.000 & 610.000 & 334.000 & 554.000 & 430.000 & 590.000 & 492.000 & 345.000 & 251.000 & 406.000 & 334.000 & 479.000 & 827.000 & 366.000 & 256.000 & 282.000 \\
\hline $\begin{array}{l}\text { Proteína Plasmática Total } \\
\text { (g/dL) }\end{array}$ & 7 & 6,2 & 6,5 & 6,8 & 6,8 & 6,4 & 6 & 5,8 & 6,8 & 7,2 & 6,6 & 6,4 & 6,4 & 5,6 & 6,4 & 6,6 & 5,8 & 5,8 & 5,8 \\
\hline
\end{tabular}

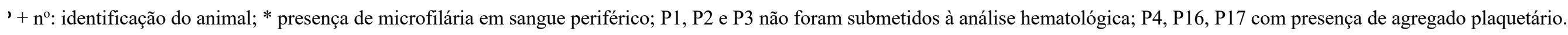


APÊNDICE C - Continuação da tabela do APÊNDICE B.

\begin{tabular}{|c|c|c|c|c|c|c|c|c|c|c|c|c|c|c|c|c|c|c|c|}
\hline & $\mathbf{P 2 1}$ & $\mathbf{P 2 2}$ & $\mathbf{P 2 3}$ & P24 & P25 & P26 & $\mathbf{P 2 7}$ & P28 & $\mathbf{P 2 9}$ & P30 & P31 & P32 & P33* & P34 & P35 & P36 & $\mathbf{P 3 7}$ & P38 & P39 \\
\hline Hemácias $\left(\times 10^{6} / \mu \mathrm{L}\right)$ & 7,16 & 6,51 & 8,85 & \multirow{21}{*}{ 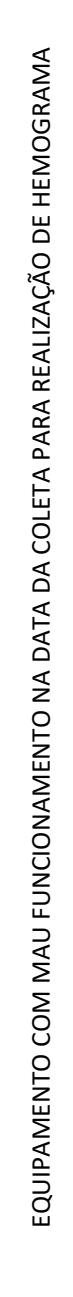 } & 6,38 & 4,23 & 6,57 & 7,69 & 5,67 & 7,48 & 5,11 & 4,51 & 6,1 & 4,7 & 5,02 & 3,81 & 7,83 & 8,46 & 6,56 \\
\hline Hemoglobina $(\mathrm{g} / \mathrm{dL})$ & 15,2 & 13,3 & 18,5 & & 14,9 & 8,9 & 13,3 & 16,6 & 12,6 & 15,1 & 11,4 & 10,1 & 14,2 & 10,5 & 12,6 & 9,5 & 17,4 & 17,3 & 13,8 \\
\hline Hematócrito (\%) & 44,4 & 40,7 & 58,2 & & 44,7 & 28,2 & 40,8 & 51,2 & 37,9 & 47,6 & 34,2 & 30,2 & 43 & 32 & 38 & 27,2 & 53,6 & 53,3 & 43 \\
\hline $\mathrm{VCM}(\mathrm{fL})$ & 62 & 62 & 66 & & 70 & 67 & 62 & 67 & 67 & 64 & 67 & 67 & 70 & 68 & 76 & 72 & 69 & 63 & 66 \\
\hline $\mathrm{HCM}(\mathrm{pg})$ & 21,3 & 20,5 & 20,9 & & 23,4 & 21,1 & 20,2 & 21,6 & 22,3 & 20,1 & 22,2 & 22,4 & 23,2 & 22,3 & 25,1 & 25,1 & 22,2 & 20,4 & 21,1 \\
\hline CHCM (g/dL) & 34,3 & 32,8 & 31,8 & & 33,5 & 31,7 & 32,6 & 32,5 & 33,3 & 31,7 & 33,2 & 33,5 & 33 & 32,8 & 33,1 & 35,1 & 32,4 & 32,4 & 32,1 \\
\hline Leucócitos & 4200 & 8100 & 10900 & & 9300 & 7700 & 5800 & 6600 & 12300 & 6600 & 13400 & 5200 & 6750 & 12600 & 6750 & 13500 & 7400 & 6300 & 11500 \\
\hline $\begin{array}{c}\text { Neutrófilos segmentados } \\
(\%)\end{array}$ & 23 & 43 & 84 & & 26 & 58 & 46 & 49 & 85 & 50 & 91 & 64 & 72 & 60 & 59 & 74 & 81 & 27 & 58 \\
\hline $\begin{array}{c}\text { Neutrófilos segmentados } \\
(\mu \mathrm{L})\end{array}$ & 966 & 3483 & 9156 & & 2418 & 4466 & 2668 & 3234 & 10455 & 3300 & 12194 & 3328 & 4860 & 7560 & 3982,5 & 9990 & 5994 & 1701 & 6670 \\
\hline Neutrófilos bastonetes (\%) & 0 & 0 & 0 & & 0 & 0 & 0 & 0 & 0 & 0 & 0 & 0 & 0 & 0 & 0 & 0 & 0 & 0 & 0 \\
\hline Neutrófilos bastonetes $(\mu \mathrm{L})$ & 0 & 0 & 0 & & 0 & 0 & 0 & 0 & 0 & 0 & 0 & 0 & 0 & 0 & 0 & 0 & 0 & 0 & 0 \\
\hline Eosinófilos (\%) & 0 & 3 & 1 & & 0 & 5 & 2 & 5 & 1 & 6 & 1 & 10 & 1 & 5 & 1 & 0 & 0 & 0 & 1 \\
\hline Eosinófilos $(\mu \mathrm{L})$ & 0 & 243 & 109 & & 0 & 385 & 116 & 330 & 123 & 396 & 134 & 520 & 67,5 & 630 & 67,5 & 0 & 0 & 0 & 115 \\
\hline Basófilos $(\mu \mathrm{L})$ & 3 & 0 & 0 & & 3 & 4 & 1 & 0 & 0 & 0 & 1 & 1 & 1 & 2 & 6 & 0 & 0 & 0 & 0 \\
\hline Basófilos $(\mu \mathrm{L})$ & 126 & 0 & 0 & & 279 & 308 & 58 & 0 & 0 & 0 & 134 & 52 & 67,5 & 252 & 405 & 0 & 0 & 0 & 0 \\
\hline Linfócitos (\%) & 72 & 49 & 13 & & 69 & 31 & 48 & 46 & 13 & 43 & 6 & 21 & 25 & 31 & 33 & 23 & 18 & 69 & 35 \\
\hline Linfócitos $(\mu \mathrm{L})$ & 3024 & 3969 & 1417 & & 6417 & 2387 & 2784 & 3036 & 1599 & 2838 & 804 & 1092 & 1687,5 & 3906 & 2227,5 & 3105 & 1332 & 4347 & 4025 \\
\hline Monócitos (\%) & 2 & 5 & 2 & & 2 & 2 & 3 & 0 & 1 & 1 & 1 & 4 & 1 & 2 & 1 & 3 & 1 & 4 & 2 \\
\hline Monócitos $(\mu \mathrm{L})$ & 84 & 405 & 218 & & 186 & 154 & 174 & 0 & 123 & 66 & 134 & 208 & 67,5 & 252 & 67,5 & 405 & 74 & 252 & 230 \\
\hline Plaquetas $(\mu \mathrm{L})$ & 256.000 & 282.000 & 412.000 & & 370.000 & 654.000 & 396.000 & 312.000 & 435.000 & 446.000 & 481.000 & 497.000 & 633.000 & 642.000 & 624.000 & 475.000 & 225.000 & 268.000 & 419.000 \\
\hline $\begin{array}{c}\text { Proteína Plasmática Total } \\
(\mathrm{g} / \mathrm{dL})\end{array}$ & 5,8 & 5,8 & 6 & & 6 & 5,7 & 6 & 6,8 & 6 & 6,4 & 5,6 & 6,2 & 6,6 & 5,8 & 6 & 7 & 6,8 & 7 & 7,2 \\
\hline
\end{tabular}

P + número: identificação do animal capturado; * animais com presença de microfilária em sangue periférico; 
APÊNDICE D - Resultados do PRNT. Títulos dados pela última diluição em que a redução do número de plaques foi maior ou igual a $50 \%$ e pelo método de ajuste de curva (regressão da resposta de dose não linear) calculado no GraphPad Prism 8, conforme o guia da WHO (2017).

\begin{tabular}{|c|c|c|c|c|c|c|}
\hline Local & Amostras & Fluido & Espécie & PRNT 50 (17DD) & $\mathrm{PRNT}_{50}(\mathrm{JabSPM02})$ & PRNT $_{50}(\mathrm{JabSPM}$ 2) EndPoint \\
\hline \multirow{3}{*}{$\begin{array}{l}\text { GVE XXIV } \\
\text { /DRS XIII }\end{array}$} & $\mathrm{P} 1 \mathrm{Sa} 0418$ & Plasma & Callithrix penicillata & 0 & 10 & 8.69 \\
\hline & $\mathrm{P} 2 \mathrm{Sa} 0618$ & Plasma & Callithrix penicillata & 0 & 10 & 29.75 \\
\hline & P3Sa0618 & Plasma & Callithrix penicillata & 0 & 0 & 0 \\
\hline \multirow{12}{*}{$\begin{array}{l}\text { Quinta da Boa } \\
\text { Vista "B" }\end{array}$} & $\mathrm{P} 4 \mathrm{Sa} 0618$ & Plasma & Callithrix penicillata & 0 & 20 & 446.03 \\
\hline & P5Sa0618 & Plasma & Callithrix penicillata & 0 & 160 & 282.56 \\
\hline & $\mathrm{P} 6 \mathrm{Sa} 0618$ & Plasma & Callithrix penicillata & 0 & 10 & 43.85 \\
\hline & P7Sa0618 & Plasma & Callithrix penicillata & 0 & 20 & 15.90 \\
\hline & P8Sa0618 & Plasma & Callithrix penicillata & 0 & 80 & 269.90 \\
\hline & P9Sa0618 & Plasma & Callithrix penicillata & 0 & 10 & 71.37 \\
\hline & $\mathrm{P} 10 \mathrm{Sa} 0618$ & Plasma & Callithrix penicillata & 0 & 0 & 0 \\
\hline & $\mathrm{P} 11 \mathrm{Sa} 0618$ & Plasma & Callithrix penicillata & 0 & 20 & 25.81 \\
\hline & $\mathrm{P} 12 \mathrm{Sa} 0618$ & Plasma & Callithrix penicillata & 0 & 0 & 0 \\
\hline & $\mathrm{P} 13 \mathrm{Sa} 0618$ & Plasma & Callithrix penicillata & 0 & 20 & 2644.10 \\
\hline & $\mathrm{P} 14 \mathrm{Sa} 0718$ & Plasma & Callithrix penicillata & 0 & 10 & 11.42 \\
\hline & $\mathrm{P} 15 \mathrm{Sa} 0718$ & Plasma & Callithrix penicillata & 0 & 10 & 112.29 \\
\hline \multirow{11}{*}{$\begin{array}{c}\text { Hospital Santa } \\
\text { Tereza de Ribeirão } \\
\text { Preto }\end{array}$} & $\mathrm{P} 16 \mathrm{Sa} 0718$ & Plasma & Callithrix penicillata & 0 & 20 & 9.31 \\
\hline & $\mathrm{P} 17 \mathrm{Sa} 0718$ & Plasma & Callithrix penicillata & 0 & 10 & 134.84 \\
\hline & $\mathrm{P} 18 \mathrm{Sa} 0718$ & Plasma & Callithrix penicillata & 0 & 10 & 123.51 \\
\hline & $\mathrm{P} 19 \mathrm{Sa} 0718$ & Plasma & Callithrix penicillata & 0 & 10 & 402 \\
\hline & $\mathrm{P} 20 \mathrm{Sa} 0718$ & Plasma & Callithrix penicillata & 0 & 160 & 382.40 \\
\hline & $\mathrm{P} 21 \mathrm{Sa} 0718$ & Plasma & Callithrix penicillata & 0 & 20 & 16.93 \\
\hline & $\mathrm{P} 22 \mathrm{Sa} 0718$ & Plasma & Callithrix penicillata & 0 & 20 & 46.88 \\
\hline & $\mathrm{P} 23 \mathrm{Sa} 0718$ & Plasma & Callithrix penicillata & 0 & 10 & 288 \\
\hline & $\mathrm{P} 24 \mathrm{Sa} 0718$ & Soro & Callithrix penicillata & 0 & 10 & 9.08 \\
\hline & $\mathrm{P} 25 \mathrm{Sa} 0818$ & Plasma & Callithrix penicillata & 0 & 10 & 1.28 \\
\hline & $\mathrm{P} 26 \mathrm{Sa} 0818$ & Soro & Callithrix penicillata & 0 & 40 & 58 \\
\hline \multirow{9}{*}{$\begin{array}{l}\text { Quinta da Boa } \\
\text { Vista "A" }\end{array}$} & $\mathrm{P} 27 \mathrm{Sa} 0818$ & Plasma & Callithrix penicillata & 0 & 20 & 30.29 \\
\hline & $\mathrm{P} 28 \mathrm{Sa} 0818$ & Plasma & Callithrix penicillata & 0 & 160 & 182.88 \\
\hline & $\mathrm{P} 29 \mathrm{Sa} 0818$ & Plasma & Callithrix penicillata & 0 & 20 & 123.65 \\
\hline & P30Sa0818 & Soro & Callithrix penicillata & 0 & 0 & 0 \\
\hline & P31Sa0818 & Soro & Callithrix penicillata & 0 & 160 & 354.35 \\
\hline & $\mathrm{P} 32 \mathrm{Sa} 0818$ & Plasma & Callithrix penicillata & 0 & 80 & 239 \\
\hline & P33Sa0918 & Plasma & Callithrix penicillata & 0 & 80 & 245.09 \\
\hline & P34Sa0918 & Soro & Callithrix penicillata & 0 & 40 & 55.43 \\
\hline & $\mathrm{P} 35 \mathrm{Sa} 0918$ & Plasma & Callithrix penicillata & 0 & 10 & 219.34 \\
\hline \multirow{4}{*}{$\begin{array}{l}\text { Estação Ecológica } \\
\text { de Ribeirão Preto }\end{array}$} & P36MP0918 & Soro & Sapajus nigritus & 0 & 80 & 507.09 \\
\hline & P37Sa1118 & Soro & Callithrix penicillata & 0 & 0 & 0 \\
\hline & P38Sa1118 & Plasma & Callithrix penicillata & 0 & 160 & 243.72 \\
\hline & P39Sa1118 & Soro & Callithrix penicillata & 0 & 20 & 36.19 \\
\hline
\end{tabular}


ANEXOS 
ANEXO A - FICHA DE IDENTIFICAÇÃO DE PRIMATAS - Secretaria de Vigilância em Saúde/ Ministério da Saúde.

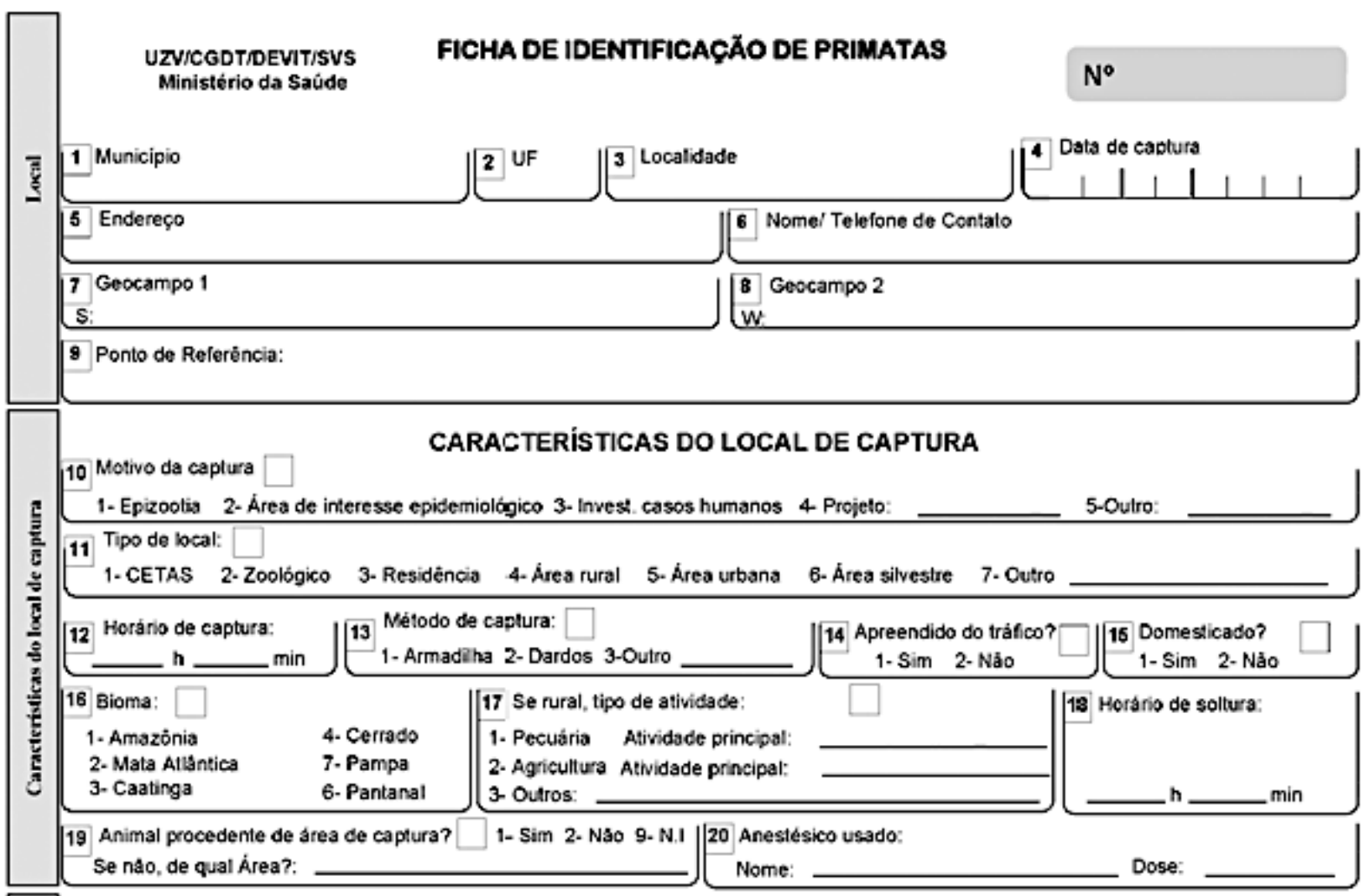

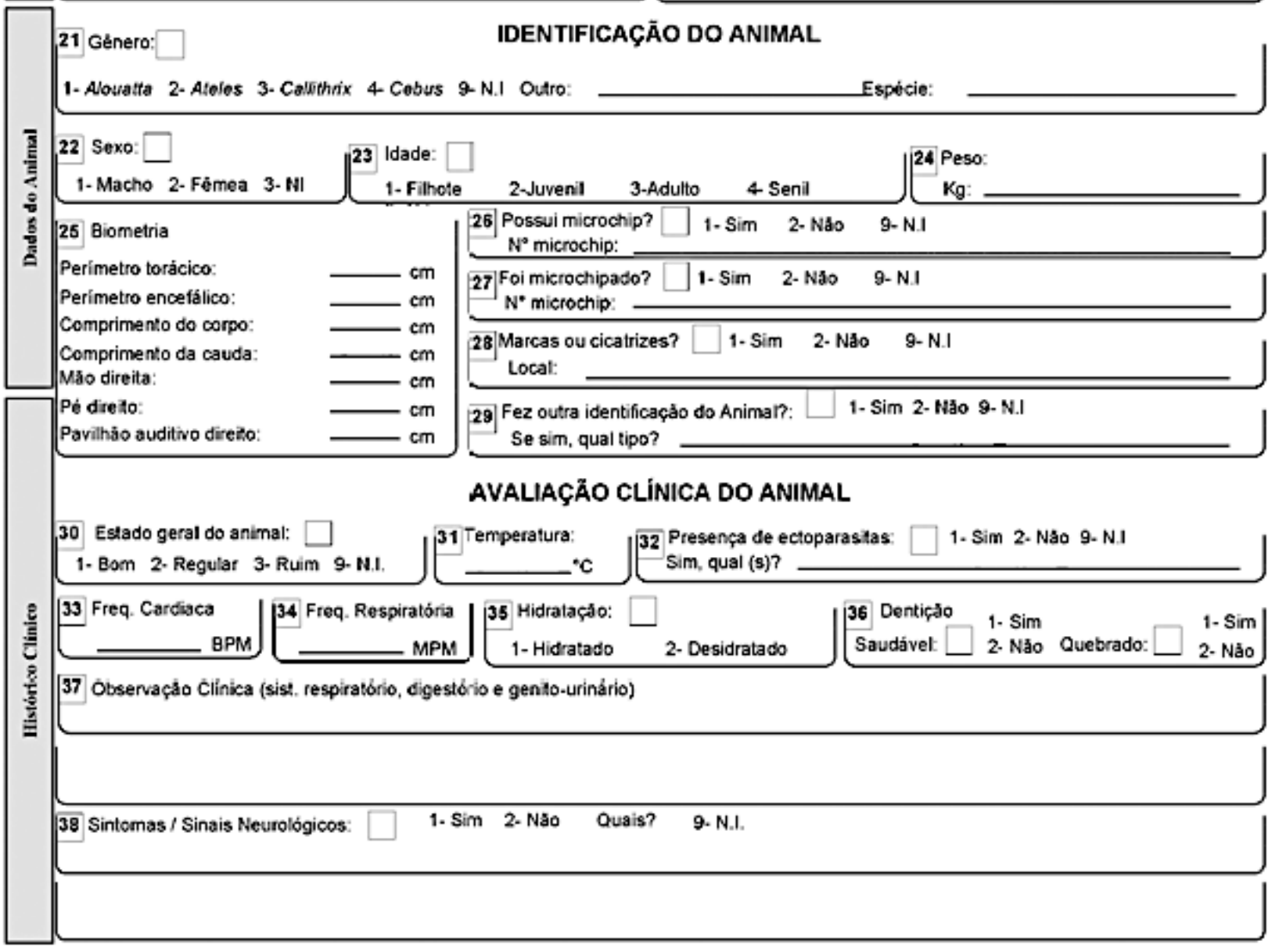




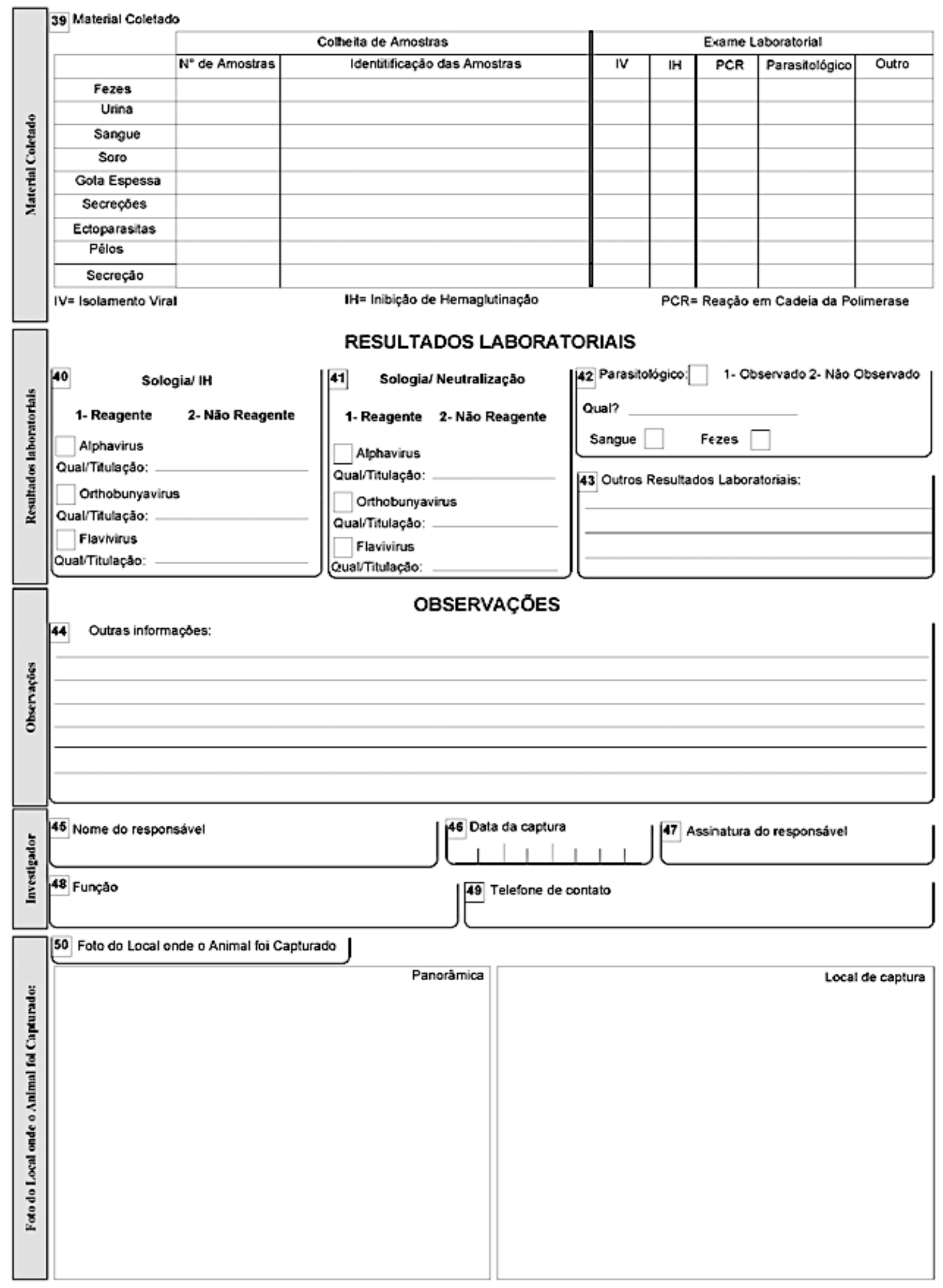




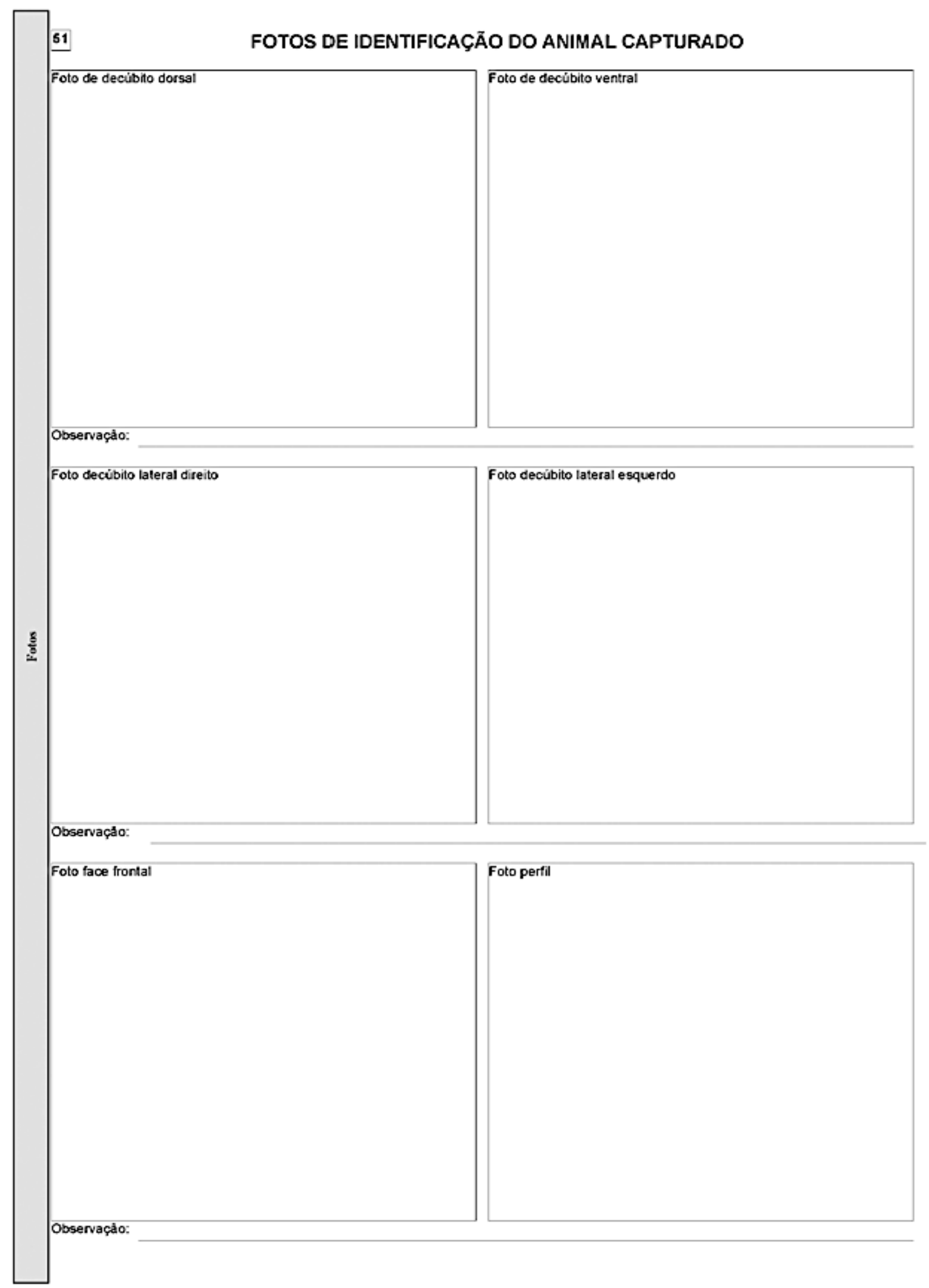




\section{ANEXO B - Autorização de captura expedida pelo Instituto Chico Mendes de Conservação da Biodiversidade (ICMBio/SISBIO/MMA)}

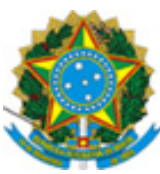

Ministério do Meio Ambiente - MMA

Instituto Chico Mendes de Conservação da Biodiversidade - ICMBio

Sistema de Autorização e Informação em Biodiversidade - SISBIO

\section{Autorização para atividades com finalidade científica}

\begin{tabular}{l|l|l} 
Número: 61391-1 & Data da Emissão: 12/01/2018 11:20 & Data para Revalidação*: 11/02/2019
\end{tabular}

* De acordo com o art. 28 da IN 03/2014, esta autorização tem prazo de validade equivalente ao previsto no cronograma de atividades do projeto, mas deverá ser revalidada anualmente mediante a apresentação do relatório de atividades a ser enviado por meio do Sisbio no prazo de até 30 dias a contar da data do aniversário de sua emissão.

Dados do titular

\begin{tabular}{|l|l|l}
\hline Nome: Márcio Junio Lima Siconelli & CPF:
\end{tabular}

Título do Projeto: AVALIAÇÃO DA IMPORTÂNCIA DOS PRIMATAS NÃO HUMANOS NA POSSÍVEL REURBANIZAÇÃO DA FEBRE AMARELA ? MUNICÍPIO DE RIBEIRÃO PRETO/SP, 2017

Nome da Instituição : FACULDADE DE MEDICINA DE RIBEIRÃO PRETO - USP CNPJ: 63.025.530/0026-62

Cronograma de atividades

\begin{tabular}{|c|c|}
\hline$\#$ & Descrição da atividade \\
\hline 1 & Mapeamento, captura, colheita de material e processamento
\end{tabular} Início (mês/ano) $\quad$ Fim (mês/ano)

Observações e ressalvas

As atividades de campo exercidas por pessoa natural ou jurídica estrangeira, em todo o território nacional, que impliquem o deslocamento de recursos humanos e

1 materiais, tendo por objeto coletar dados, materiais, espécimes biológicos e minerais, peças integrantes da cultura nativa e cultura popular, presente e passada,

obtidos por meio de recursos e técnicas que se destinem ao estudo, à difusão ou à pesquisa, estão sujeitas a autorização do Ministério de Ciência e Tecnologia. Esta autorização NÃO exime o pesquisador titular e os membros de sua equipe da necessidade de obter as anuências previstas em outros instrumentos legais, bem

2 como do consentimento do responsável pela área, pública ou privada, onde será realizada a atividade, inclusive do órgão gestor de terra indígena (FUNAI), da

unidade de conservação estadual, distrital ou municipal, ou do proprietário, arrendatário, posseiro ou morador de área dentro dos limites de unidade de conservação federal cujo processo de regularizacão fundiária encontra-se em curso.

Este documento somente poderá ser utilizado para os fins previstos na Instrução Normativa ICMBio $n^{\circ} 03 / 2014$ ou na Instrução Normativa ICMBio ${ }^{\circ} 10 / 2010$, no que

3 especifica esta Autorização, não podendo ser utilizado para fins comerciais, industriais ou esportivos. O material biológico coletado deverá ser utilizado para atividades científicas ou didáticas no âmbito do ensino superior.

4 A autorização para envio ao exterior de material biológico não consignado deverá ser requerida por meio do endereço eletrônico www.ibama.gov.br (Serviços on-line -

Licença para importação ou exportação de flora e fauna - CITES e não CITES).

O titular de licença ou autorização e os membros da sua equipe deverão optar por métodos de coleta e instrumentos de captura direcionados, sempre que possível,

5 ao grupo taxonômico de interesse, evitando a morte ou dano significativo a outros grupos; e empregar esforço de coleta ou captura que não comprometa a viabilidade de populacões do grupo taxonômico de interesse em condicão in situ.

O titular de autorização ou de licença permanente, assim como os membros de sua equipe, quando da violacão da legislação vigente, ou quando da inadequação,

6 omissão ou falsa descrição de informações relevantes que subsidiaram a expedição do ato, poderá, mediante decisão motivada, ter a autorização ou licença suspensa ou revogada pelo ICMBio, nos termos da legislação brasileira em vigor.

Este documento não dispensa o cumprimento da legislação que dispõe sobre acesso a componente do patrimônio genético existente no território nacional na

7 plataforma continental e na zona econômica exclusiva, ou ao conhecimento tradicional associado ao patrimônio genético, para fins de pesquisa científica,

bioprospecção e desenvolvimento tecnológico. Veja maiores informações em www.mma.gov.br/cgen.

8 Em caso de pesquisa em UNIDADE DE CONSERVAÇÃO, o pesquisador titular desta autorização deverá contactar a administração da unidade a fim de CONFIRMAR AS DATAS das expedições, as condições para realização das coletas e de uso da infra-estrutura da unidade.

Equipe

\begin{tabular}{|l|l|l|l|l|l|}
\hline$\#$ & \multicolumn{1}{|c|}{ Nome } & \multicolumn{1}{|c|}{ Função } & CPF & Doc. Identidade & Nacionalidade \\
\hline 1 & Benedito Antonio Lopes da Fonseca & Orientador & & Brasileira \\
\hline 2 & Pedro Henrique Ferreira Teles & Médico Veterinário & & Brasileira \\
\hline
\end{tabular}

Locais onde as atividades de campo serão executadas

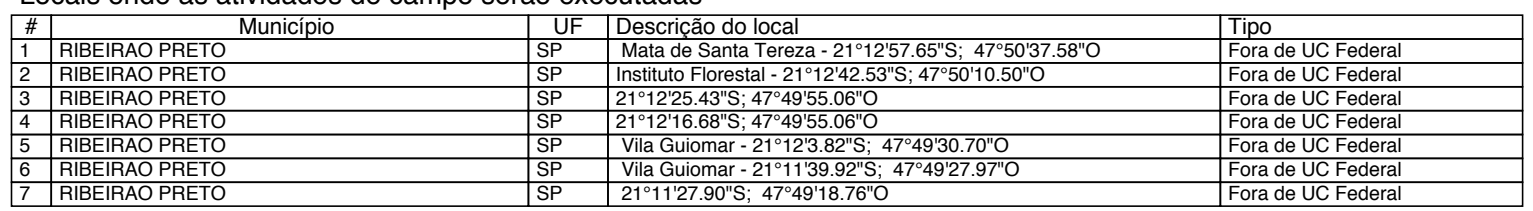

Este documento (Autorização para atividades com finalidade científica) foi expedido com base na Instrução Normativa $n^{\circ} 03 / 2014$. Através do código de autenticação abaixo, qualquer cidadão poderá verificar a autenticidade ou regularidade deste documento, por meio da página do Sisbio/ICMBio na Internet (www.icmbio.gov.br/sisbio).

Código de autenticação: 54669294 
Ministério do Meio Ambiente - MMA

Instituto Chico Mendes de Conservação da Biodiversidade - ICMBio

Sistema de Autorização e Informação em Biodiversidade - SISBIO

\section{Autorização para atividades com finalidade científica}

\begin{tabular}{|l|c|c|}
\hline Número: 61391-1 & Data da Emissão: 12/01/2018 11:20 & Data para Revalidação*: 11/02/2019 \\
\hline $\begin{array}{l}\text { * De acordo com o art. } 28 \text { da IN 03/2014, esta autorização tem prazo de validade equivalente ao previsto no cronograma de atividades do projeto, } \\
\text { mas deverá ser revalidada anualmente mediante a apresentação do relatório de atividades a ser enviado por meio do Sisbio no prazo de até 30 dias } \\
\text { a contar da data do aniversário de sua emissão. }\end{array}$
\end{tabular}

Dados do titular

\begin{tabular}{|l|l|l}
\hline Nome: Márcio Junio Lima Siconelli & CPF:
\end{tabular}

Título do Projeto: AVALIAÇÃO DA IMPORTÂNCIA DOS PRIMATAS NÃO HUMANOS NA POSSÍVEL REURBANIZAÇÃO DA FEBRE AMARELA ? MUNICÍPIO DE RIBEIRÃO PRETO/SP, 2017

Nome da Instituição : FACULDADE DE MEDICINA DE RIBEIRÃO PRETO - USP CNPJ: 63.025.530/0026-62

\begin{tabular}{|c|c|c|c|c|}
\hline 8 & RIBEIRAO PRETO & SP & 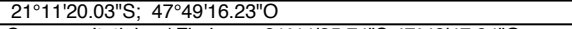 & Fora de UC Federal \\
\hline 10 & RIBEIRAO PRETO & SP & Cruz. Visc. Abaeté e Garibaldi-21 ${ }^{\circ} 11^{\prime 2} 22.98^{\prime \prime} \mathrm{S} ; 47^{\circ} 48^{\prime} 46.14^{\prime \prime O}$ & Fora de UC Federal \\
\hline 11 & RIBEIRAO PRETO & SP & Praça Camões - $21^{\circ} 10^{\prime} 51.94^{\prime \prime S} ; 47^{\circ} 48^{\prime} 48.20^{\prime \prime O}$ & Fora de UC Federal \\
\hline 12 & RIBEIRAO PRETO & SP & Praça 7 de setembro - $21^{\circ} 10^{\prime} 57.07^{\prime \prime S} ; 47^{\circ} 48^{\prime} 18.11^{\prime \prime O}$ & Fora de UC Federal \\
\hline 15 & RIBEIRAO PRETO & SP & $21^{\circ} 10^{\prime} 19.42^{\prime \prime} \mathrm{S} ; 47^{\circ} 48^{\prime} 47.93^{\prime \prime} \mathrm{O}$ & Fora de UC Federal \\
\hline 16 & RIBEIRAO PRETO & $\mathrm{SP}$ & Praça XV de novembro - $21^{\circ} 10^{\prime} 31.25^{\prime \prime} \mathrm{S} ; 47^{\circ} 48^{\prime} 30.14^{\prime \prime} \mathrm{O}$ & Fora de UC Federal \\
\hline 17 & RIBEIRAO PRETO & SP & Bosque Zoológico - $21^{\circ} 10^{\prime} 23.48^{\prime \prime} \mathrm{S} ; 47^{\circ} 48^{\prime} 7.47^{\prime \prime O} \mathrm{O}$ & Fora de UC Federal \\
\hline 18 & RIBEIRAO PRETO & SP & Praça da Escola Sinhá Junqueira-21 ${ }^{\circ} 10^{\prime} 7.96^{\prime \prime S} ; 47^{\circ} 49^{\prime} 1.33^{\prime \prime O}$ & Fora de UC Federal \\
\hline 21 & RIBEIRAO PRETO & SP & $21^{\circ} 9^{\prime} 33.94^{\prime \prime S} ; 47^{\circ} 48^{\prime} 37.95^{\prime \prime O}$ & Fora de UC Federal \\
\hline 22 & RIBEIRAO PRETO & $\mathrm{SP}$ & Praça Rômulo Morandi - $21^{\circ} 9^{\prime} 31.02^{\prime \prime S} ; 47^{\circ} 48^{\prime} 19.52^{\prime \prime} \mathrm{O}$ & Fora de UC Federal \\
\hline 23 & RIBEIRAO PRETO & SP & Mata Av. Lafayete Costa Couto- $21^{\circ} 8^{\prime} 48.36^{\prime \prime S}$; $47^{\circ} 48^{\prime} 29.14^{\prime \prime O}$ & Fora de UC Federal \\
\hline 24 & RIBEIRAO PRETO & $\mathrm{SP}$ & Ipanema Club - $21^{\circ} 9^{\prime} 6.66^{\prime \prime S} ; 47^{\circ} 48^{\prime} 28.68^{\prime \prime O}$ & Fora de UC Federal \\
\hline 25 & RIBEIRAO PRETO & SP & $21^{\circ} 8138.96^{\prime \prime} \mathrm{S} ; 47^{\circ} 48^{\prime} 9.20^{\prime \prime O}$ & Fora de UC Federal \\
\hline 26 & RIBEIRAO PRETO & SP & $21^{\circ} 8^{\prime} 50.18^{\prime \prime S} ; 47^{\circ} 47^{\prime} 55.30^{\prime \prime} \mathrm{O}$ & Fora de UC Federal \\
\hline 27 & RIBEIRAO PRETO & SP & $21^{\circ} 8^{\prime} 51.03^{\prime \prime S} ; 47^{\circ} 47^{\prime} 49.77^{\prime \prime O}$ & Fora de UC Federal \\
\hline 28 & RIBEIRAO PRETO & SP & $21^{\circ} 8^{\prime} 10.61^{\prime \prime} \mathrm{S} ; 47^{\circ} 48^{\prime} 7.82^{\prime \prime O}$ & Fora de UC Federal \\
\hline 34 & RIBEIRAO PRETO & SP & Cruz. Est.5 c/ Rafael Defina - $21^{\circ} 7^{\prime} 42.39^{\prime \prime} \mathrm{S} ; 47^{\circ} 47^{\prime} 59.98^{\prime \prime} \mathrm{O}$ & Fora de UC Federal \\
\hline 35 & RIBEIRAO PRETO & SP & Cruz. Est. $4 \mathrm{c} / 5-21^{\circ} 77^{\prime} 39.37^{\prime \prime} \mathrm{S} ; 47^{\circ} 48^{\prime} 0.13^{\prime \prime O}$ & Fora de UC Federal \\
\hline 36 & RIBEIRAO PRETO & SP & $21^{\circ} 7^{\prime} 28.51^{\prime \prime} \mathrm{S} ; 47^{\circ} 47^{\prime} 57.28^{\prime \prime} \mathrm{O}$ & Fora de UC Federal \\
\hline 37 & RIBEIRAO PRETO & $\mathrm{SP}$ & Praça Rua Ludovico Bestetti - $21^{\circ} 7^{\prime 2} 23.85^{\prime \prime S}$; 4748'19.21"O & Fora de UC Federal \\
\hline 38 & RIBEIRAO PRETO & $\mathrm{SP}$ & Mata do Savegnago - $21^{\circ} 7 ' 25.18^{\prime \prime} \mathrm{S} ; 47^{\circ} 48^{\prime} 32.41^{\prime \prime} \mathrm{o}$ & Fora de UC Federal \\
\hline 39 & RIBEIRAO PRETO & SP & $21^{\circ} 7^{\prime} 16.73^{\prime \prime} \mathrm{S} ; 47^{\circ} 48^{\prime} 50.20^{\prime \prime O}$ & Fora de UC Federal \\
\hline 40 & RIBEIRAO PRETO & SP & Mata Av. João Batista Duarte - $21^{\circ} 7^{\prime} 5.37^{\prime \prime} \mathrm{S} ; 47^{\circ} 48^{\prime} 44.05^{\prime \prime} \mathrm{O}$ & Fora de UC Federal \\
\hline 41 & RIBEIRAO PRETO & SP & $21^{\circ} 6^{\prime} 58.37^{\prime \prime} \mathrm{S} ; 47^{\circ} 48^{\prime} 37.29^{\prime \prime} \mathrm{O}$ & Fora de UC Federal \\
\hline 42 & RIBEIRAO PRETO & SP & $21^{\circ} 6^{\prime} 59.07^{\prime \prime} \mathrm{S} ; 47^{\circ} 48^{\prime} 31.22^{\prime \prime} \mathrm{O}$ & Fora de UC Federal \\
\hline 43 & RIBEIRAO PRETO & SP & Mata via norte $1-21^{\circ} 6^{\prime} 58.35^{\prime \prime S}$; $47^{\circ} 48^{\prime} 16.93^{\prime \prime} \mathrm{O}$ & Fora de UC Federal \\
\hline 44 & RIBEIRAO PRETO & $\mathrm{SP}$ & Mata via norte 2 - $21^{\circ} 6^{\prime} 44.26^{\prime \prime} \mathrm{S} ; 47^{\circ} 48^{\prime} 26.30^{\prime \prime} \mathrm{O}$ & Fora de UC Federal \\
\hline 45 & RIBEIRAO PRETO & SP & $21^{\circ} 6^{\prime} 43.51^{\prime \prime} \mathrm{S} ; 47^{\circ} 48^{\prime} 19.31^{\prime \prime O}$ & Fora de UC Federal \\
\hline 46 & RIBEIRAO PRETO & SP & Mata via norte 3 - $21^{\circ} 6{ }^{\prime} 29.69^{\prime \prime} \mathrm{S} ; 47^{\circ} 48^{\prime} 35.98^{\prime \prime} \mathrm{O}$ & Fora de UC Federal \\
\hline 47 & RIBEIRAO PRETO & SP & Mata empresa Ambient - $21^{\circ} 6^{\prime} 20.78^{\prime \prime} \mathrm{S} ; 47^{\circ} 48^{\prime} 36.68^{\prime \prime} \mathrm{O}$ & Fora de UC Federal \\
\hline 48 & RIBEIRAO PRETO & $\mathrm{SP}$ & Mata ciliar $1-21^{\circ} 5^{\prime} 37.06^{\prime \prime S}$; $47^{\circ} 48^{\prime} 37.50^{\prime \prime} \mathrm{O}$ & Fora de UC Federal \\
\hline
\end{tabular}

Este documento (Autorização para atividades com finalidade científica) foi expedido com base na Instrução Normativa ${ }^{\circ}$ 03/2014. Através do código de autenticação abaixo, qualquer cidadão poderá verificar a autenticidade ou regularidade deste documento, por meio da página do Sisbio/ICMBio na Internet (www.icmbio.gov.br/sisbio).

Código de autenticação: 54669294

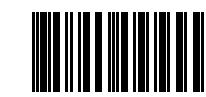

Página 2/5 
Ministério do Meio Ambiente - MMA

Instituto Chico Mendes de Conservação da Biodiversidade - ICMBio

Sistema de Autorização e Informação em Biodiversidade - SISBIO

\section{Autorização para atividades com finalidade científica}

Número: 61391-1

Data da Emissão: 12/01/2018 11:20

Data para Revalidação*: 11/02/2019

* De acordo com o art. 28 da IN 03/2014, esta autorização tem prazo de validade equivalente ao previsto no cronograma de atividades do projeto, mas deverá ser revalidada anualmente mediante a apresentação do relatório de atividades a ser enviado por meio do Sisbio no prazo de até 30 dias a contar da data do aniversário de sua emissão.

Dados do titular

Nome: Márcio Junio Lima Siconelli CPF:

Título do Projeto: AVALIAÇÃO DA IMPORTÂNCIA DOS PRIMATAS NÃO HUMANOS NA POSSÍVEL REURBANIZAÇÃO DA FEBRE AMARELA ? MUNICÍPIO DE RIBEIRÃO PRETO/SP, 2017

Nome da Instituição : FACULDADE DE MEDICINA DE RIBEIRÃO PRETO - USP CNPJ: 63.025.530/0026-62

\begin{tabular}{|l|l|l|l|l|}
\hline 56 & RIBEIRAO PRETO & SP & Mata Cond. Golf Resort - $21^{\circ} 13^{\prime} 21.54^{\prime \prime} \mathrm{S} ; 47^{\circ} 49^{\prime} 54.69^{\prime \prime} \mathrm{O}$ & Fora de UC Federal \\
\hline 57 & RIBEIRAO PRETO & SP & $21^{\circ} 13^{\prime} 33.69^{\prime \prime} \mathrm{S} ; 47^{\circ} 49^{\prime} 56.48^{\prime \prime} \mathrm{O}$ & Fora de UC Federal \\
\hline 58 & RIBEIRAO PRETO & SP & $21^{\circ} 13^{\prime} 20.75 " \mathrm{~S} ; 47^{\circ} 50^{\prime} 14.47^{\prime \prime} \mathrm{O}$ & Fora de UC Federal \\
\hline 59 & RIBEIRAO PRETO & SP & $21^{\circ} 13^{\prime} 53.80^{\prime \prime} \mathrm{S} ; 47^{\circ} 49^{\prime} 33.85^{\prime \prime} \mathrm{O}$ & Fora de UC Federal \\
\hline 60 & RIBEIRAO PRETO & SP & Rod. Alexand. Balbo (Km 265$)-21^{\circ} 66^{\prime} 46.79^{\prime \prime} \mathrm{S} ; 47^{\circ} 49^{\prime} 36.72^{\prime \prime} \mathrm{O}$ & Fora de UC Federal \\
\hline 61 & RIBEIRAO PRETO & SP & Espaço Le Coq $-21^{\circ} 7 ' 23.52^{\prime \prime} \mathrm{S} ; 47^{\circ} 50^{\prime} 0.62^{\prime \prime} \mathrm{O}$ & Fora de UC Federal \\
\hline 62 & RIBEIRAO PRETO & SP & Mansão Galo Bravo $-21^{\circ} 77^{\prime} 35.96^{\prime \prime} \mathrm{S} ; 47^{\circ} 50^{\prime} 15.05^{\prime \prime} \mathrm{O}$ & Fora de UC Federal \\
\hline
\end{tabular}

Atividades X Táxons

\begin{tabular}{|l|l|l|}
\hline$\#$ & \multicolumn{1}{|c|}{ Atividade } & \multicolumn{1}{c|}{ Táxons } \\
\hline 1 & Captura de animais silvestres in situ & Callitrix penicillata, Alouatta caraya, Sapajus \\
\hline 2 & Coleta/transporte de amostras biológicas in situ & Callitrix penicillata, Alouatta caraya, Sapajus \\
\hline
\end{tabular}

Material e métodos

\begin{tabular}{|l|l|l|}
\hline 1 & Amostras biológicas (Primatas) & Animal encontrado morto ou partes (carcaça)/osso/pele, Sangue \\
\hline
\end{tabular}

\begin{tabular}{|l|l|l}
\hline 1 & Amostras biologicas (Primatas) & Animal encontrado morto ou partes (carcaça)/osso/pele, Sangue \\
\hline 2 & Método de captura/coleta (Primatas) & Puçá, Armadilha tipo gaiola com atração por iscas (“Box Trap/Tomahawk/Sherman”) \\
\hline 3 & Método de marcação (Primatas) & Microchip \\
\hline
\end{tabular}

Destino do material biológico coletado

\begin{tabular}{|c|c|c}
\hline$\#$ & Nome local destino & Tipo Destino \\
\hline 1 & FACULDADE DE MEDICINA DE RIBERAO PRETO -USP
\end{tabular}

Este documento (Autorização para atividades com finalidade científica) foi expedido com base na Instrução Normativa $n^{\circ} 03 / 2014$. Através do código de autenticação abaixo, qualquer cidadão poderá verificar a autenticidade ou regularidade deste documento, por meio da página do Sisbio/ICMBio na Internet (www.icmbio.gov.br/sisbio).

\section{Código de autenticação: 54669294}


Ministério do Meio Ambiente - MMA

Instituto Chico Mendes de Conservação da Biodiversidade - ICMBio

Sistema de Autorização e Informação em Biodiversidade - SISBIO

\section{Autorização para atividades com finalidade científica}

\begin{tabular}{|l|c|c|}
\hline Número: 61391-1 & Data da Emissão: 12/01/2018 11:20 & Data para Revalidação*: 11/02/2019 \\
\hline $\begin{array}{l}\text { * De acordo com o art. } 28 \text { da IN 03/2014, esta autorização tem prazo de validade equivalente ao previsto no cronograma de atividades do projeto, } \\
\text { mas deverá ser revalidada anualmente mediante a apresentação do relatório de atividades a ser enviado por meio do Sisbio no prazo de até } 30 \text { dias } \\
\text { a contar da data do aniversário de sua emissão. }\end{array}$
\end{tabular}

Dados do titular

\begin{tabular}{|l|l|l}
\hline Nome: Márcio Junio Lima Siconelli & CPF:
\end{tabular}

Título do Projeto: AVALIAÇÃO DA IMPORTÂNCIA DOS PRIMATAS NÃO HUMANOS NA POSSÍVEL REURBANIZAÇÃO DA FEBRE AMARELA ? MUNICÍPIO DE RIBEIRÃO PRETO/SP, 2017

Nome da Instituição : FACULDADE DE MEDICINA DE RIBEIRÃO PRETO - USP CNPJ: $63.025 .530 / 0026-62$

\section{Registro de coleta imprevista de material biológico}

De acordo com a Instrução Normativa $n^{\circ}$ 03/2014, a coleta imprevista de material biológico ou de substrato não contemplado na autorização ou na licença permanente deverá ser anotada na mesma, em campo específico, por ocasião da coleta, devendo esta coleta imprevista ser comunicada por meio do relatório de atividades. O transporte do material biológico ou do substrato deverá ser acompanhado da autorização ou da licença permanente com a devida anotação. O material biológico coletado de forma imprevista, deverá ser destinado à instituição científica e, depositado, preferencialmente, em coleção biológica científica registrada no Cadastro Nacional de Coleções Biológicas (CCBIO).

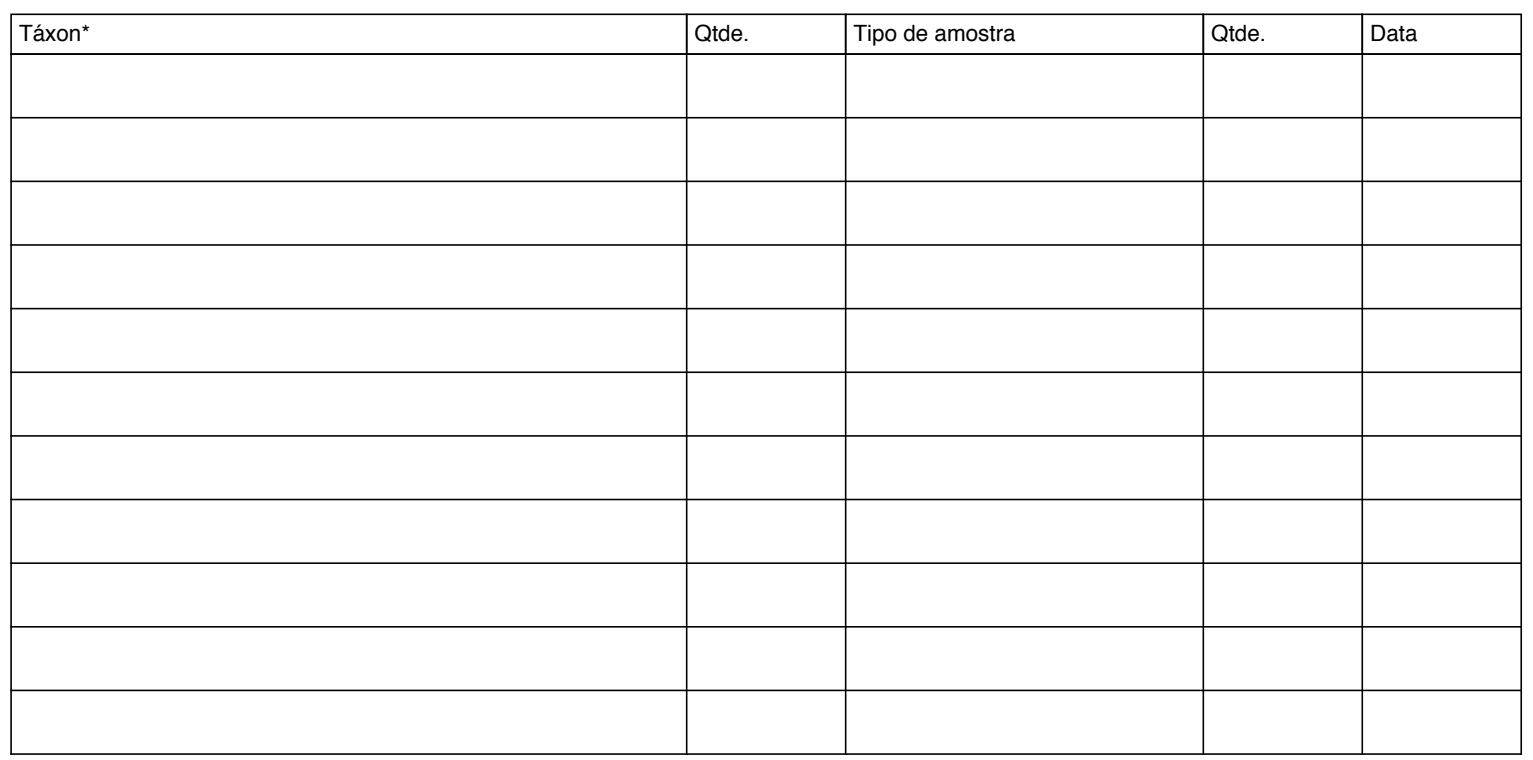

Este documento (Autorização para atividades com finalidade científica) foi expedido com base na Instrução Normativa $n^{\circ}$ 03/2014. Através do código de autenticação abaixo, qualquer cidadão poderá verificar a autenticidade ou regularidade deste documento, por meio da página do Sisbio/ICMBio na Internet (www.icmbio.gov.br/sisbio).

Código de autenticação: 54669294 
Ministério do Meio Ambiente - MMA

Instituto Chico Mendes de Conservação da Biodiversidade - ICMBio

Sistema de Autorização e Informação em Biodiversidade - SISBIO

\section{Autorização para atividades com finalidade científica}

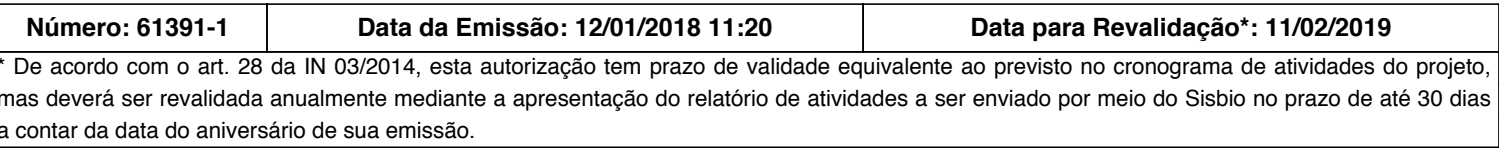

Dados do titular

\begin{tabular}{|l|l|l}
\hline Nome: Márcio Junio Lima Siconelli & CPF:
\end{tabular}

Título do Projeto: AVALIAÇÃO DA IMPORTÂNCIA DOS PRIMATAS NÃO HUMANOS NA POSSÍVEL REURBANIZAÇÃO DA FEBRE AMARELA ?

MUNICÍPIO DE RIBEIRÃO PRETO/SP, 2017

\begin{tabular}{|l|l|l|l}
\hline Nome da Instituição : FACULDADE DE MEDICINA DE RIBEIRÃO PRETO - USP & CNPJ: 63.025.530/0026-62
\end{tabular}

* Identificar o espécime no nível taxonômico possível.

Este documento (Autorização para atividades com finalidade científica) foi expedido com base na Instrução Normativa $n^{\circ}$ 03/2014. Através do código de autenticação abaixo, qualquer cidadão poderá verificar a autenticidade ou regularidade deste documento, por meio da página do Sisbio/ICMBio na Internet (www.icmbio.gov.br/sisbio).

Código de autenticação: 54669294

Página 5/5 


\section{ANEXO C - Parecer da Comissão de Ética no Uso de Animais da FMRP/USP.}

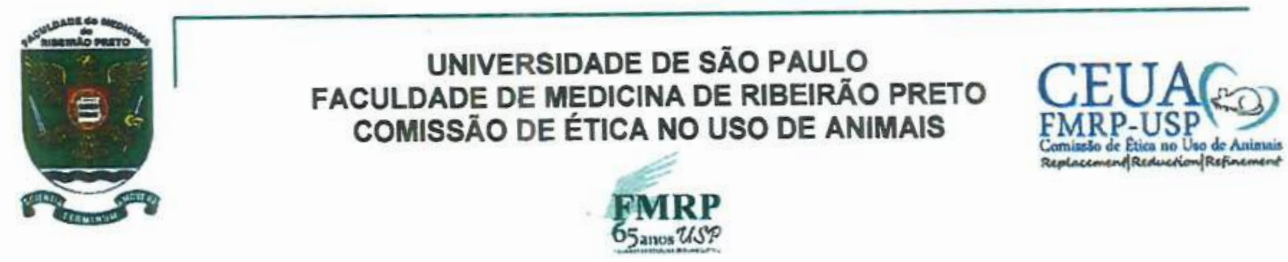

\section{CERTIFICADO}

Certificamos que o Protocolo intitulado "Avaliação da importância dos primatas näo humanos na possivel reurbanização da febre amarela - município de Ribeirão Preto/SP, 2017", registrado com o número 010/2018, sob a responsabilidade do Prof. Dr. Benedito Antonio Lopes da Fonseca, envolvendo a produção, manutençăo ou utilização de animais pertencentes ao filo Chordata, subfilo Vertebrata (exceto humanos) para fins de pesquisa científica, encontra-se de acordo com os preceitos da Lei $n^{0} 11.794$ de 8 de outubro de 2008, do Decreto $\mathrm{n}^{\circ} 6.899$ de 15 de julho de 2009 e com as normas editadas pelo Conselho Nacional de Controle de Experimentação Animal (CONCEA), e foi APROVADO pela Comissão de Ética no Uso de Animais da Faculdade de Medicina de Ribeirão Preto da Universidade de São Paulo em reunião de 26 de fevereiro de 2018.

Este Protocolo prevê a utilização de 20 primatas Sapajus $s p, 06$ primatas Alouatta caraya e 24 primatas Callithrix penicillata, com peso, idade e sexo variáveis na dependência da captura. Os animais serão capturados em seus habitat naturais e, após os devidos procedimentos e completa recuperação anestésica, serão devolvidos à natureza. Vigência da autorização: 26/02/2018 a 01/02/2020.

We certify that the Protocol $n^{\circ} 010 / 2018$, entitled "Evaluation of the importance of non-human primates in the possible rebanization of yellow fever - municipality of Ribeirâo Preto / SP, 2017", is in accordance with the Ethical Principles in Animal Research adopted by the National Council for Control of Animal Experimentation (CONCEA) and was approved by the Local Animal Ethical Committee from Ribeiräo Preto Medical School of the University of São Paulo in 02/26/2018. This protocol involves the production, maintenance or use of animals from phylum Chordata, subphylum Vertebrata (except humans) for research purposes and includes the use of 20 primates Sapajus sp, 06 primates Alouatta caraya and 24 primates Callithrix penicillata with variable weight, age and sex depending on the catch. The animals will be captured in their natural habitats and will be returned to the nature after procedures and complete anesthesia recovery. This certificate is valid until 02/01/2020.

Ribeirão Preto, 26 de feyereiro de 2018

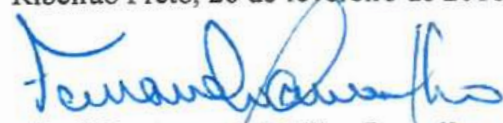

Prof. Dr. Fernando Silva Ramalho

Coordenador da CEUA-FMRP - USP

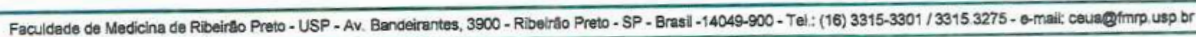




\section{ANEXO D - Parecer da Comissão Técnico Científica (COTEC) - Instituto Florestal, Secretaria Estadual de Meio Ambiente.}

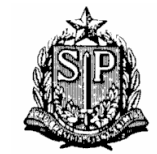

PROCESSO SMA N. ${ }^{\circ}$

INTERESSADO

ASSUNTO

EQUIPE

VIGÊNCIA

\section{SECRETARIA DO MEIO AMBIENTE}

INSTITUTO FLORESTAL

Rua do Horto, 931 - CEP 02377-000 - S. Paulo, SP - Brasil - Fone: (0xx11) 2231-8555 www.iflorestal.sp.gov.br

: $260108-004.824 / 2018$

: Benedito Antônio Lopes da Fonseca

: Encaminha o projeto de pesquisa: “Avaliação da importância dos primatas não humanos na possível reurbanização da febre amarela - Município de Ribeirão Preto/SP, 2017”

: Benedito Antônio Lopes da Fonseca, Márcio Junio Lima Siconelli e Pedro Henrique Ferreira Teles

: Fevereiro de 2018 a Fevereiro de 2020

\section{Carta COTEC n 367/2018 D62/2018 PM}

São Paulo, 31 de Julho de 2018

\section{Senhor}

Benedito Antônio Lopes da Fonseca

Rua Sargento Silvio Delmar Hollenbach, 638

Ribeirão Preto-SP

CEP: $14.096-590$

Tel.: (16) 3315-3249

E-mail: baldfons@fmrp.usp.br - Benedito Antônio Lopes da Fonseca marcio_siconelli@outlook.com - Márcio Junio Lima Siconelli

Apraz-nos informar que o projeto "Avaliação da importância dos primatas não humanos na possível reurbanização da febre amarela - Município de Ribeirão Preto/SP, 2017”, constante do processo em referência, de autoria de Benedito Antônio Lopes da Fonseca, Márcio Junio Lima Siconelli e Pedro Henrique Ferreira Teles, foi aprovado para ser executado, no período de Fevereiro de 2018 a Fevereiro de 2020, na seguinte Unidade:

\begin{tabular}{|c|c|c|}
\hline $\begin{array}{c}\text { UNIDADE e } \\
\text { RESPONSÁVEL }\end{array}$ & $\begin{array}{c}\text { ENDEREÇO DA UNIDADE DE } \\
\text { CONSERVAÇÃO }\end{array}$ & OBSERVAÇÕES \\
\hline $\begin{array}{l}\text { Estação } \\
\text { Ecológica de } \\
\text { Ribeirão Preto } \\
\text { Ao responsável } \\
\text { pela Unidade } \\
\text { Gestora: } \\
\text { Alessandra Célia } \\
\text { Pinezi }\end{array}$ & $\begin{array}{l}\text { a) Sede Administrativa: } \\
\text { Endereço: Rodovia Prefeito Antônio } \\
\text { Duarte Nogueira, km } 317 \\
\text { Jardim Progresso } \\
\text { Ribeirão Preto-SP } \\
\text { CEP: } 14.031-800 \\
\text { Telefones para informação: } \\
\text { (16) 3637-1939 } \\
\text { E-mail: ec.ribpreto@fflorestal.sp.gov.br } \\
\text { alessandracp@fflorestal.sp.gov.br } \\
\text { Dias e horário de funcionamento: de } \\
\text { segunda-feira a sexta-feira das } 7 \mathrm{~h} \text { às } \\
\text { 11h e das 12h às 16h. } \\
\text { b) Visitação: } \\
\text { Endereço: Rodovia Prefeito Antônio } \\
\text { Duarte Nogueira, km } 317 \\
\text { Jardim Progresso } \\
\text { Ribeirão Preto-SP } \\
\text { CEP: } 14.031-800 \\
\text { Dias e horário de funcionamento: } \\
\text { Visitação somente para Educação } \\
\text { Ambiental e realização de pesquisa } \\
\text { científica mediante agendamento. }\end{array}$ & $\begin{array}{l}\text { - Com relação à realização do projeto na Estação Ecológica } \\
\text { de Ribeirão Preto, manifestamo-nos: De acordo com a } \\
\text { execução do projeto; } \\
\text { - Com relação aos resultados do projeto, as informações } \\
\text { geradas serão de: Alta prioridade; } \\
\text { - Com relação ao planejamento da Unidade, a Estação } \\
\text { Ecológica de Ribeirão Preto possui: Plano de Manejo; } \\
\text { - Com relação às atividades previstas pelo projeto existem } \\
\text { restrições quanto: ao Plano de Manejo; } \\
\text { - } \quad \text { As seguintes colocações devem ser observadas pelos } \\
\text { autores, por ocasião da visita a esta Unidade: } \\
\text { - A Unidade não dispõe de alojamento; } \\
\text { - O horário de circulação na Unidade de Conservação é no } \\
\text { período entre 8h:00 h e 17h:00 h; } \\
\text { - As datas das visitas e coletas deverão ser comunicadas à } \\
\text { gestora com pelo menos } 10 \text { dias de antecedência, pelo } \\
\text { endereço eletrônico alessandracp@fflorestal.sp.gov.br ou pelo } \\
\text { telefone (16) 9-9638- 6875; } \\
\text { - Todos os envolvidos que farão as visitas à Estação } \\
\text { Ecológica de Ribeirão Preto deverão estar vacinados contra a } \\
\text { febre amarela, sendo obrigatória a apresentação da carteira } \\
\text { de vacinação como forma de comprovação; } \\
\text { - A instalação de sinalização indicativa é permitida, desde } \\
\text { que biodegradável, sendo aceitas as justificativas para o uso } \\
\text { de materiais de maior durabilidade, contanto que os mesmos } \\
\text { sejam retirados após o término da pesquisa; } \\
\text { - É proibido abertura ou alargamento de trilhas, acessos ou } \\
\text { picadas na Zona Primitiva e em áreas que permeiam a mesma; } \\
\text { - Ao término do projeto, uma cópia da pesquisa }\end{array}$ \\
\hline
\end{tabular}




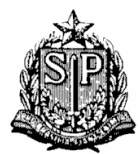

PROCESSO SMA N. ${ }^{\circ}$ INTERESSADO

ASSUNTO

EQUIPE

VIGÊNCIA

\section{SECRETARIA DO MEIO AMBIENTE}

INSTITUTO FLORESTAL

Rua do Horto, 931 - CEP 02377-000 - S. Paulo, SP - Brasil - Fone: (0xx11) 2231-8555 www.iflorestal.sp.gov.br

: $260108-004.824 / 2018$

: Benedito Antônio Lopes da Fonseca

: Encaminha o projeto de pesquisa: “Avaliação da importância dos primatas não humanos na possível reurbanização da febre amarela - Município de Ribeirão Preto/SP, 2017"

: Benedito Antônio Lopes da Fonseca, Márcio Junio Lima Siconelli e Pedro Henrique Ferreira Teles

: Fevereiro de 2018 a Fevereiro de 2020

\begin{tabular}{|c|c|l|}
\hline $\begin{array}{c}\text { UNIDADE e } \\
\text { RESPONSÁVEL }\end{array}$ & $\begin{array}{c}\text { ENDEREÇO DA UNIDADE DE } \\
\text { CONSERVAÇÃO }\end{array}$ & \multicolumn{1}{c|}{ OBSERVAÇÕES } \\
\hline & & $\begin{array}{l}\text { desenvolvida deverá ser disponibilizada para o acervo da } \\
\text { Estação Ecológica de Ribeirão Preto; } \\
\text { Relatórios parciais e finais encaminhados à COTEC devem } \\
\text { também ser remetidos à administração da Estação Ecológica } \\
\text { de Ribeirão Preto, para serem juntados ao acervo da Unidade. }\end{array}$ \\
\hline
\end{tabular}

"Haverá captura e coleta de primatas não humanos devidamente documentados e autorizadas pela Licença Sisbio n 61.391-1 com validade até 11/02/2019. Além da referida licença, a documentação apresentada também está em conformidade com a Lei 13.123/2015 de acesso ao patrimônio genético (SISGEN) via cadastro $n^{\circ}$ AB9F205 e parecer da comissão de ética da USP sob protocolo $10 / 2018$.

Projeto de alta relevância que objetiva realizar sorologias em primatas não humanos no município de Ribeirão Preto para o vírus da febre amarela. Também serão realizados monitoramentos do uso da paisagem, marcação individual através da individualização dos animais e testes de titulação de anticorpos e testes sorológicos a partir de soro conversões. Haverá apoio das Secretarias de Saúde estaduais e municipais nos processos de captura e monitoramento. Equipe qualificada para execução das atividades e protocolos de captura, sedação e coleta de materiais em conformidade com a legislação e ética animal. Na Unidade de Conservação proposta, macacos prego e sagüis são abundantes e habituados com os seres humanos, fato que facilitará a logística e captura dos animais. Sugere-se o apoio técnico e logístico da Unidade, de modo a facilitar os trabalhos."

Por ocasião das visitas nesta Unidade, solicitamos:

1. Agendar os trabalhos de campo junto à administração da Unidade, com antecedência mínima de 15 dias, fornecendo o nome de todos os membros da equipe visitante;

2. Visitas de pesquisadores, representantes de outras instituições, convidados, pesquisadores estrangeiros, alunos, amigos, fotógrafos, imprensa, etc., não relacionados no projeto original como membro da equipe executora devem ser previamente notificadas e autorizadas pela administração da Unidade;

3. Permitir acompanhamento por pessoal da Unidade, quando o responsável pela Unidade assim estabelecer;

4. Atividades não previstas no projeto original estão vetadas, devendo ser previamente notificadas e submetidas à análise e aprovação do Instituto Florestal;

5. Portar a licença do SISBIO/IBAMA. Quando renovada, apresentar cópia para ser anexada ao processo;

6. Somente os autores nomeados na licença do SISBIO/IBAMA poderão efetuar coletas;

7. Questionários, formulários, entrevistas orais e outras formas de abordagem de pessoal local e do público visitante devem ter o roteiro previamente submetido à ciência do responsável pela administração da Unidade;

8. Atividades de coleta de amostras da biodiversidade estão condicionadas à apresentação de cópia da licença SISBIO/IBAMA. Quando renovada, apresentar cópia para ser anexada ao processo;

9. As intervenções a serem executadas na Unidade, como colocação de placas, pregos, faixas, distribuição de folhetos, etc. devem ser previamente e formalmente autorizadas pelo responsável pela administração da Unidade; 


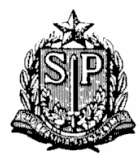

PROCESSO SMA N. ${ }^{\circ}$ INTERESSADO

ASSUNTO

EQUIPE

VIGÊNCIA
SECRETARIA DO MEIO AMBIENTE

INSTITUTO FLORESTAL

Rua do Horto, 931 - CEP 02377-000 - S. Paulo, SP - Brasil - Fone: (0xx11) 2231-8555 www.iflorestal.sp.gov.br

: 260108 - 004.824/2018

: Benedito Antônio Lopes da Fonseca

: Encaminha o projeto de pesquisa: “Avaliação da importância dos primatas não humanos na possível reurbanização da febre amarela - Município de Ribeirão Preto/SP, 2017"

: Benedito Antônio Lopes da Fonseca, Márcio Junio Lima Siconelli e Pedro Henrique Ferreira Teles

: Fevereiro de 2018 a Fevereiro de 2020

10. Não deixar no campo vestígios da passagem no local como resíduos, buracos, embalagens, armadilhas, tambores, etc. Trincheiras e escavações devem ser seguidas de processos de recuperação, minimizando o dano local;

11. Havendo necessidade de acompanhamento por mateiros, guarda-parques, consultar a Unidade sobre possível disponibilidade, com antecedência mínima de 15 dias e;

12. Havendo necessidade de deslocamento de equipamentos, realizar por conta própria ou consultar a Unidade sobre possível disponibilidade de auxiliares, com antecedência mínima de 15 dias.

Responsáveis por projetos com previsão de coletas devem providenciar a autorização SISBIO/IBAMA na página http://www.ibama.gov.br/sisbio/index.php?id_menu=205. Obtida a autorização, encaminhar cópia à Comissão Técnico-Científica - COTEC para ser anexado no processo respectivo. A partir de janeiro de 2008, toda e qualquer forma de coleta nas UCs deverá ser formalmente licenciada pelo SISBIO/IBAMA.

Conforme estabelece a Portaria do Diretor Geral de 23/01/90, e cientificado à V. Senhoria nos Termos de Compromisso e de Responsabilidade assinados em 23/05/2018, há necessidade de encaminhar à COTEC, um relatório anual, no mês de Dezembro de cada ano. Nos relatórios assinalar a área de estudos em GPS/coordenadas geográficas.

Relatórios parciais e final encaminhados à COTEC devem também ser remetidos à administração das Unidades de Conservação, para serem juntados ao acervo da Unidade.

Cópia da dissertação, tese, artigos, resumos em eventos científicos e outras formas de publicações podem ser apresentados como relatório parcial e final. Não havendo possibilidade de cópias, solicita-se o encaminhamento da(s) referência(s) bibliográfica(s), que possibilite $(m)$ o acesso a todas as informações geradas no projeto.

A utilização para outros fins que não seja a pesquisa científica, de fotografias, imagens, vídeos e outras mídias registradas nas Unidades a título deste projeto devem ser objetos de termo específico, conforme a Portaria CINP, de 09/02/1999, publicada no DOE de 10/02/1999.

Esta aprovação não implica em suporte financeiro de qualquer natureza por parte do Instituto Florestal. A participação e ou auxílio financeiro por parte do Instituto Florestal, quando houver, deverá ser detalhado e formalizado através de contratos, convênios e outros instrumentos legais pertinentes, cuja cópia deve ser juntada ao presente processo.

Para qualquer informação ou eventualidade, colocamo-nos à sua inteira disposição.

Por prestigiar a nossa instituição, agradecemos.

Atenciosamente,

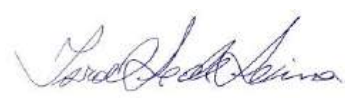

Israel Luiz de Lima

COTEC - Comissão Técnico-Científica

Instituto Florestal

Rua do Horto, $n^{\circ} 931$

02377-000 - São Paulo - SP

Fone: (011) 2231- 8555 - Ramal 2071 Fax: Ramal 2220

cotec2@gmail.com

cotec@if.sp.gov.br 